UNIVERSIDADE DE SÃO PAULO

INSTITUTO DE FÍSICA DE SÃO CARLOS

OLAVO AMORIM SANTOS

DESENVOLVIMENTO DE NANOFLORES DE OURO FOTOATIVAS PARA TERAPIA E DIAGNÓSTICO DE CÂNCER 

OLAVO AMORIM SANTOS

\section{DESENVOLVIMENTO DE NANOFLORES DE OURO FOTOATIVAS PARA TERAPIA E DIAGNÓSTICO DE CÂNCER}

Dissertação apresentada ao Programa de Pós-Graduação em Física do Instituto de Física de São Carlos da Universidade de São Paulo, para obtenção do título de Mestre em Ciências.

Área de concentração: Física Aplicada Opção: Física Biomolecular Orientador: Prof. Dr. Valtencir Zucolotto Co-orientadora: Dra. Juliana Cancino Bernardi

\section{Versão Corrigida}

(versão original disponível na Unidade que aloja o Programa) 
AUTORIZO A REPRODUÇÃO E DIVULGAÇÃO TOTAL OU PARCIAL DESTE TRABALHO, POR QUALQÜER MEIO CONVENCIONAL OU ELETRÔNICO PARA FINS DE ESTUDO E PESQUISA, DESDE QUE CITADA A FONTE.

Ficha catalográfica revisada pelo Serviço de Biblioteca e Informação do IFSC, com os dados fornecidos pelo(a) autor(a)

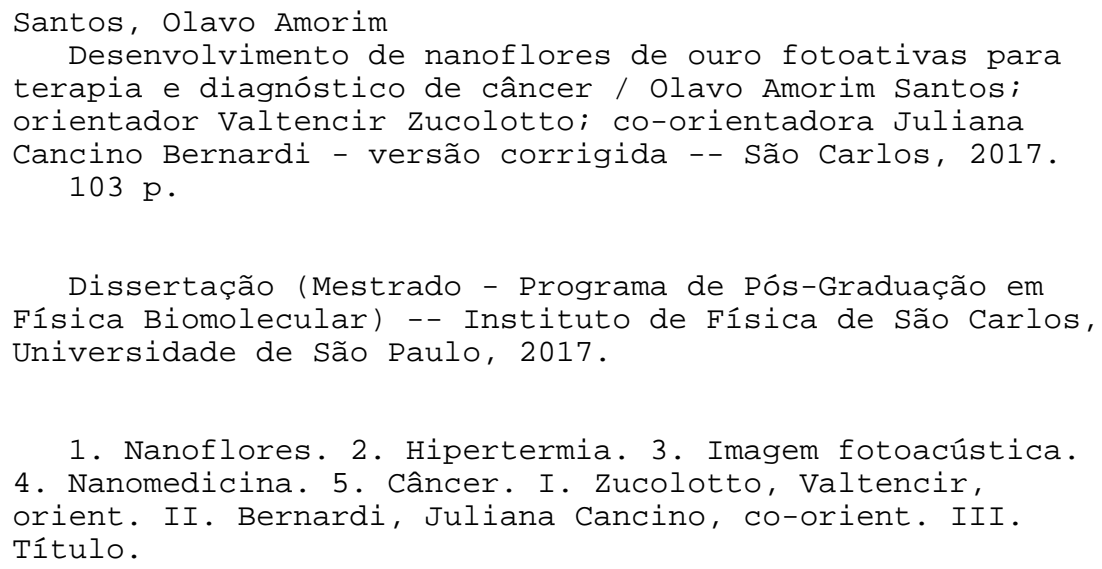

1. Nanoflores. 2. Hipertermia. 3. Imagem fotoacústica. 4. Nanomedicina. 5. Câncer. I. Zucolotto, Valtencir, orient. II. Bernardi, Juliana Cancino, co-orient. III. Título. 
À todas as células que morreram para tornar esse trabalho possivel.

Às queimadas pelo laser, às intoxicadas pelas nanopartículas.

Sem vocês este trabalho não seria possível. 



\section{AGRADECIMENTOS}

Aos meus pais, Antonio Carlos e Katia, e à minha irmã, Júlia, que sempre me apoiaram em minhas decisões e em minhas teimosias. Obrigado pela confiança, carinho e apoio que sempre me dão.

À Mariana que sempre esteve comigo me dando suporte e segurança nos momentos difíceis e compartilhando das alegrias de cada conquista. Sem você esse percurso seria muito mais difícil.

À toda minha família, sendo ela de sangue ou não: à família Santos e à família Amorim; Ao Rafael, ao Vitor, à Maíra, à Isabela, ao Guilherme e ao Eric que desde a graduação me acompanham; aos que estão sempre presentes desde muito tempo, Fernando, Ray, Bruno, Júlio e Camilo; ao Pedro, ao Luiz, ao Ted, ao Henrique e ao Bruno que enfrentaram comigo os desafios e percalços do oriente.

Ao Prof. Valtencir Zucolotto, à Juliana Cancino e aos demais membros do grupo do Grupo de Nanomedicina e Nanotoxicologia por todo o apoio, estrutura, ajuda e discussões durante esse processo. Em especial, à Laís R. e à Paula por todas as conversas e discussões regadas a café que sempre me ensinaram muito e me ajudaram a superar as dificuldades que enfrentei na realização desse trabalho; e, ao Romeu pela ajuda no ajuste do sistema de hipertermia.

Ao Prof. Théo Pavan e ao Diego Sampaio do Grupo de Inovação em Instrumentação Médica e Ultrassom (GIIMUS), do Departamento de Física da FFCLRP-USP pela parceria nos experimentos de fotoacústica.

À CAPES pelo apoio financeiro e ao Instituto de Física de São Carlos pela estrutura que me proporcionaram essa obra.

Finalmente, a você que está lendo esse trabalho. Espero que possa acrescentar-lhe de alguma forma.

A todos vocês e mais aqueles que não citei explicitamente: De coração, obrigado. 



\section{RESUMO}

SANTOS, O. A. Desenvolvimento de nanoflores de ouro fotoativas para terapia e diagnóstico de câncer. 2017. 103 p. Dissertação (Mestrado em Ciências) - Instituto de Física de São Carlos, Universidade de São Paulo, São Carlos, 2017.

Nanopartículas de ouro têm mostrado enorme potencial de aplicação em modalidades diagnósticas e terapêuticas fotoativadas. Em especial, nanoestruturas de ouro anisotrópicas ramificadas apresentam excelente desempenho atuando tanto como contrastes de imagens fotoacústicas, quanto como agentes ativos para terapias fototérmicas de câncer. Apesar dos avanços nas suas rotas de síntese, o desenvolvimento dessas nanoestruturas de forma simples e reprodutível ainda é desafiador. O presente trabalho visou o desenvolvimento de nanopartículas de ouro anisotrópicas ramificadas, ou "nanoflores", que sejam fotoativas no infravermelho-próximo para a terapia e diagnóstico de câncer. Em particular, buscou-se o desenvolvimento de uma síntese simples para sua obtenção, assim como a verificação de sua atuação como agente de contraste fotoacústico e como agente ativo para hipertermia de tumores. Para tanto, desenvolveu-se uma síntese in situ que permitiu a obtenção de nanoflores monodispersas com tamanho e propriedades ópticas controláveis. Através da variação de aspectos da síntese, como a temperatura e a concentração de ouro, foi possível sintonizar a atividade óptica das partículas entre 590 e $960 \mathrm{~nm}$. Sua formação foi confirmada por microscopia eletrônica de varredura, espalhamento de luz dinâmico e espectroscopia UV-visível. As partículas apresentaram boa estabilidade de suas características físico-químicas por dois meses e meio. Ainda, as nanoflores se mostraram estáveis, também, quando suspensas em meio de cultura, sob irradiação de lasers, e quando mantidas a temperatura corpórea por longos intervalos. Sua resposta fotoacústica foi caracterizada, apresentando sinais significativos e permitindo a obtenção de imagens claras de sua localização, mesmo em baixas concentrações. Testes realizados em cultura de células mostraram que as nanoflores foram eficazes na hipertermia de uma linhagem de hepatocarcinoma de rato (HTC), ao mesmo tempo que não apresentaram sinais de toxicidade a uma linhagem de fibroblastos de camundongos $(\mathrm{FC} 3 \mathrm{H})$. Esses resultados revelam uma possibilidade simples de fabricação de 
nanoestruturas de ouro anisotrópicas ramificadas, que podem servir como uma plataforma promissora para o diagnóstico e terapia do câncer.

Palavras-chave: Nanoflores de ouro. Hipertermia. Imagem Fotoacústica. Nanotecnologia. Nanomedicina. Câncer. 


\section{ABSTRACT}

SANTOS, O. A. Development of photoactive gold nanoflowers for therapy and diagnostic of cancer. 2017. 103

p. Dissertação (Mestrado em Ciências) - Instituto de Física de São Carlos, Universidade de São Paulo, São Carlos, 2017.

Gold nanoparticles have shown enormous potential of application in photodiagnostic and in phototherapeutic procedures. Notably, branched anisotropic gold nanostructures present distinguished performance acting as contrast agents of photoacoustic images and as active agents for photothermal therapies for cancer. Despite advances in their synthesis routes, the growth of these nanostructures in a simple and reproducible way is still challenging. The present study was aimed at developing branched anisotropic gold nanoparticles, coined nanoflowers, that are photoactive in the near-infrared for therapy and diagnosis of cancer. In particular, we sought to develop a simple synthesis route, as well as to verify its application for both, as photoacoustic contrast agents and as active agents for tumor hyperthermia. An in situ synthesis was developed which allowed the development of monodisperse nanoflowers with controllable size and optical properties. Through variations of certain aspects of this procedure, such as temperature and gold ions concentration, it was possible to tune the optical activity of the particles between 590 and $960 \mathrm{~nm}$. The nanostructure morphology was confirmed by scanning electron microscopy, dynamic light scattering and UV-visible spectroscopy. The particles exhibited consistent physicochemical characteristics and good stability for two and a half months. Furthermore, the nanoflowers were also stable when suspended in cell culture medium, under laser irradiation and when maintained at body temperature for long intervals. Its photoacoustic response was characterized, presenting significant responses and generating clear images of its location, even at low concentrations. In vitro tests revealed that these nanoflowers were effective therapeutic agents for photothermal therapy of a rat hepatocarcinoma (HTC) lineage, while showing no signs of toxicity to mouse fibroblast $(\mathrm{FC} 3 \mathrm{H})$ cell line. These results reveal a simple procedure of synthesizing branched anisotropic gold nanostructures, which can serve as a promising platform for cancer diagnosis and therapy. 
Keywords: Gold nanoflowers. Hyperthermia. Photoacoustic imaging. Nanotechnology. Nanomedicine. Cancer. 


\section{LISTA DE FIgURAS}

Figura 1 - Ressonância de plasmon de superfície........................................................................... 23

Figura 2 - Influência da geometria no fenômeno de LSPR ……………………………………….....25

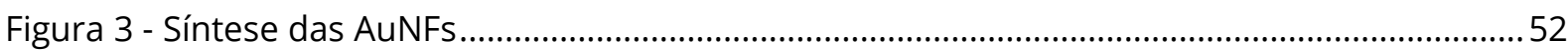

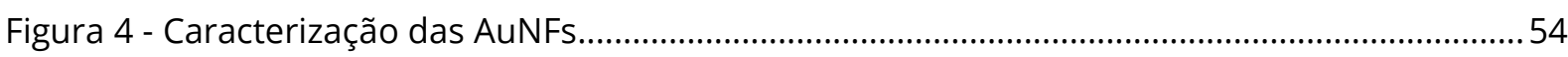

Figura 5 - Influência da presença de íons de prata na formação das AuNFs.......................................56

Figura 6 - Influência da temperatura na formação das AuNFs ..........................................................59

Figura 7 - Influência da concentração de ouro na formação de AuNFs.............................................61

Figura 8 - Caracterização das AuNFs sintetizadas pelo protocolo otimizado ......................................63

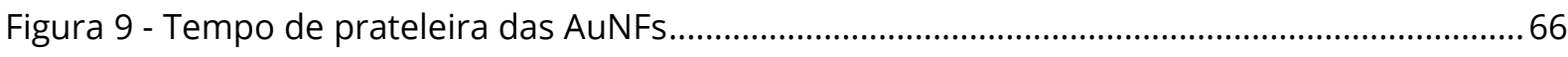

Figura 10 - Estabilidade com o aumento de temperatura ..................................................................68

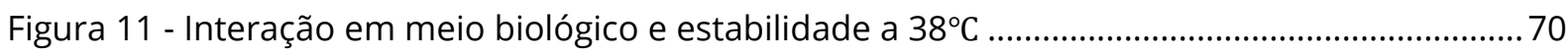

Figura 12 - Estabilidade das AuNFs à irradiação por um laser pulsado ............................................. 73

Figura 13 - Estabilidade das AuNFs à irradiação por um laser contínuo ............................................. 74

Figura 14 - Configuração experimental do sistema de fotoacústica ..................................................77

Figura 15 - Caracterização fotoacústica das AuNFs ......................................................................... 78

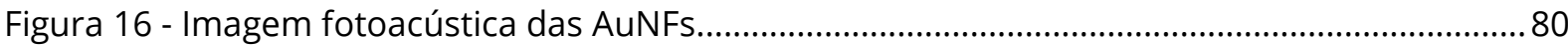

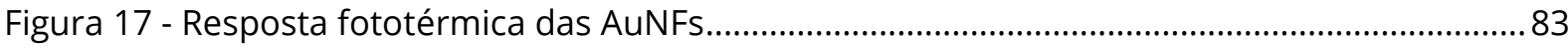

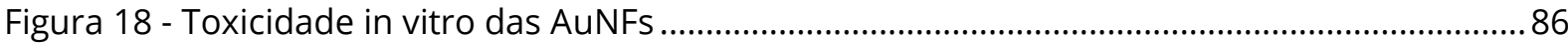

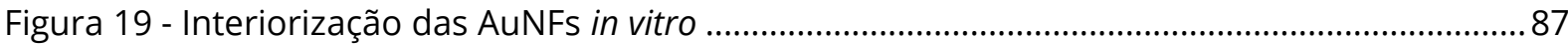

Figura 20 - Eficiência terapêutica das AuNFs ........................................................................................ 88 



\section{LISTA DE TABELAS}

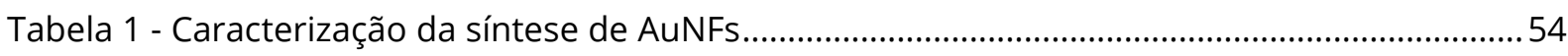

Tabela 2 - Influência da presença de íons de prata na formação das AuNFs ......................................56

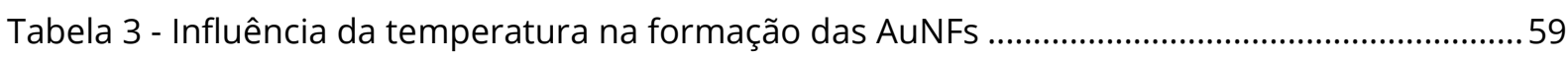

Tabela 4 - Influência da concentração de ouro na formação das AuNFs ..........................................61

Tabela 5 - Caracterização das AuNFs sintetizadas pelo protocolo otimizado ....................................63

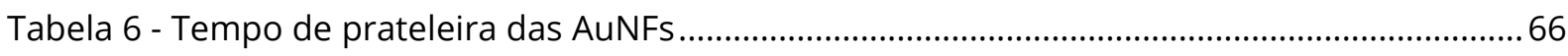

Tabela 7 - Estabilidade com o aumento de temperatura .................................................................67

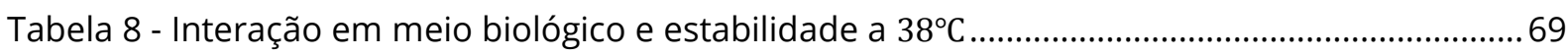

Tabela 9 - Estabilidade das AuNFs à irradiação por um laser pulsado ................................................73 



\section{SUMÁRIO}

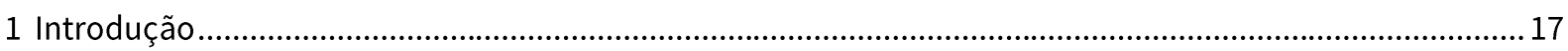

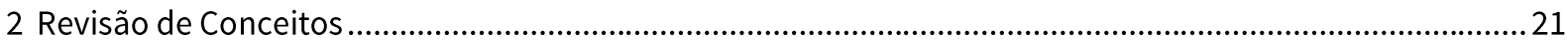

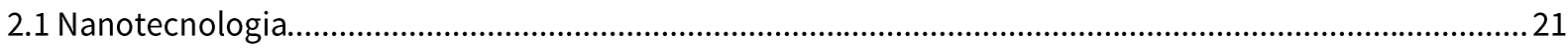

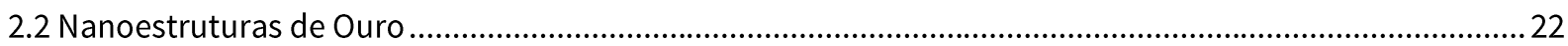

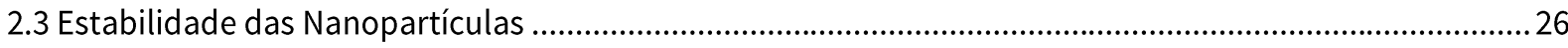

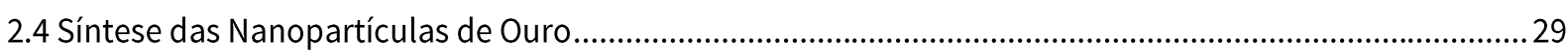

2.5 Modalidades Fotoativadas para Terapia e Diagnóstico de Tumores...............................................................32

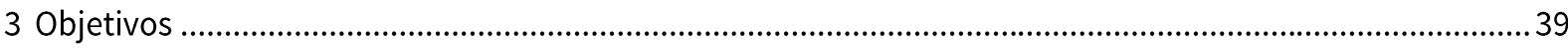

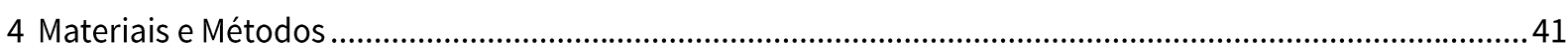

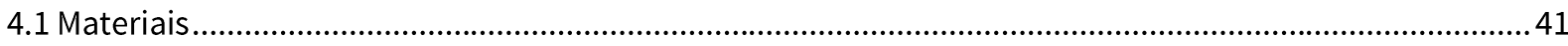

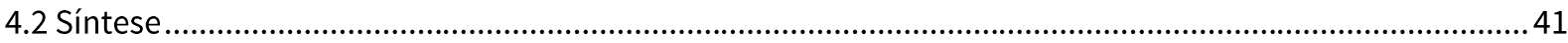

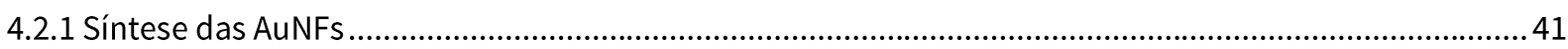

4.2.2 Limpeza da Solução e Armazenamento..................................................................................................... 41

4.3 Técnicas de Caracterização ...............................................................................................................42

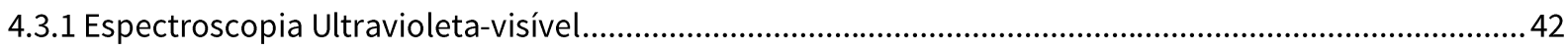

4.3.2 Espalhamento de Luz Dinâmico ............................................................................................................... 42

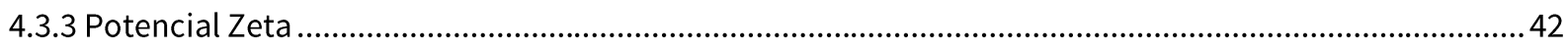

4.3.4 Microscopia Eletrônica de Varredura .........................................................................................................43

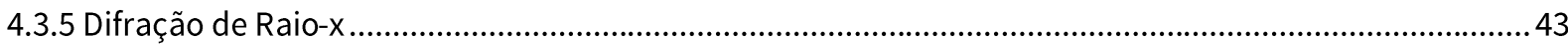

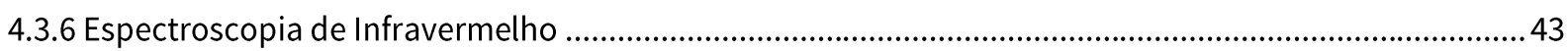

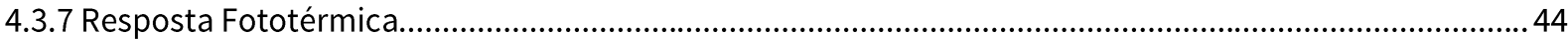

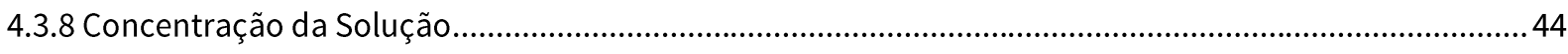

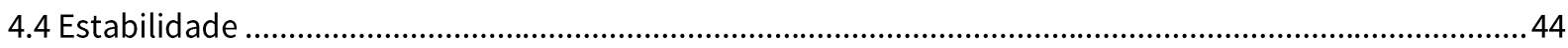

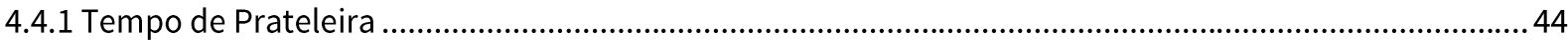

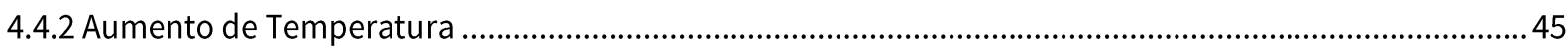

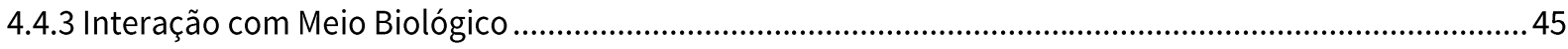

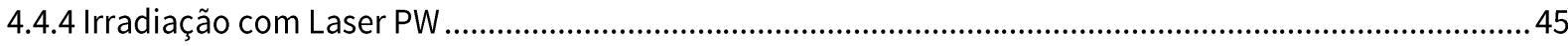


4.4.5 Irradiação com Laser CW

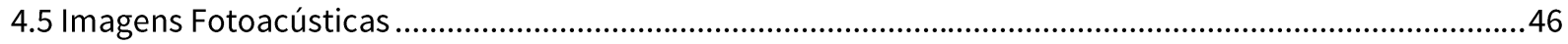

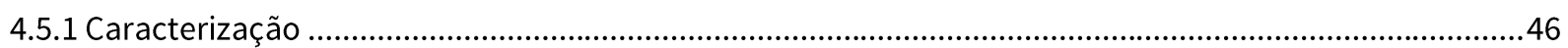

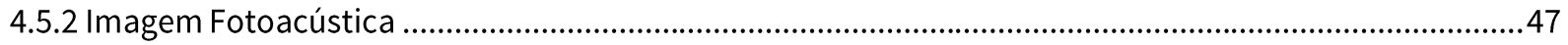

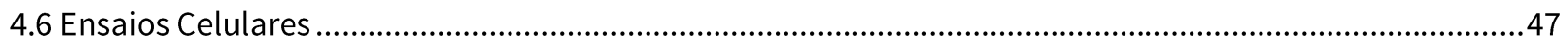

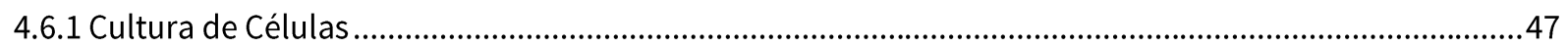

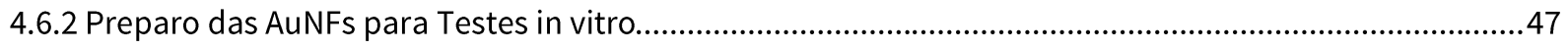

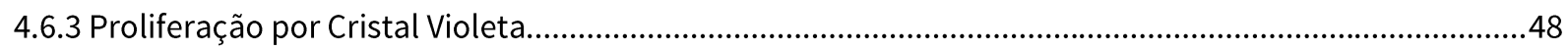

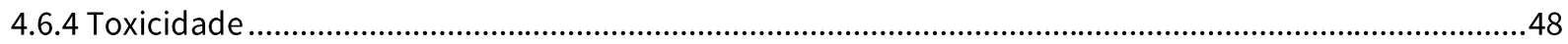

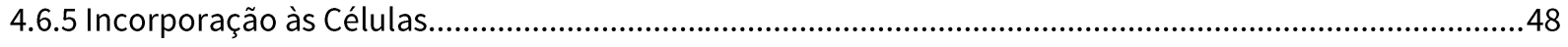

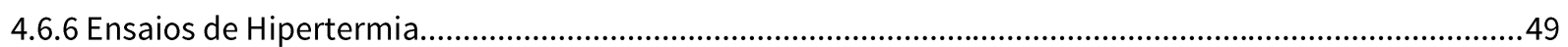

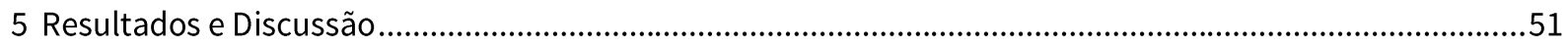

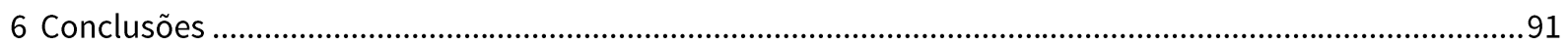

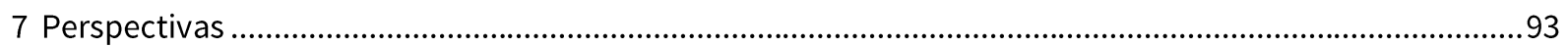

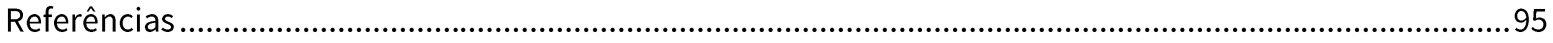




\section{INTRODUÇÃO}

A nanotecnologia é uma área de pesquisa e desenvolvimento extremamente ampla e multidisciplinar. Nas últimas décadas, avanços tecnológicos possibilitaram maior controle na manipulação, visualização e produção da matéria na escala molecular, acarretando um desenvolvimento acelerado da nanociência e em sua aplicação em diferentes setores. (1) Nos últimos anos, já observamos o surgimento de muitos produtos contendo nanotecnologia disponíveis no mercado, com sua inclusão, por exemplo, na indústria têxtil, alimentícia, automobilística, na geração de energias limpas e no setor de saúde. (1-2)

O uso de nanoestruturas na medicina é uma das direções importantes na qual a área vem sendo desenvolvida. (3) Esse campo é conhecido como nanomedicina e visa a combinação da nanotecnologia com ciências farmacêuticas e biomédicas. Tal combinação possibilita não apenas a expansão dos procedimentos já existentes, mas, também, o desenvolvimento de novas ferramentas promissoras. (4-6) Particularmente, seu uso em estudos oncológicos vem se mostrando como extremamente promissor e sendo explorado nos últimos anos. Os métodos tradicionais da terapêutica do câncer são, em geral, demasiadamente invasivos e podem apresentar efeitos colaterais tóxicos. Além disso, tais métodos são, muitas vezes, ineficazes na eliminação total do tumor, culminando na sua recidiva e na baixa expectativa de vida do paciente. (7) Nesse cenário, a inclusão de nanopartículas como agentes terapêuticos possibilita a criação de metodologias alternativas com procedimentos menos agressivos e com ação terapêutica mais localizada do que aqueles usualmente aplicados.

Em especial, nanopartículas de ouro são candidatas particularmente interessantes a serem utilizadas em tais procedimentos. Essas estruturas possuem características inerentes extremamente relevantes para aplicações biomédicas, incluindo baixa reatividade, baixa toxicidade, alta biocompatibilidade e alta capacidade de funcionalização (8-9). Ademais, um dos aspectos mais marcantes nas nanopartículas de ouro são suas propriedades ópticas, representado pelo efeito de ressonância de plasmon 
de superfície localizado (LSPR, do Inglês Localized Surface Plasmon Resonance). (4) Tal efeito surge da interação das nanopartículas com a luz que, em comprimentos de ondas específicos, estimulam os elétrons da superfície das partículas a oscilarem, resultando na dissipação de calor para seu ambiente. (10) Esse fenômeno é amplamente explorado e pode ser utilizado em diversas modalidades terapêuticas, diagnósticas e teranósticas (terapia + diagnóstico). (11-12)

Tratamentos térmicos são utilizados na área médica há centena de anos e se fundamentam na sensibilidade das células ao incremento de temperaturas. (9) Seu uso na oncologia é conhecido como hipertermia e busca elevar a temperatura dos tumores ao intervalo clinicamente relevante, localizado entre $41-48^{\circ} \mathrm{C}$. (13) Entretanto, um aquecimento generalizado pode causar danos irreversíveis não apenas ao tecido doente, mas, também, a tecidos saudáveis e conseguir um aumento de temperatura localizado pode não ser trivial. (14) Dessa maneira, ao se utilizar o efeito de LSPR, torna-se possível o aquecimento controlado e localizado do tumor pela irradiação das nanopartículas de ouro por uma fonte de luz, tornando-as excelentes agentes ativos para hipertermia. (14)

Além da terapia, a conversão fototérmica das nanopartículas de ouro também pode ser utilizada para a obtenção de imagens, como é feito na técnica fotoacústica (PA, do inglês photoacoustic). (9) Utilizando sequências de pulsos de laser, são induzidos ciclos de aquecimento e resfriamento que, devido a uma expansão termoelástica dos tecidos, produzem ondas acústicas que podem ser detectadas utilizando um transdutor de ultrassom. (15) Contudo, a maioria dos tecidos apresenta um contraste fotoacústico baixo, tornando-o indistinguível através da técnica. Assim, através do aquecimento gerado pelas nanopartículas de ouro, o sinal fotoacústico é consideravelmente acentuado, tornando-as ótimas candidatas para atuarem como agentes de contraste de modalidades PA. (12)

Entretanto, o uso de técnicas baseadas na ativação por lasers possui o empecilho de que a água e os tecidos possuem alta absorção em grande parte dos comprimentos de onda. Isso acarreta numa considerável perda de energia do estímulo, podendo causar danos não-específicos aos tecidos e inviabilizando seu uso. (4) Visando minimizar tais efeitos, busca-se desenvolver sistemas opticamente ativos em comprimentos de onda que se encontram em regiões do espectro em que a absorção pelos tecidos seja mínima. Tais 
regiões são conhecidas como janelas biológicas e possuem duas regiões principais no infravermelho-próximo (NIR, do inglês near infrared). (14)

Nanopartículas de ouro tipicamente apresentam atividade óptica em regiões fora das janelas de absorção, sendo usualmente localizada entre $500-600 \mathrm{~nm}$. (16) No entanto, através de protocolos de síntese específicos, é possível obter partículas anisotrópicas, que são ativas nessas regiões. (4) Em especial, nanopartículas anisotrópicas ramificadas, como as nanoflores de ouro (AuNFs, do inglês gold nanoflowers), apresentam elevada sensibilidade de sua LSPR, bem como alta capacidade de sintonização de sua atividade óptica no NIR. (17) Entretanto, tais protocolos podem tornar o processo de síntese complexo, longo, com baixa reprodutibilidade ou com alta polidispersividade de tamanhos e morfologias, dificultando sua produção em larga escala e seu uso clínico. $(4,17)$

Assim, a escolha das características das nanopartículas, bem como a de sua rota de síntese, é de suma importância, sendo necessário estabelecer protocolos que sejam capazes de produzir sistemas nanoparticulados com as propriedades desejadas, ao mesmo tempo que seja simples, escalável, reprodutível e que produza nanoestruturas monodispersas. Com base nisso, o presente trabalho visou o desenvolvimento de nanopartículas de ouro teranósticas com absorção no NIR. Para tanto, foi desenvolvida uma síntese, realizada em uma única etapa e que produz AuNFs com tamanhos homogêneos e máximo de absorção sintonizável. As partículas se mostraram estáveis por longos períodos, mantendo suas características mesmo após mais de dois meses de sua síntese, além de preservarem suas características físico-químicas em diferentes meios, e sob irradiação de lasers. Ademais, as AuNFs apresentaram uma excelente resposta fotoacústica e boa conversão fototérmica na região do NIR. Por fim, a eficiência terapêutica das nanopartículas foi avaliada através de testes in vitro em células de hepatocarcinoma de rato $(\mathrm{HTC})$ e fibroblastos de camundongos $(\mathrm{FC} 3 \mathrm{H})$, apresentando seletividade terapêutica pela linhagem tumoral. A nanopartícula desenvolvida se mostrou uma candidata promissora para atuação como sistema teranóstico, podendo apresentar aplicações relevantes na terapêutica de tumores, assim como em estudos de nanotoxicidade. 


\section{REVISÃo de CONCEITOS}

\subsection{NANOTECNOLOGIA}

A nanotecnologia é o ramo da ciência, engenharia e tecnologia que visa o desenvolvimento e o estudo de nanomateriais. Como definido na ISO/TS 80004-1:2015, estes são materiais com qualquer dimensão externa na nanoescala ou com estrutura interna ou de superfície na nanoescala, onde nanoescala representa dimensões entre 1 e $100 \mathrm{~nm}$. Contudo, sua verdadeira essência está em propriedades únicas observada nestes materiais decorrentes dessa escala que não são manifestadas quando estão em escalas maiores. $(1,18)$ Tais propriedades surgem devido a dois conceitos fundamentais: ao grande aumento da sua área de superfície específica; e, ao confinamento quântico.

O aumento da razão entre a área de superfície e o volume $(S / V)$ de uma estrutura, gera um aumento da sua reatividade. Isso resulta do fato de que, com a redução do seu tamanho, uma porcentagem crescente de seus átomos fica exposta na superfície. Esses átomos possuem um menor número de átomos vizinhos quando comparados com aqueles do interior da estrutura e apresentam ligações insatisfeitas (dangling bonds). (19) Isso os torna mais propensos a formar ligações com moléculas adsorvidas. (1, 19-20) Tal característica é o que garante que alguns metais nobres, como o ouro, se comportem como catalisadores extremamente eficientes na sua forma particulada, podendo ser aplicado, por exemplo, em células fotovoltaicas e na detecção de substâncias químicas. (1, 21-22) Ademais, os átomos da superfície são termodinamicamente menos estáveis, resultando em variações de características físico-químicas do material, por exemplo, um menor ponto de fusão. (19)

O segundo fenômeno importante é o confinamento quântico. Nesse contexto, a palavra confinamento significa que o movimento randômico dos elétrons é limitado a níveis de energias específicos. Quando o tamanho do material é reduzido, as dimensões de confinamento diminuem, tornando os níveis de energia discretos e aumentando a lacuna das bandas de energia. (1) Tal mudança resulta em propriedades únicas em nanopartículas 
metálicas, como a fotoluminescência e a dependência da cor de sua suspensão coloidal com o tamanho das partículas. $(4,23)$

Com base nas propriedades resultantes desses fenômenos, vemos novas aplicações dos nanomateriais surgirem constantemente, buscando introduzir tais características nas mais diversas áreas do conhecimento. Dentre elas, sua aplicação na área médica tem se mostrado extremamente promissora, possibilitando tanto a melhora de procedimentos já existentes, quanto à criação de novas modalidades. $(4,24)$ Dentre as muitas classes de nanomateriais, as nanopartículas de ouro são uma das mais versáteis e mais exploradas pela comunidade científica. (4)

\subsection{NANOESTRUtURAS DE OURO}

Nanoestruturas de ouro têm sido utilizadas desde tempos antigos devido às suas propriedades ópticas. Exemplos de seu uso podem ser encontrados dando a coloração vermelha de vitrais e a cor peculiar do Copo de Licurgo. $(4,25)$ Contudo, investigações sistemáticas dessas estruturas remontam aos dias de Michael Faraday. No final do século XIX, o cientista descobriu que partículas poderiam ser formadas através do tratamento de ácido cloroáurico $\left(\mathrm{HAuCl}_{4}\right)$ com fósforo dissolvido em dissulfeto de carbono, dando origem a uma solução de cor avermelhada vibrante. (26)

$\mathrm{Na}$ área médica, seu uso tem sido explorado devido às suas características particulares, que incluem baixa reatividade, baixa toxicidade, biocompatibilidade, alta capacidade de funcionalização, assim como propriedades ópticas únicas e altamente controláveis. (8-9) Seu uso em aplicações biológicas ganhou força nas últimas décadas e sua baixa toxicidade aguda tem sido documentada por vários estudos in vitro e in vivo. (9) Isso tem levado ao avanço de testes clínicos de formulações contendo nanoestruturas de ouro para a terapia e diagnóstico de diversas doenças, incluindo aterosclerose e câncer. $(27-32)$

$\mathrm{Na}$ escala nanométrica, o ouro passa a apresentar propriedades ópticas singulares, dentre as quais o fenômeno mais representativo é conhecido como LSPR. (4) Com a incidência de um campo eletromagnético em uma nanoestrutura de ouro, parte da 


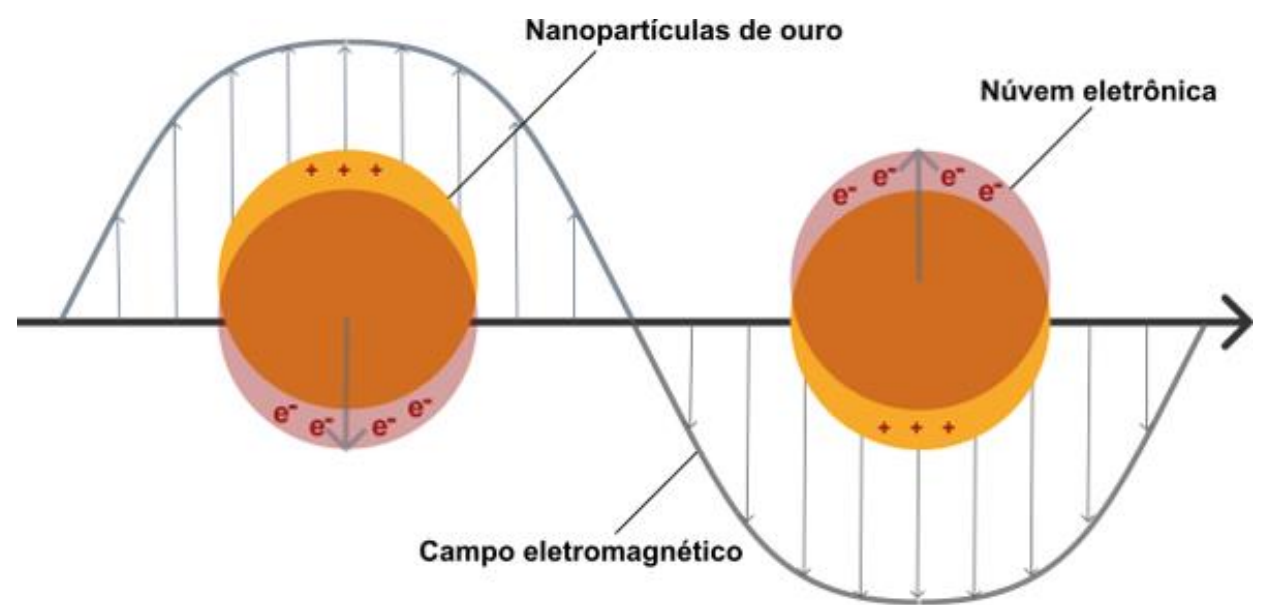

Figura 1 - Ressonância de plasmon de superfície: Representação esquemática do fenômeno de ressonância de plasmon de superfície localizado.

Fonte: Elaborada pelo autor.

radiação é absorvida e parte é espalhada. Tal interação entre as nanopartículas e o campo depende das características das partículas, de forma que nanopartículas de ouro esféricas menores que $20 \mathrm{~nm}$ praticamente não apresentam espalhamento. (33) Pela porção absorvida, os elétrons livres da superfície da nanoestrutura respondem ao campo, começando a oscilar coletivamente em relação à rede de íons positivos (Figura 1). Quando a frequência do campo incidente é igual à frequência de oscilação eletrônica, atinge-se a condição de ressonância. Com isso, parte da energia incidente absorvida é dissipada na forma de calor, resultando em um aquecimento das partículas e do seu ambiente. (10)

A faixa de frequências que levam os elétrons livres à ressonância é conhecida como banda plasmônica e é comumente visualizada através de espectroscopia de ultravioletavisível (UV-visível) (Figura 2b, d e f). As características dessa banda são determinadas a partir de um conjunto de parâmetros das nanoestruturas, incluindo seu tamanho, sua morfologia, bem como o ambiente ao redor de sua superfície. (34-35) Através do controle desses parâmetros, é possível sintonizar a banda plasmônica das nanopartículas no espectro, que podem possuir máximos entre $500-1200 \mathrm{~nm}$. (36-38)

Além de tais propriedades, a síntese de nanoestruturas de ouro é extremamente versátil, permitindo o controle preciso de seu tamanho e formato. Em particular, mudanças na morfologia das nanoestruturas resultam em alterações significativas das suas propriedades ópticas que são, muitas vezes, superiores àquelas das nanopartículas esféricas. (4, 39-41) Com isso, há um grande número de trabalhos reportando 
nanoestruturas com uma variedade enorme de morfologias. Nesse aspecto, as nanopartículas de ouro são a classe de nanopartículas que apresentam a maior variedade de formas. (41) Dentre elas, inclui-se clusters (42), esferas (43), bastões (44), placas (45), cascas (46), gaiolas (47) e flores (48), assim como outras geometrias menos convencionais, como nanocubos côncavos. (49-50)

As nanopartículas de ouro esféricas (AuNPs, do inglês gold nanoparticles) foram vastamente estudadas nas últimas décadas. O efeito LSPR permite uma alta conversão do estímulo luminoso em calor e possui um único modo de oscilação (Figura 2a). Seu espectro UV-visível possui uma banda plasmônica característica bem definida localizada na região visível, usualmente centrada entre $500-600 \mathrm{~nm}$ (Figura 2b). (4) Contudo, o deslocamento da banda das AuNPs para comprimentos de ondas maiores é um desafio, necessitando, por exemplo, da criação de estruturas com múltiplas camadas conhecidas como nanomatrioshkas. (51-52)

Por outro lado, nanopartículas anisotrópicas permitem a obtenção de nanoestruturas com bandas localizadas no NIR de maneira mais simples e eficiente, tornando-as particularmente interessantes para certas aplicações biológicas. Nanobastões de ouro (AuNRs, do inglês gold nanorods) são uma das classes de nanopartículas de ouro anisotrópicas mais exploradas na literatura. (4) Por ter um formato alongado, essas estruturas possuem duas dimensões importantes e, consequentemente, dois modos de ressonância plasmônica (Figura 2c). Isso resulta em um espectro UV-visível característico dessas partículas apresentando duas bandas: uma banda transversal menos intensa na região do visível e uma banda intensa longitudinal que, em geral, se encontra no NIR (Figura 2d). Diferentemente das AuNPs, a posição, o formato e a intensidade da banda plasmônica longitudinal dos AuNRs é extremamente sensível às suas dimensões. Particularmente, essa banda possui grande dependência com sua razão de aspecto, a razão entre seu comprimento longitudinal e transversal. $(4,53)$ Com o aumento dessa razão, sua banda longitudinal tende a ser deslocada para o NIR, podendo atingir máximos centrados até em $1300 \mathrm{~nm}$. (54) 


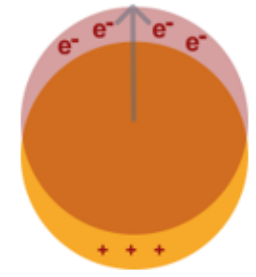

(a)

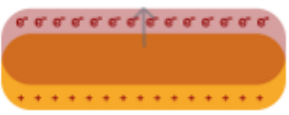

(c)

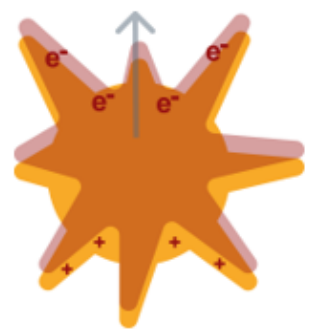

(e)

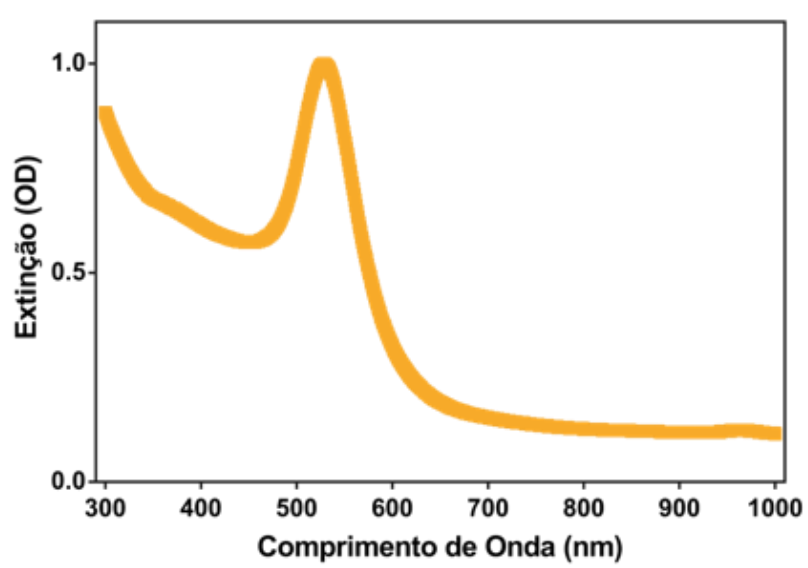

(b)

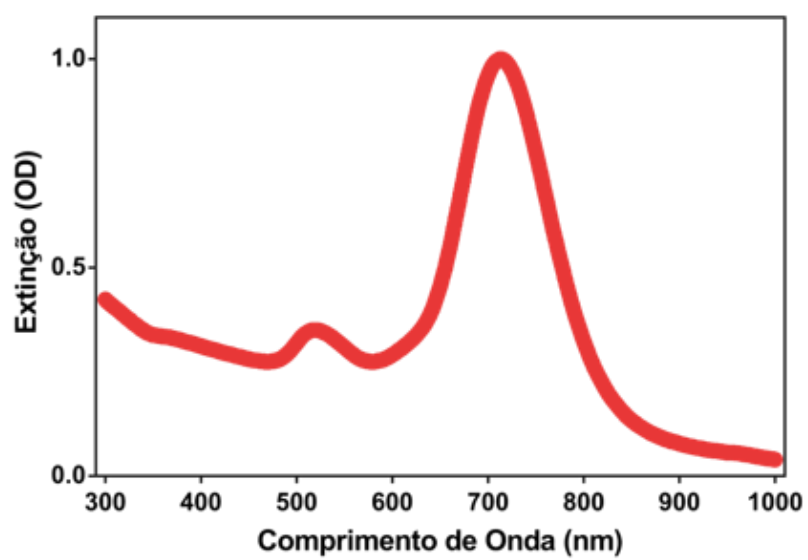

(d)

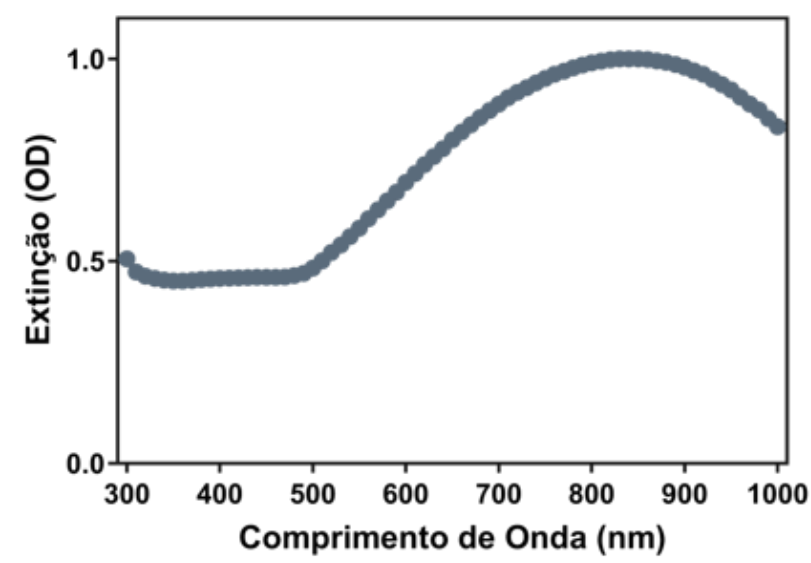

(f)

Figura 2 - Influência da geometria no fenômeno de LSPR: (a), (c) e (e) são representações esquemáticas do fenômeno de LSPR de nanopartículas de ouro esféricas, nanobastões e nanoflores, respectivamente. (b), (d) e (f) apresentam os espectros de extinção UV-visível, respectivamente, de nanopartículas de ouro esféricas, nanobastões e nanoflores.

Fonte: Elaborada pelo autor. 
Os avanços nos processos de síntese permitiram a obtenção de nanopartículas de ouro com múltiplas ramificações. Sua nomenclatura ainda não é bem estabelecida e é baseada na morfologia de suas ramificações, podendo ser denominadas nanoestrelas, nanoflores e até nanoouriços. $(49,55-56)$ Dada sua morfologia peculiar, essas estruturas apresentam um aumento do campo eletromagnético em torno das suas ramificações, resultando em excelentes propriedades ópticas, eletrônicas, magnéticas e catalíticas. (49, 57-58) Com isso, essas nanoestruturas vêm sendo usadas em uma enorme variedade de aplicações, mostrando desempenho ímpar, por exemplo, em catálise, espectroscopia Raman amplificada por superfície (SERS, do inglês surface-enhanced Raman spectroscopy), imagem fotoacústica e terapia fototérmica. (59) Quando consideramos essas estruturas ramificadas, o efeito LSPR se torna mais complexo (Figura 2e). (60) Essa estrutura pode ser dividida em duas partes, um núcleo esférico e suas ramificações. A LSPR é resultado da interação das ressonâncias ocorridas nessas duas partes, ocorrendo uma hibridização dos plasmons. (60-61) Tal hibridização entre núcleo-ramificações e entre ramificações resulta em um espectro UV-visível com uma banda intensa, extremamente larga e, em geral, localizada no NIR (Figura 2f). (61) Além disso, a morfologia ramificada garante uma grande área de superfície, tornando-as altamente reativas e propensas à geração de calor. (62-63)

Com tamanha variedade de geometrias e tamanhos, a escolha das nanoestruturas, de sua síntese e modificações são fundamentais no desenvolvimento de nanoestruturas para aplicações médicas. Diferentemente de suas estruturas na macroescala, características como tamanho, geometria, propriedades de superfície, composição, estabilidade e solubilidade são extremamente significativas no seu uso em meios biológicos. Tais fatores têm enormes influências na sua aplicabilidade, tanto na sua eficiência terapêutica, quanto na sua precisão de diagnóstico. (20)

\subsection{ESTABILIDADE DAS NANOPARTíCULAS}

A agregação de sistemas nanoparticulados refere-se ao fenômeno da aderência entre partículas que, em geral, é irreversível e leva à formação de grandes agregados. (64) Como vimos, as propriedades das nanoestruturas estão intrinsicamente relacionadas ao 
seu tamanho. Dessa forma, com sua agregação, o sistema perde suas propriedades resultantes da escala nanométrica, perdendo, assim, sua aplicabilidade.

A estabilidade do sistema de nanopartículas em solução é determinado pela interação resultante de forças intermoleculares e de superfície, como as forças de Van der Waals, eletrostáticas e magnéticas. (64) Caso não haja mecanismos para compensar as forças atrativas, as nanopartículas tendem a agregar-se. (65) Para tanto, busca-se estabilizar o sistema via estabilização eletrostática, estérea ou pela combinação de ambas. (66)

A estabilização eletrostática baseia-se na adsorção de cargas na superfície das nanopartículas. (66) A maioria dos nanomateriais carrega alguma carga de superfície em suspensões aquosas, devido à adsorção de moléculas e íons carregados em sua superfície ou devido à ionização/dissociação de grupos de superfície. (64) Devido à essa carga, formase uma camada de contraíons adsorvida na superfície das nanopartículas, conhecida como camada de Stern; e, uma segunda camada formada por íons livres atraídos pela primeira camada, conhecida por camada difusa. (64) Com a formação dessa dupla camada elétrica, as forças de atração entre as partículas são balanceadas pela repulsão eletrostática, garantindo a estabilidade do sistema. Um exemplo muito conhecido consiste nas nanopartículas de ouro estabilizadas com citrato, nas quais forma-se uma bicamada elétrica constituída por citrato, íons cloreto e cátions adsorvidos em sua superfície. (65)

A estabilização estérea, por sua vez, é o processo na qual as nanoestruturas são estabilizadas pela adsorção de moléculas longas na sua superfície dando origem a uma camada protetora. (64) Este é o mecanismo mais comum para aumentar a estabilidade das nanoestruturas e é geralmente alcançado através do uso de polímeros, como polietilenoglicol (PEG), e surfactantes, como o brometo de cetiltrimetilamônio (CTAB, do inglês cetyltrimethylammonium bromide). (67) Tal estabilidade é garantida uma vez que, com a aproximação das nanopartículas, a densidade de moléculas adsorvidas aumenta significativamente na região entre as partículas. Isso causa uma redução na entropia, resultando na redução da estabilidade termodinâmica do sistema devido ao aumento da energia livre. (65-66) No entanto, a estabilização estérea só é eficaz se o revestimento 
formado for uniforme na superfície da partícula. Em casos onde a camada é irregular, o sistema fica suscetível à agregação. (64)

Atualmente, a melhoria do desempenho das nanoestruturas in vivo ainda é um desafio. (68) Quando inseridas em meios biológicos, a estabilidade das nanopartículas é significativamente alterada devido à alta força iônica do meio e à interação inespecífica com macromoléculas do meio, como proteínas. (64)

A dupla camada elétrica que mantém o sistema estável depende não apenas das características das nanoestruturas, mas também do meio no qual estão inseridas. A força iônica do meio influencia o tamanho da camada difusa, de forma que baixas forças iônicas resultam em uma camada extensa; já altas forças, resultam em uma camada reduzida e, consequentemente, menor estabilidade. (69) Dessa forma, nanopartículas estabilizadas eletrostaticamente tendem a demonstrar baixa estabilidade nos meios biológicos. $(64,69)$

Por outro lado, as interações não-específicas entre nanopartículas e proteínas, como imunoglobulina, lipoproteínas e fatores de coagulação, podem resultar na ligação dessas moléculas nas partículas. Com isso, ocorre a formação de uma nova camada proteica entre as partículas e o sistema biológico, conhecida como corona. (70-71) Essa camada pode reduzir a estabilidade das nanoestruturas, podendo potencialmente alterar a interação das nanopartículas com seus alvos. Além disso, a corona pode tornar os nanomateriais mais visíveis para células fagocíticas, influenciando consideravelmente sua biodistribuição, seu tempo de circulação, seu metabolismo, sua depuração e sua resposta imune. (71-72) Um dos fatores identificados que apresenta grande influência nessa interação é a carga de superfície das nanopartículas, de forma que partículas neutras ou zwitteriônicas se mostram mais estáveis e biocompatíveis. (68) Com base nisso, a estabilização estérea se mostra mais efetiva, principalmente quando realizada com moléculas que reduzem a carga do sistema, como o PEG. (73) Isso ocorre pois além de servirem como barreira para prevenir a interação entre partículas, as moléculas protegem a superfície das nanoestruturas reduzindo a adsorção das proteínas. (64)

Dessa forma, a elaboração do sistema nanoparticulado deve ser realizada de forma a considerar sua interação no meio biológico. Com isso, a escolha do agente estabilizante, 
da forma de ligá-lo às nanoestruturas e, consequentemente, a rota de síntese é fundamental para uma aplicação bem-sucedida.

\subsection{Síntese das Nanopartículas de OURO}

O tamanho, a morfologia e as propriedades das nanopartículas dependem do seu método de preparo. A síntese das nanopartículas de ouro pode ser realizada por duas rotas, top-down ou bottom-up, podendo ser categorizados em processos físicos, químicos e biológicos. (74-76).

Em procedimentos top-down, um precursor é sistematicamente quebrado em estruturas menores até atingir partículas do tamanho desejado. Contudo, a formação de nanopartículas por esse método é limitada, considerando que o controle do tamanho, da geometria e da distribuição do tamanho é difícil de ser alcançado. (77)

Procedimentos bottom-up, por outro lado, possibilitam um melhor controle das características físico-químicas das partículas produzidas. (16) Neles, o preparo das nanopartículas é geralmente baseado em rotas químicas em fase líquida, incluindo a redução química de sais de ouro, as rotas eletroquímicas e a decomposição de compostos organometálicos. (77) Tais rotas são amplamente utilizadas, sendo geralmente simples e permitindo a obtenção de nanopartículas uniformes de diversos tamanhos e morfologias. $(65,77)$

A obtenção de nanopartículas através do método de redução química pode ser dividida em duas etapas: a nucleação e o crescimento. Primeiramente ocorre a reação de redução, na qual o sal de ouro é reduzido originando átomos de ouro $\left(A u^{0}\right)$. (4) Sua redução resulta na supersaturação de ouro da solução, que precipita como núcleos na forma de partículas subnanométricas em um processo conhecido como nucleação. Em seguida, os núcleos formados crescem através da deposição de camadas de ouro em sua superfície. (16) Para melhorar a estabilidade do sistema, esse processo é feito na presença de agentes estabilizantes que adsorvem na superfície dos núcleos, garantindo uma estabilidade eletrostática ou estérea. (65) Para estabilização das nanopartículas, é comum serem utilizadas estruturas com ligantes orgânicos que possuem alta afinidade com a superfície 
de ouro, como as terminações tiol. Estas incluem dissulfetos, dendrímeros e polímeros com grupos mercapto ou modificados com terminações tiol. (65)

As sínteses químicas são realizadas de duas maneiras: in situ, e mediadas por semente (4). Nas sínteses in situ, tanto a nucleação quanto o crescimento das nanopartículas ocorrem em um único processo. Já sínteses mediadas por semente ocorrem em duas etapas, separando o passo de nucleação e o de crescimento das nanopartículas. (16) Na primeira etapa, núcleos com poucos nanômetros de diâmetro, conhecidos como sementes, são formados para serem utilizados para o crescimento das nanopartículas. As características desses núcleos têm enorme influência na estrutura final, determinando seu tamanho, sua morfologia e suas propriedades de superfície. Na segunda etapa, as sementes são adicionadas a uma solução de crescimento composta por sal de ouro, agentes estabilizantes e redutores. (16) Ao adicioná-las na solução, átomos de ouro $\mathrm{Au}$ crescem na sua superfície, evoluindo os núcleos para as nanoestruturas maiores. De modo geral, os agentes redutores usados na segunda etapa são redutores fracos. Dessa forma, o ouro só é reduzido na presença das sementes que funcionam como catalisadores, garantindo que os $A u^{0}$ recém reduzidos na solução de crescimento só irão crescer na superfície das sementes e não irão formar novos núcleos. (77)

Com base nessas metodologias, é possível sintetizar nanoestruturas de ouro em uma enorme variedade de tamanhos e geometrias. A grande maioria dos métodos propostos para a obtenção de nanopartículas anisotrópicas segue a síntese mediada por sementes. (41) Contudo, o resultado final dessa metodologia tende a ser extremamente sensível aos parâmetros da síntese e de difícil reprodutibilidade.

No campo da síntese das nanopartículas anisotrópicas, os AuNRs são as estruturas que possuem o protocolo mais bem estabelecido em termos do controle de tamanho, forma e monodispersividade. (78) Uma síntese comumente usada consiste no uso de sementes estabilizadas com o surfactante CTAB, que passam pela etapa de crescimento utilizando o mesmo estabilizante na presença de íons de prata. (54) Ainda que não haja um consenso sobre o mecanismo que resulta no crescimento assimétrico dessas nanoestruturas, foram formuladas algumas teorias para explicar o fenômeno baseando-se na observação empírica de sua formação. (4) Uma delas afirma que há a ocorrência de 
deposição em regime de subtensão (UPD, do inglês underpotential deposition) dos íons de prata nas várias faces cristalinas do ouro, resultando na quebra de simetria das partículas. (78) Tal deposição relaciona-se com a formação de uma monocamada de prata na superfície de ouro em potenciais mais positivos do que o potencial de Nernst. Isso ocorre uma vez que a ligação entre a prata adsorvida e o ouro é mais forte que a ligação entre os átomos de prata. (79) Estudos mostram que a UPD da prata na superfície de ouro é decrescente nas faces $\{110\},\{100\}$ e $\{111\}$ devido ao número de primeiros vizinhos do átomo adsorvido, que decresce na mesma ordem. Com base nisso, constrói-se a hipótese de que, com a formação da monocamada de prata ocorre uma inibição da deposição de átomos, reduzindo a taxa de crescimento do ouro nas faces $\{110\}$. As demais faces, devido a uma formação parcial da monocamada de prata, tendem a crescer mais rapidamente resultando no crescimento assimétrico da estrutura. $(4,78)$

Assim como as AuNRs, as nanoestruturas ramificadas, como a das nanoflores de ouro (AuNFs, do inglês gold nanoflowers), também podem ser obtidas através do uso de agentes de recobrimento que direcionam o crescimento. (80) Contudo, sua síntese em geral é considerada mais desafiadora, uma vez que seu crescimento anisotrópico deve ocorrer em múltiplos locais de um núcleo e deve ser mantido para a formação dos vários ramos. (4)

AuNFs podem ser sintetizadas tanto por métodos mediados por semente quanto por métodos in situ. (80-81) Em geral, o método mediado por semente é mais utilizado, tipicamente permitindo melhor controle sobre a morfologia, cristalinidade e distribuição de tamanho das partículas. (4) Assim como as AuNRs, muitos métodos utilizam o CTAB como agente estabilizante. Contudo, dada sua citotoxicidade e a dificuldade de remoção do CTAB, muitos procedimentos buscam sua substituição por outros agentes, como a laurilsulfobetaína zwiteriônica, a poli (vinilpirrolidona) e o Triton X-100. (81-83) Por outro lado, sínteses in situ representam uma forma mais simples e direta de obtenção das AuNFs. Alguns protocolos foram propostos para sínteses in situ, utilizando, por exemplo, o ácido 4(2-hidroxietil)-1-piperazinoetanossulfónico (HEPES, do inglês 4-(2-hydroxyethyl)-1piperazineethanesulfonic acid), a glucosamina e, mais recentemente, o ácido gálico, todos os quais funcionam como agentes redutores e estabilizantes simultaneamente. $(59,80,84)$ 
Dada sua complexidade, a obtenção de populações monodispersas e com morfologias e tamanhos bem definidos é dificultada. (4) Dessa forma, metodologias que sejam simples, escaláveis, reprodutíveis, ao mesmo tempo que permitam o controle da morfologia e que produzam populações homogêneas ainda estão sendo buscadas.

\subsection{Modalidades Fotoativadas para Terapia E Diagnóstico de TUMORES}

Segundo a Organização Mundial de Saúde (WHO, do inglês World Health Organization), o câncer é a segunda principal causa de morte em todo o mundo sendo responsável por aproximadamente 1 em cada 6 mortes. No Brasil, estima-se a ocorrência de quase 600 mil novos casos entre 2016-2017. (85) Devido a sua natureza extremamente agressiva e baixa taxa de sobrevivência, o câncer de fígado é uma preocupação séria para a saúde pública mundial. Esse tipo de tumor se desenvolve a partir de mutações das células do fígado. Sua incidência está relacionada a infecções crônicas por hepatite B e C, que podem desencadear o desenvolvimento desse tumor. Contudo, a cirrose hepática é o principal fator de risco para o surgimento do câncer de fígado. Estima-se que, em 2012, este foi o quinto tipo mais incidente, sendo responsável por $9,1 \%$ do total de mortes por câncer em todo o mundo. (86)

Atualmente, as metodologias comumente empregadas para a terapia do câncer de fígado incluem a quimioterapia, a radioterapia, cirurgias, bem como a combinação desses métodos. Entretanto, tais procedimentos contam com graves problemas, incluindo efeitos colaterais sistêmicos, danos inespecíficos a tecidos saudáveis, alto índice de recidiva, além de limites cumulativos de doses. (87-88)

Nesse contexto, novos procedimentos que buscam melhores eficiências terapêuticas, reduções dos efeitos colaterais e diagnósticos mais precisos estão sendo desenvolvidos. Dentre eles, modalidades fotoativadas surgem como candidatas promissoras. (62)

Apesar de fototerapias serem utilizadas desde tempos antigos, a pesquisa sistemática de sua aplicação ganhou força apenas no século XX. (89) Hoje, elas são mundialmente empregadas para terapia e diagnóstico. (90) Seu funcionamento baseia-se 
no uso de fontes luminosas, como lasers, para a indução de respostas resultantes da absorção da luz. Tais respostas podem ser obtidas pela simples irradiação do tecido doente ou pela irradiação de um agente ativo. Uma vez irradiados, três efeitos principais podem ocorrer: a geração de calor, a emissão de luz e a ativação de reações fotoquímicas. $(89,91)$

A natureza de interação entre laser e tecido é determinada conjuntamente pelas características do laser, que incluem seu comprimento de onda, sua potência de irradiação e seu modo de operação, que pode ser contínuo (CW, do inglês continuous wavelength) ou pulsado (PW, do inglês pulsed wavelength). (89) Contudo, aplicações baseadas em lasers são dificultadas devido ao alto coeficiente de extinção dos tecidos humanos em grande parte do espectro UV-visível e NIR. (14) Com isso, a eficiência do procedimento pode ser prejudicada e, como a interação com a luz ocorre tanto em tecidos doentes quanto em saudáveis, o procedimento pode acarretar em danos inespecíficos. (14)

Entretanto, a redução das interações não-específicas pode ser alcançada. Para tanto, deve-se utilizar lasers com comprimentos de ondas localizados em regiões do espectro em que os tecidos são parcialmente transparentes. (89) Em tais regiões, o coeficiente de extinção dos tecidos é reduzido, resultando em menor interação com o feixe de luz. (14) Existem duas regiões no espectro UV-vis-NIR com essa característica:

- A primeira janela biológica, entre $700-980 \mathrm{~nm}$, corresponde ao intervalo definido entre a região de absorção da hemoglobina na região visível e a banda de absorção da água em $980 \mathrm{~nm}$. (14) Nela, apesar de ainda haver interação devido ao espalhamento da luz pelos tecidos, a absorção é reduzida significativamente.

- A segunda janela biológica, localizada entre $1000-1400 \mathrm{~nm}$, é limitada pelas bandas de absorção da água. (14) Diferentemente da primeira janela, a absorção não desaparece completamente devido ao coeficiente de absorção da água, entretanto seu espalhamento é minimizado.

Além do uso de comprimentos de onda nessas regiões, o uso de agentes ativos localizados na região doente pode aumentar significativamente a eficiência do procedimento. Além disso, tais agentes absorvem muito mais luz do que os tecidos, permitindo que a potência do laser utilizada seja consideravelmente reduzida. (14) 
Nesse âmbito, a incorporação de nanomateriais como agentes ativos dos procedimentos fotoativados permite o desenvolvimento de metodologias minimamente invasivas, com ação seletiva e localizada. (90) Para alcançar tais características, as nanoestruturas devem ser opticamente ativas na região do espectro do laser utilizado. Com isso, nanopartículas de ouro com absorção no NIR têm sido vastamente empregadas como agentes ativos, tanto em modalidades diagnósticas, quanto em modalidades terapêuticas. (90)

\section{MODALIDADES DIAGNÓSTICAS: IMAGEM FOTOACÚSTICA}

Modalidades diagnósticas fotoativadas são amplamente utilizadas, sendo empregadas para a obtenção de imagens in vivo e para a detecção de tumores. Seu uso inclui, por exemplo, imagens moleculares, imagens multimodais, tomografia de coerência óptica e tomografia por emissão de pósitrons. (90) Dentre elas, as imagens fotoacústicas apresentam um enorme potencial clínico. Combinando vantagens das imagens óptica com àquelas das imagens ultrassonográficas, essa técnica apresenta alta penetração em tecidos e excelente resolução espacial. (92-94)

Descoberto no século XIX, o efeito fotoacústico representa a produção de uma onda acústica após a absorção de luz em um dado meio. (90) O sinal fotoacústico possui uma dependência direta e linear com o número de fótons absorvidos, sendo descrito por:

$$
P=F \mu_{a} \gamma
$$

onde $P$ é o sinal fotoacústico, $F$ é a fluência do laser, $\mu_{a}$ é o coeficiente de absorção óptica do meio e $\gamma$ é o parâmetro de Grüneisen que descreve as características de transferência de calor do meio.

Baseada nesse fenômeno, a imagem fotoacústica é uma técnica de imagem emergente que permite a visualização de tecidos in vivo em tempo real, sem a sua remoção. (91) Ela é obtida através da irradiação de tecidos por um laser que, ao absorver o estímulo, libera calor para suas imediações. Com a variação de temperatura, o ambiente sofre expansão térmica rápida e localizada que, ao contrair-se para seu estado original, produz uma onda acústica de alta amplitude. Tal onda pode ser detectada usando transdutores de 
ultrassom e técnicas de reconstrução de imagem, resultando em um mapa da energia absorvida pelo tecido irradiado. (90)

Por ser um fenômeno baseado apenas na absorção da luz, o sinal fotoacústico pode ser obtido mesmo sem agentes ativos, permitindo a visualização de tecido, como hemoglobinas oxigenadas e desoxigenadas, melanina e lipídios. (92) Entretanto, a introdução de agentes ativos localizados no tecido doente que possuam alta absorção óptica permite a obtenção de contraste seletivo dessas estruturas no NIR.

Combinando sua biocompatibilidade com suas propriedades ópticas, as nanopartículas de ouro consistem em uma das classes de nanopartículas mais utilizadas como agentes de contraste fotoacústico. (92) Tais características, aliadas com a resolução espacial da imagem fotoacústica, podem melhorar significativamente o processo de diagnóstico de tumores em estágios iniciais. (91) Seu uso para formação de imagens fotoacústicas de tumores ainda permanece na fase de pesquisa pré-clínica, embora vários estudos interessantes tenham sido explorados. (92)

Dentre as várias nanoestruturas de ouro utilizadas, o uso das AuNFs como agentes de contraste fotoacústico tem ganhado atenção devido a sua alta absorção no NIR e sua grande área de superfície. (95) Seu uso se mostrou extremamente versátil apresentando resposta fotoacústica em ambas janelas biológicas e permitindo, ainda, a realização simultânea do procedimento terapêutico. $(94,96)$

\section{MODALIDADES TERAPÊUTICAS: TERAPIA FOTOTÉRMICA}

As terapias fotoativadas consistem em técnicas nas quais faz-se uso da luz para ativar o processo terapêutico. Em geral, tais técnicas são procedimentos não-cirúrgicos e minimamente invasivos e já são usados para o controle de diversos tipos de tumores, incluindo de pulmão, de pele e de cabeça e pescoço. (97) Dentre as diversas modalidades, a terapia fototérmica tem se mostrado uma alternativa promissora para o tratamento de câncer. (98) Seu funcionamento baseia-se na indução de morte celular localizada através do aumento da temperatura do tecido doente pela irradiação por um laser. (91) 
Terapias térmicas vêm sendo empregadas na terapêutica de tumores desde o século XIX. Sua eficiência é definida por dois fatores principais: a magnitude do incremento de temperatura e a duração do tratamento. (14) Existem três intervalos de temperaturas relevantes para a técnica: diatermia (até $\left.41^{\circ} \mathrm{C}\right)$; hipertermia $\left(41-48^{\circ} \mathrm{C}\right)$; e a região de danos irreversíveis (acima de $48^{\circ} \mathrm{C}$ ). Dentre os intervalos, o de hipertermia é considerado o intervalo clinicamente relevante. (13)

A resposta das células expostas a altas temperaturas depende tanto da duração da exposição quanto da magnitude da temperatura. O incremento da temperatura celular para valores acima até a região de hipertermia pode causar não apenas a desnaturação de proteínas, mas também a inativação celular temporária por algumas horas. Elevando a temperatura para valores entre $43-45^{\circ} \mathrm{C}$, observa-se um aumento significativo das taxas de reações bioquímicas, resultando em estresse oxidativo e danos às células. Já em temperaturas $45-48^{\circ} \mathrm{C}$, produz-se morte celular necrótica em células. (14) Por outro lado, a maioria dos tecidos saudáveis não é danificado pelo tratamento em temperatura de até $44^{\circ} \mathrm{C}$ por até $1 h$. (13)

Atingir um aumento preciso e localizado da temperatura não é uma tarefa simples. Pequenas variações de temperatura podem causar danos irreversíveis não apenas para tecidos doentes, mas também para os saudáveis. (13) Nesse aspecto, a introdução de nanopartículas de ouro no processo terapêutico permite alcançar um aumento de temperatura controlado, localizado do tecido doente e ativado à distância através de sua irradiação. (62)

Ao irradiar uma dispersão de nanopartículas de ouro em sua banda plasmônica, os elétrons dos nanocristais absorvem parte da energia e entram em ressonância, passando a oscilar coletivamente. Buscando retornar ao equilíbrio térmico, a energia cinética dos elétrons oscilantes é transferida para a estrutura cristalina pelo acoplamento elétron-fônon após alguns pico-segundos. (99) Em seguida, a energia da estrutura é transferida para o meio por interações fônon-fônon após algumas centenas de pico-segundos. (100) Nesse processo, o calor é dissipado pela interface partículas-meio, aumentando a temperatura da solução para resfriar a nanoestrutura. (101) 
Uma grande variedade de nanopartículas de ouro já foi empregada como agente ativo de terapia fototérmica, incluindo AuNPs, AuNRs e AuNFs. (91) No caso das nanoflores, sua alta razão entre absorção/espalhamento na região do NIR as tornam excelentes produtoras de calor. (62) Isso vem sendo confirmado através de diversos trabalhos que validam sua aplicação para hipertermia de tumores, sendo reportadas repostas terapêuticas utilizando densidades de potências de até $0,2 \mathrm{~W} \cdot \mathrm{cm}^{-2}$, uma das mais baixas já reportadas utilizando lasers PW. (102) Ainda, foi relatado seu uso como agente ativo para fototermia que, aliado com a técnica de SERS e imagens fotoacústicas, permitiu a realização da terapia e do monitoramento simultaneamente. $(59,103)$ 


\section{OBJetivos}

Como objetivo geral, o presente trabalho visou o desenvolvimento de nanopartículas de ouro anisotrópicas teranósticas para aplicações em modalidades fotoativadas para terapia e diagnóstico de câncer.

Como objetivo específico, visou-se o desenvolvimento de uma síntese simples, reprodutível e escalável, que seja capaz de produzir nanopartículas anisotrópicas ramificadas monodispersas e fotoativas no infravermelho próximo com vistas às suas aplicações como agentes de contraste de imagens fotoacústica e como agentes terapêuticos para a hipertermia de células tumorais in vitro. 


\section{MATERIAIS E MÉTODOS}

\subsection{MateriaIS}

Todas as soluções foram preparadas utilizando água ultrapura $(18,2 \mathrm{M} \Omega . \mathrm{cm}$ à $\left.25^{\circ} \mathrm{C}\right)$. Ácido tetracloroáurico $\left(\mathrm{HAuCl}_{4} \cdot 3 \mathrm{H}_{2} \mathrm{O}\right)$, ácido L-ascórbico, nitrato de prata $\left(\mathrm{AgNO}_{3}\right)$, poli(etilenoglicol) metil éter tiol $(M W=10000)$ (PEG-tiol), hidróxido de sódio $(\mathrm{NaOH})$, azul de trypan foram adquiridos da Sigma-Aldrich (USA). Meios de cultura Dulbecco's modified Eagle's médium (DMEM), soro fetal bovino (FBS, do inglês fetal bovine sorum) e a solução de tripsina (EDTA) foram adquiridos da Vitrocell (Campinas, Brasil).

Todas as vidrarias e barras magnéticas utilizadas foram limpas antes de cada experimento utilizando uma formulação de água régia $\left(\mathrm{HCl}\right.$ e $\mathrm{HNO}_{3}$ na proporção 1:3) recém preparada. Ademais, todos os reagentes utilizados na cultura de células foram previamente autoclavados e os procedimentos realizados em uma câmara de fluxo laminar utilizando materiais estéreis.

\subsection{SÍNTESE}

\subsubsection{SÍNTESE DAS AUNFS}

Em uma síntese típica, $35 \mu \mathrm{L}$ de $\mathrm{HAuCl}_{4}(10 \mathrm{mM})$ foi adicionada a $1 \mathrm{~mL}$ de solução de PEG-tiol (0,056 mM). Adicionou-se, então, $15 \mu \mathrm{L}$ de $\mathrm{AgNO}_{3}(10 \mathrm{mM})$, e, em seguida, $150 \mu \mathrm{L}$ de ácido L-ascórbico $(100 \mathrm{mM})$. Durante todo o procedimento, a solução foi mantida à $23^{\circ} \mathrm{C}$ e sob agitação de $400 \mathrm{rpm}$ por uma barra magnética. Após $5 \mathrm{~min}, 100 \mu \mathrm{L}$ de uma solução de PEG-tiol $(0,448 \mathrm{mM})$ foi adicionada e a solução mantida sob sonicação por $30 \mathrm{~min}$. Por fim, a solução final foi posta sob agitação branda por cerca de $13 \mathrm{~h}$ à $4^{\circ} \mathrm{C}$.

\subsubsection{LIMPEZA DA SOLUÇÃo E ARMAZENAMENTO}

Utilizando uma centrífuga (Eppendorf 5804 R), a solução obtida foi centrifugada a $7500 \mathrm{~g}$ por $10 \mathrm{~min}$ à $4^{\circ} \mathrm{C}$. O sobrenadante translúcido foi descartado e as partículas 
ressuspendidas em água ultrapura. Após sua limpeza, as AuNFs foram armazenadas em um vidro âmbar protegido por papel alumínio à $4^{\circ} \mathrm{C}$.

\subsection{TÉCNICAS de CARACTERIZAÇÃo}

\subsubsection{ESPECTROSCOPIA ULTRAVIOLETA-VISÍVEL}

As medidas de extinção das amostras foram realizadas utilizando um espectrofotômetro UV-visível SpectraMax M3 (Molecular Devices) obtidas entre 300 $1000 \mathrm{~nm}$, em uma cubeta de quartzo de $1 \mathrm{~cm}$ de caminho óptico. Valores de extinção da mesma cubeta contendo água ultrapura ou meio de cultura foram subtraídos como linhas de base, de acordo com a solução utilizada. Para valores obtidos fora do intervalo de confiança do equipamento (ext. > 2), as amostras foram diluídas por um fator conhecido.

\subsubsection{ESPALHAMENTO DE LUZ DinÂMICO}

A aferição do tamanho hidrodinâmico e do estado de agregação dos nanomateriais foi realizada in situ com base na técnica de espalhamento de luz dinâmico (DLS, do inglês dynamic light scattering) utilizando um equipamento Zetasizer Nano ZS-90 (Malvern). As medidas foram obtidas operando em $632,8 \mathrm{~nm}$ a $25^{\circ} \mathrm{C}$, com detector posicionado a $90^{\circ} \mathrm{em}$ relação ao feixe incidente. A medida de cada amostra foi realizada em triplicata e a distribuição de tamanho final considerada foi a média das distribuições das três medidas.

\subsubsection{Potencial Zeta}

Medidas de potencial zeta foram obtidas in situ utilizando o equipamento Zetasizer Nano ZS-90 (Malvern), dispondo de uma célula capilar descartável de policarbonato dotada de contatos metálicos banhados a ouro, específica para tal análise. As amostras foram analisadas em triplicadas, a $25^{\circ} \mathrm{C}$ e o potencial final considerado foi obtido com base na média das medidas. 


\subsubsection{MICROSCOPIA ELETRÔNICA DE VARREDURA}

Para análise da morfologia das AuNFs, foram realizadas medidas de microscopia eletrônica de varredura com emissão de campo (FEG-SEM, do inglês field-emission scanning electron microscopy). Para isso, substratos de silício (Sigma-Aldrich) foram limpos utilizando acetona, isopropanol, etanol e água em um banho de ultrassom por $10 \mathrm{~min}$ cada e, em seguida, foram secos utilizando um fluxo de nitrogênio gasoso. Em seguida, as amostras diluídas em água ultrapura foram colocadas no substrato e secas à vácuo em um dessecador, no qual permaneceram por $12 \mathrm{~h}$. As imagens foram, então, obtidas utilizando um Zeiss Sigma VP FEG-SEM a $3 k V$ em modo de alto vácuo.

\subsubsection{DIFRAÇÃO DE RAIO-X}

Para a obtenção dos espectros de difração de raio-x (XRD, do inglês $x$-ray diffraction), $10 \mathrm{~mL}$ de AuNFs foram sintetizados e centrifugados a $4^{\circ} \mathrm{C}$ por $10 \mathrm{~min}$ a $7800 \mathrm{~g}$. O sobrenadante foi descartado e as nanopartículas ressuspensas em $1 \mathrm{~mL}$. A solução foi, então, seca à vácuo em um dessecador sobre uma lamínula de vidro. A amostra foi analisada utilizando uma unidade de raios-x Rigaku Rotaflex RU200B, com tensão de $40 \mathrm{kV}$ e $60 \mathrm{~mA}$ com ânodo de $\mathrm{Cu}$. Utilizou-se uma varredura normal de $5-100^{\circ}$ com passo de $0,0200 /$ segundo e velocidade de $1^{o}$. minuto $^{-1}$.

\subsubsection{ESPECTROSCOPIA DE INFRAVERMELHO}

O espectro vibracional no infravermelho próximo (FTIR, do inglês Fourier transform infrared spectroscopy) foi obtido utilizando um espectrofotômetro iS50 (Nicolet) na faixa de $400-4000 \mathrm{~cm}^{-1}$, com resolução de $4 \mathrm{~cm}^{-1}$. Cada espectro foi obtido a partir da média de 128 medidas no modo de transmitância. Para o preparo, as amostras utilizadas foram secas à vácuo em um dessecador. Após sua secagem, as amostras foram misturadas com $\mathrm{KBr}$ na proporção de 1: 80 e prensadas, formando pastilhas de $0,5 \mathrm{~cm}$ de diâmetro. 


\subsubsection{RESPOSTA FOTOTÉRMICA}

Para análise da resposta fototérmica das AuNFs, a solução estoque de nanoestruturas foi sonicada por $10 \mathrm{~min}$ e centrifugada por $10 \mathrm{~min}$ a $7800 \mathrm{~g}$ e $4^{\circ} \mathrm{C}$. $\mathrm{O}$ sobrenadante translúcido foi descartado, as nanopartículas ressuspensas em meio de cultura e armazenadas por $6 \mathrm{~h}$. Soluções com concentrações apropriadas foram preparadas em porções de $500 \mu L$. As amostras foram, então, irradiadas em uma cubeta de quartzo transparente utilizando um laser CW de diodo de $808 \mathrm{~nm}$ (iZi, LASERline) com área circular de $0,32 \mathrm{~cm}^{2}$. A temperatura da solução foi monitorada utilizando um termômetro óptico (FOT Lab Kit Fluoroptic Thermometer, LUXTRON). A temperatura inicial das medidas foi mantida em aproximadamente $23^{\circ} \mathrm{C}$.

\subsubsection{CONCENTRAÇÃO DA SOLUÇÃo}

A concentração das nanoestruturas foi estimada com base na secagem da amostra. Resumidamente, $1 \mathrm{~mL}$ da solução de nanopartículas foi colocada em um recipiente de peso conhecido e posta para secar por $12 \mathrm{~h}$ em uma estufa mantida a $60^{\circ} \mathrm{C}$. Uma vez seca, a amostra foi pesada e o peso do recipiente foi subtraído para determinação do peso da amostra, obtendo-se a concentração em massa por volume. Todas as medidas foram realizadas em triplicatas.

\subsection{ESTABILIDADE}

\subsubsection{Tempo de PRATELEIRA}

Para o monitoramento do tempo de prateleira das AuNFs, a solução estoque foi sonicada por 10 min e, então, alíquotas foram retiradas para análise. As amostras foram, então, devidamente diluídas e submetidas a análises de UV-visível e DLS. A solução foi monitorada até 74 dias após sua síntese. 


\subsubsection{AUMENTO DE TEMPERATURA}

A dependência da estabilidade das nanopartículas com a temperatura foi avaliada em dois experimentos distintos. A análise do diâmetro hidrodinâmico e do índice de polidispersividade foi realizada utilizando o equipamento Zetasizer Nano ZS-90 (Malvern) que permite o controle da temperatura. Resumidamente, uma solução de AuNFs foi diluída $10 x$ e seu diâmetro hidrodinâmico foi monitorado entre $23-60^{\circ} \mathrm{C}$, com um passo de $2^{\circ} \mathrm{C}$. As medidas para cada temperatura foram realizadas em triplicata e o valor final utilizado consistiu na média das medidas.

O monitoramento do espectro de extinção UV-visível foi realizado utilizando-se um espectrofotômetro UV-visível SpectraMax M3 (Molecular Devices) que permitia o controle da temperatura. O espectro foi obtido entre $300-1000 \mathrm{~nm}$, em uma cubeta de quartzo de $1 \mathrm{~cm}$ de caminho óptico, com uma solução de AuNFs sem diluição, entre as temperaturas $23-60^{\circ} \mathrm{C}$, com um passo de $2^{\circ} \mathrm{C}$. Valores de extinção da mesma cubeta contendo água ultrapura foram subtraídos como linhas de base.

\subsubsection{INTERAÇÃo COM MEIO BIOLÓGICO}

Para a avaliação da interação das nanopartículas com meio biológico, a solução estoque foi sonicada por $10 \mathrm{~min}$ e alíquotas foram centrifugadas à $4^{\circ} \mathrm{C}$ por $10 \mathrm{~min}$ a $7800 \mathrm{~g}$. Seu sobrenadante translúcido foi descartado e as partículas foram ressuspensas em água ultrapura ou meio de cultura. Em seguida, as amostras foram sonicadas por $10 \mathrm{~min}$ e caracterizadas. As amostras foram colocadas sob agitação branda à $38^{\circ} \mathrm{C}$ por $16 \mathrm{~h}$ e foram, então, novamente centrifugadas nas condições descritas. Após sua ressuspensão, as AuNFs foram sonicadas por $10 \mathrm{~min}$ e caracterizadas.

\subsubsection{IRRADIAÇÃO COM LASER PW}

A estabilidade das AuNFs sob irradiação de um laser PW foi verificada utilizando um sistema de laser pulsado Brilliant b Quantel $(850 \mathrm{~mJ})$ com um sistema Rainbow OPO. Para tanto, $1 \mathrm{~mL}$ de nanopartículas foi colocado em um eppendorf e a amostra foi irradiada por 
1000 pulsos com $12 \mathrm{~mJ}$ de energia em $770 \mathrm{~nm}$, com frequência de pulsos de $10 \mathrm{~Hz}$. A solução irradiada foi, então, caracterizada por DLS, espectroscopia UV-visível, potencial zeta e MEV.

\subsubsection{IRRADIAÇÃO COM LASER CW}

Para verificar sua estabilidade sob irradiação de um laser CW, a solução estoque de nanoestruturas foi sonicada por $10 \mathrm{~min}$ e uma alíquota foi retirada. A amostra foi, então, irradiada em uma cubeta de quartzo transparente utilizando um laser CW de diodo de $808 \mathrm{~nm}$ (iZi, LASERline) com área circular de $0,32 \mathrm{~cm}^{2}$ com 2,42 W. $\mathrm{cm}^{-2}$ por $1 \mathrm{~h}$ e $42 \mathrm{~min}$. A solução irradiada foi, então, devidamente diluída e caracterizada por DLS, espectroscopia UV-visível, potencial zeta e MEV.

\subsection{IMAgens Fotoacústicas}

\subsubsection{CARACTERIZAÇÃo}

A caracterização fotoacústica das AuNFs foi realizada utilizando um phantom anteriormente fabricado segundo o protocolo estabelecido. (104) Sucintamente, $1 \mathrm{~mL}$ de nanopartículas foram introduzidas em uma inclusão cilíndrica de cerca de $0,5 \mathrm{~cm}$ de raio localizada no centro do phantom. Gel foi colocado sobre o phantom e a sonda de ultrassom foi cuidadosamente posicionada a $90^{\circ}$ com a inclusão. Por fim, as amostras foram irradiadas com $600-1000$ pulsos em $90^{\circ}$ utilizando um laser pulsado Brilliant b Quantel (850mJ) com um sistema Rainbow OPO que permitia o ajuste do comprimento de onda entre $680-950 \mathrm{~nm}$ e o sinal acústico foi monitorado utilizando um sistema de ultrassom modificado com funcionamento em modos pulso-eco ou fotoacústico.

Com base nesse protocolo, o sinal fotoacústico das AuNFs foi monitorado variandose o comprimento de onda de excitação, a energia de irradiação e a frequência de pulsos do laser. Em todas as análises, o sinal fotoacústico da água ultrapura foi utilizado como linha de base e subtraído do sinal obtido. Ainda, o sinal fotoacústico foi monitorado utilizando-se soluções 23,8, 35,7 e 59,5 $\mu \mathrm{g} \cdot \mathrm{mL}^{-1}$ de AuNFs. 


\subsubsection{IMAGEM FOTOACÚSTICA}

Para a obtenção das imagens fotoacústicas, uma solução de $1 \mathrm{~mL}$ contendo 23,8 $\mu \mathrm{g} \cdot m L^{-1}$ de AuNFs foi inserida na inclusão cilíndrica do phantom previamente fabricado. Utilizando a configuração previamente descrita, o sistema foi irradiado por um laser pulsado Brilliant b Quantel $(850 \mathrm{~mJ})$ com um sistema Rainbow OPO em $90^{\circ}$, com comprimento de onda de $770 \mathrm{~nm}$, energia de $12 \mathrm{~mJ}$ e frequência de pulsos de $10 \mathrm{~Hz} .0$ sinal captado pelo sistema de ultrassom em modo fotoacústico foi analisado e plotado utilizando um algoritmo em MATLAB.

\subsection{Ensaios Celulares}

\subsubsection{CULTURA De CÉluLAS}

Para os estudos in vitro utilizou-se duas linhagens celulares de fígado, fibroblastos de camundongos (FC3H) e células de hepatoma de ratos (HTC), ambas obtidas do Banco de Células do Rio de Janeiro (BCRJ). Todas as linhagens celulares foram cultivadas em meio de cultura DMEM suplementado com $10 \%$ de FBS e mantidas à $37^{\circ} \mathrm{C}$ em $5 \% \mathrm{CO}_{2}$ em uma estufa. O crescimento celular foi monitorado utilizando-se um microscópio invertido Nikon Eclipse TS 100. A viabilidade celular das culturas foi aferida antes de cada experimento (dados não apresentados) utilizando ensaios de exclusão de azul de trypan, mostrando viabilidade maior que $95 \%$.

\subsubsection{PREPARO DAS AUNFs PARA TESTES IN VITRO}

Antes de serem utilizadas, a solução estoque de AuNFs foi sonicada por $10 \mathrm{~min}$ e uma alíquota era retirada e centrifugada a $7800 \mathrm{~g}$ por $10 \mathrm{~min}$ à $4^{\circ} \mathrm{C}$. O sobrenadante translúcido era descartado e as nanopartículas eram ressuspendidas em meio de cultura DMEM suplementado com $10 \%$ de FBS. A solução era, então, sonicada por 10 min para garantir a homogeneidade das partículas. 


\subsubsection{ProliferaÇão por CRistal Violeta}

Utilizando placas de 96 poços, o meio de cultura foi removido dos poços e as amostras foram cuidadosamente lavadas três vezes com PBS 1\% estéril. Em seguida, foi adicionado $100 \mu \mathrm{L}$ de etanol 70\%, e mantido por $10 \mathrm{~min}$ para fixação da cultura. Após a remoção da solução, as amostras foram cuidadosamente lavadas com PBS e $40 \mu L$ de solução de cristal violeta $(0,1 \%)$ foi adicionada. As placas foram incubadas por $25 \mathrm{~min}$ e os poços lavados cinco vezes com $100 \mu \mathrm{L}$ de PBS para remoção do excesso de cristal violeta. Em seguida, adicionou-se $100 \mu L$ de ácido acético (10\%) em cada poço e a placa com as amostras foram novamente incubadas por $30 \mathrm{~min}$. Por fim, foi realizada a leitura da absorbância em leitor de microplacas (SpectraMax M3, Molecular Devices) utilizando filtros de $540 \mathrm{~nm}$. A porcentagem relativa de viabilidade obtida foi calculada pela razão da absorbância de grupos tratados por aquela de grupos controle de cada experimento.

\subsubsection{TOXICIDADE}

A toxicidade das AuNFs foi aferida através da sua incubação com as linhagens celulares, seguida do monitoramento da viabilidade das células em até $24 h$. Sucintamente, $10^{5}$ células foram semeadas em placas de 96 poços com um volume final de $200 \mu \mathrm{L}$. Após $24 h$, as células foram tratadas em triplicata com soluções de AuNFs com 23,8, 35,7 e $59,5 \mu \mathrm{g} \cdot \mathrm{mL}^{-1}$ e um grupo controle tratado apenas com meio de cultura. As placas foram incubadas em estufa com atmosfera de $5 \%$ de $\mathrm{CO}_{2}$ e $37^{\circ} \mathrm{C}$. A viabilidade dos grupos foi aferida pela proliferação por cristal violeta após 6, 12 e $24 h$, utilizando o grupo controle descrito para a análise percentual.

\subsubsection{INCORPORAÇÃO Às CÉLULAS}

A análise de interiorização foi realizada com base no protocolo utilizado por Park e $\mathrm{Ha}$ (105) Brevemente, $5.10^{5}$ células foram semeadas em placas de 24 poços e incubadas por $24 \mathrm{~h}$. Em seguida, as amostras foram tratadas com $500 \mu \mathrm{L}$ de soluções de AuNFs com 23,8, 35,7 e 59,5 $\mu \mathrm{g} . \mathrm{mL}^{-1}$ e um grupo controle contendo apenas meio de cultura. Após 6, 12 e $24 h$, as amostras foram limpas descoladas da placa utilizando tripsina EDTA, 
centrifugadas e ressuspensas em $250 \mu L$ de PBS. As amostras foram centrifugadas e ressuspendidas mais duas vezes para remoção de detritos e excesso de nanopartículas do meio. Por fim, após homogeneização cuidadosa, o conteúdo dos poços foi transferido para tubos de polipropileno e analisados por citometria de fluxo (FACSCalibur, BD), adquirindose 10000 eventos. A análise estatística foi feita com base no grupo controle não tratado com nanopartículas. Todos os experimentos foram realizados em triplicata.

\subsubsection{ENSAIOS DE HIPERTERMIA}

Para análise da eficiência terapêutica das AuNFs em ensaios de hipertermia, $5.10^{5}$ células HTC e $5.10^{4}$ células FC3H foram semeadas em uma placa de 96 poços. Após $24 h$, o meio de cultura foi removido e as células foram tratadas com $200 \mu \mathrm{L}$ de soluções de AuNFs com $23,8,35,7$ e $59,5 \mu \mathrm{g} \cdot \mathrm{mL}^{-1}$ e dois grupos controle tratados apenas com meio. As amostras foram, então, incubadas por $6 \mathrm{~h}$ à $37^{\circ} \mathrm{C}$, com atmosfera de $5 \%$ de $\mathrm{CO}_{2}$ e lavados duas vezes com PBS. Finalmente, $100 \mu L$ de meio foi adicionado em cada poço e as células foram irradiadas utilizando o mesmo laser CW de diodo de $808 \mathrm{~nm}$ (iZi, LASERline) com área de irradiação circular de $0,32 \mathrm{~cm}^{2}$ e densidade de potência ajustada para 2,42 W. $\mathrm{cm}^{-2}$. Após exposição ao laser por $12 \mathrm{~min}$, as células foram incubadas por $2 \mathrm{~h}$ nas mesmas condições descritas e a viabilidade celular foi aferida pela proliferação por cristal violeta, utilizando um grupo não tratado e não irradiado como referência para a análise percentual. Todos os experimentos foram realizados em triplicata. 


\section{Resultados e Discussão}

O processo de desenvolvimento de um nanomaterial teranóstico é bastante complexo e extenso. Para seu uso em modalidades fotoativadas, as nanopartículas devem ser opticamente ativas em uma das duas janelas biológicas (i.e. 700 - $950 \mathrm{~nm}$; $1000-$ $1350 \mathrm{~nm}$ ). (14) Além disso, seu tamanho, sua carga e sua morfologia devem ser considerados, uma vez que terão influência direta na sua biodistribuição e na sua eficiência. Ainda, considerando que tal estrutura deverá ser utilizada para fins clínicos, sua síntese deve ser simples, rápida, reprodutível, escalável e as partículas devem apresentar estabilidade prolongada.

Com base nisso, para facilitar a discussão e o entendimento, essa sessão está dividida em três partes:

- Primeiro, discutiremos a elaboração e a padronização da síntese das nanopartículas conduzida nesta pesquisa. Nela, veremos o papel de alguns fatores importantes na formação das partículas, incluindo a temperatura e concentração de ouro, e sua influência na estrutura final obtida.

- Na segunda parte, serão explorados alguns aspectos relativos à estabilidade das nanopartículas, onde será analisada sua estabilidade com o aumento da temperatura e sob a irradiação por lasers e seu tempo de prateleira. Ademais, sua interação com meio biológico rico em proteínas será avaliada.

- Por fim, serão discutidas as aplicações dos nanomateriais nas modalidades escolhidas. Primeiramente, será discutida a caracterização e a resposta das nanopartículas na modalidade diagnóstica, atuando como contraste fotoacústico. Em seguida, será relatada a aplicação das nanoestruturas como agentes terapêuticos em ensaios de hipertermia in vitro. 


\section{Síntese e Caracterização}

Na primeira etapa desse trabalho foi desenvolvido um procedimento in situ, capaz de produzir AuNFs estabilizadas com PEG de maneira rápida e sem passos adicionais de modificação de superfície. O protocolo desenvolvido para a formação das AuNFs consistiu na redução de sal de ouro utilizando ácido ascórbico na presença do agente estabilizante PEG-tiol e de íons de prata em temperatura ambiente. Como retratado na Figura 3a, uma solução de ácido cloroáurico (10 mM) é adicionada à solução de PEG-tiol (0,056 mM). Uma vez adicionada, a coloração da solução muda de transparente para amarelo claro. Em seguida, é adicionada a solução de $\mathrm{AgNO}_{3}(10 \mathrm{mM})$, o que torna a solução levemente mais pálida. Por fim, adiciona-se ácido ascórbico $(100 \mathrm{mM})$ e, em poucos segundos, a solução torna-se transparente e, em seguida, azul escuro (Figura $\mathbf{3 b}$ ), resultado da redução do $A u^{I I I}$ para $A u^{0}$ e a formação das nanoestruturas. Como vemos na Figura 3c, as nanopartículas possuem uma estrutura anisotrópica com ramificações largas, assemelhando-se a flores.

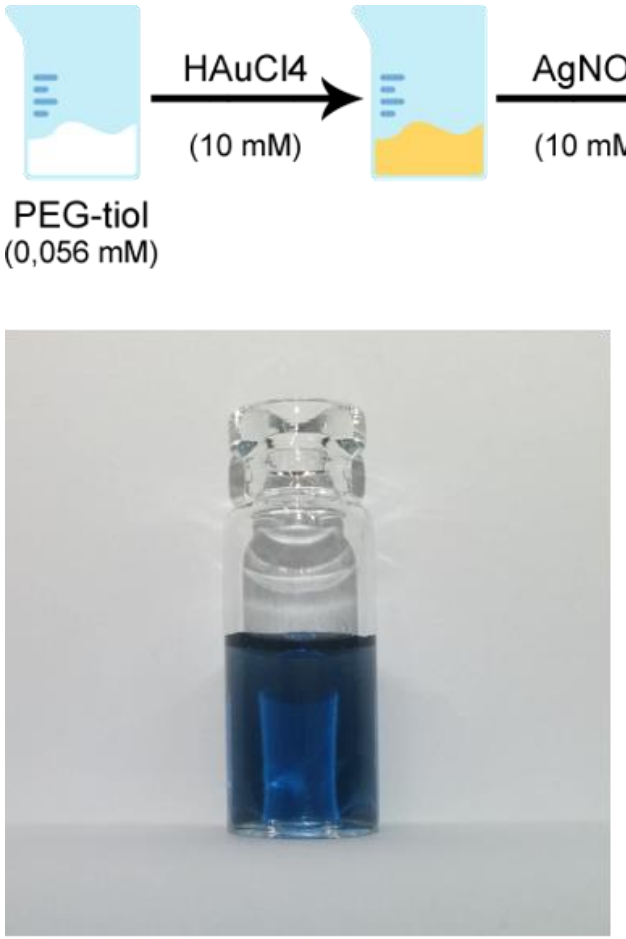

(b)

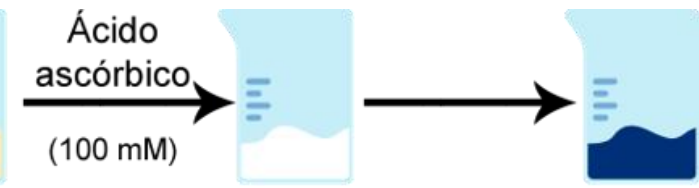

AuNFs

(a)

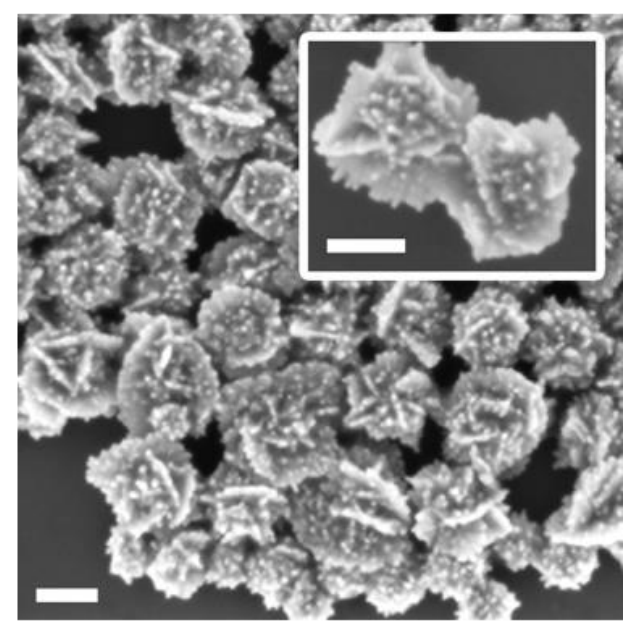

(c)

Figura 3 - Síntese das AuNFs: (a) Desenho esquemático do processo de síntese das nanopartículas. (b) Foto da solução final de nanopartículas obtidas pela síntese proposta. (c) Microscopia eletrônica de varredura das nanopartículas obtidas. As barras de escala representam $100 \mathrm{~nm}$. 
Entretanto, as nanoestruturas formadas se mostraram instáveis, apresentando sinais de agregação após $24 h$. Buscando aumentar a estabilidade das partículas, foram realizadas quatro variações da síntese contendo $0,056,0,112,0,224$ e $0,448 \mathrm{mM}$ de PEGtiol. O resultado se repetiu mesmo aumentando a concentração de PEG-tiol da síntese.

Como reportado previamente, ligações tiol tendem a interagir com a face cristalina [111] do ouro. (106) Uma explicação para esse fato é que o polímero pode ter se ligado aos núcleos durante as etapas de nucleação e crescimentos. Isso resultaria em um recobrimento incompleto das estruturas, reduzindo sua estabilidade e tornando-as mais propensas à agregação.

Para garantir que o PEG-tiol se ligue na superfície das nanopartículas formadas, uma solução de PEG-tiol 0,448 $\mathrm{mM}$ foi adicionada $5 \mathrm{~min}$ após a formação das AuNFs e mantida sob sonicação para garantir homogeneidade. A solução foi mantida por aproximadamente $13 \mathrm{~h}$ sob agitação branda à $4^{\circ} \mathrm{C}$ para preservar sua homogeneidade e, em seguida, foi centrifugada para retirar o excesso de reagentes. Assim, com a adição do polímero após a formação das estruturas, não foi mais observada agregação.

A dispersão final das nanoestruturas, apresentou uma absorção máxima em cerca de $850 \mathrm{~nm}$, um diâmetro hidrodinâmico de $170 \mathrm{~nm}$ e uma carga superficial média de $-14 \mathrm{mV}$. Além disso, o Pdl médio da solução foi de 0,048 , indicando uma população de nanoestruturas monodispersa.

As AuNFs apresentaram uma carga superficial consideravelmente negativa, algo inesperado, uma vez que o PEG é um polímero conhecido por sua capacidade de reduzir a carga da estrutura a valores próximos a zero. Para compreender melhor esse resultado, foi realizado um estudo do espectro de FTIR do PEG-tiol, ácido ascórbico e das AuNFs (Figura 4). Como vemos no espectro, as bandas características entre $1050-1150 \mathrm{~nm}^{-1}$ do PEGtiol (Figura 4a), relativas ao estiramento das ligações éter estão presentes, também, no espectro das AuNFs (Figura 4c), sendo indicativo da presença do polímero nas nanopartículas. Contudo, a baixa intensidade da banda sugere que a concentração de PEGtiol na solução é baixa. Por outro lado, ainda na Figura 4c, vemos a presença de uma banda 
(a)

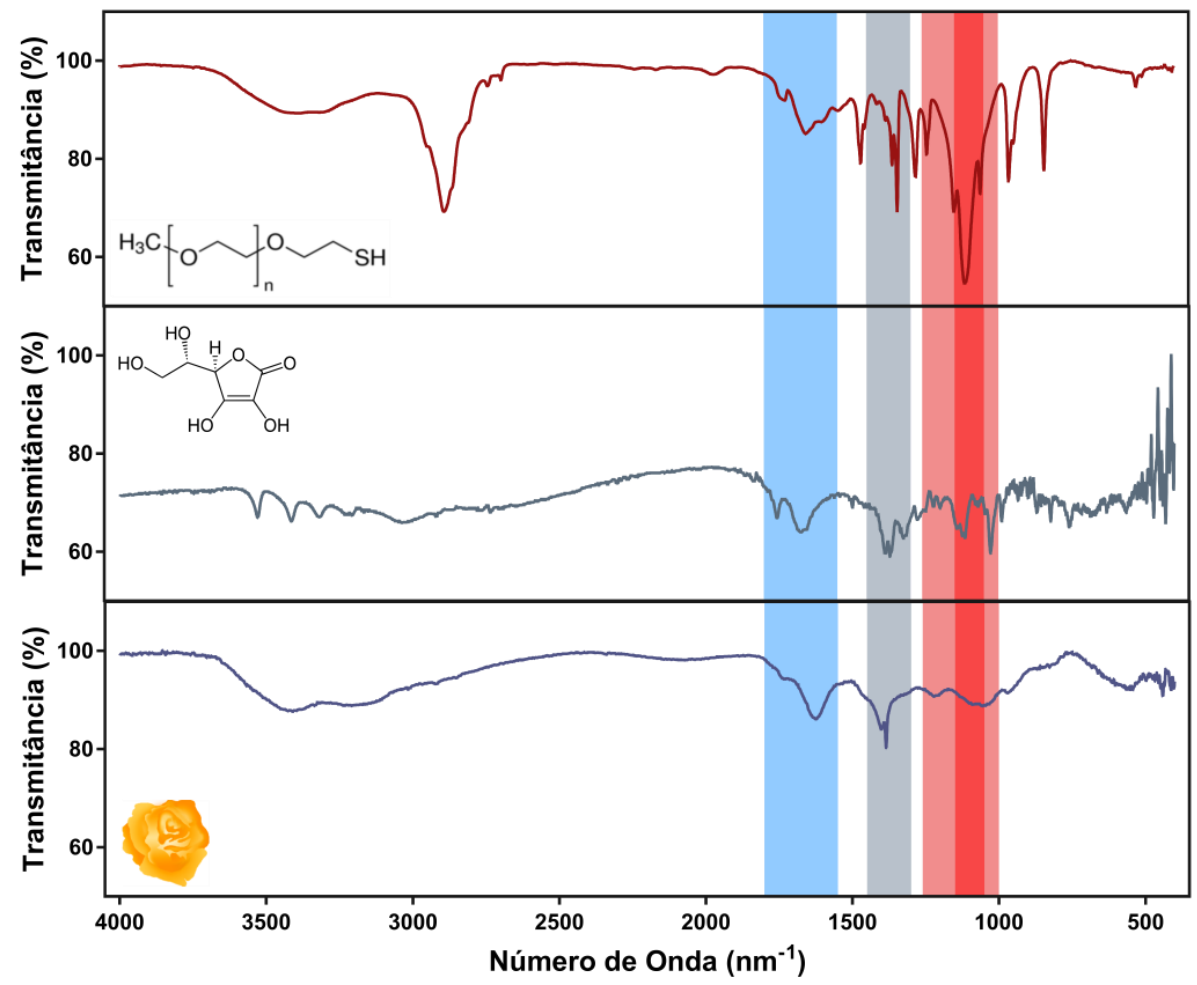

Figura 4 - Caracterização das AuNFs: Espectro de FTIR do PEG-tiol (125 $\mu \mathrm{g})$ (a), do ácido L-ascórbico $(80 \mu g)$ e da formulação final das nanopartículas $(238 \mu \mathrm{g})$ (c). As faixas delimitam as regiões das principais bandas apresentadas pelo PEG-tiol e pelo ácido ascórbico.

Fonte: Elaborada pelo autor.

Tabela 1 - Caracterização da síntese de AuNFs: Identificação das bandas do espectro de FTIR.

\begin{tabular}{|c|c|c|}
\hline \multicolumn{2}{|c|}{ Grupos } & $\begin{array}{l}\text { Bandas } \\
\left(n m^{-1}\right)\end{array}$ \\
\hline$C-O-C$ & Estiramento & $1050-1150$ \\
\hline$C-O$ & Estiramento & $1000-1260$ \\
\hline$C-H$ & Estiramento & $1300-1450$ \\
\hline $\mathrm{CH}_{2}$ & Wagging & 1389 \\
\hline$C=C$ & Estiramento & 1675 \\
\hline$C=O$ & Estiramento & 1764 \\
\hline
\end{tabular}

Fonte: Elaborada pelo autor.

bem definida em $1389 \mathrm{~cm}^{-1}$. Quando comparamos com as bandas do ácido ascórbico (Figura 4b), vemos esta é coincidente com a banda relativa ao movimento de wagging das 
ligações $\mathrm{CH}_{2}$, sendo um forte indicativo da presença de ácido ascórbico na solução de AuNFs.

Como reportado na literatura, o ácido ascórbico pode ser utilizado, também, como agente estabilizante de nanopartículas de ouro. (107) Além disso, o $p K a$ dessas molécula é 4,1 o que, considerando o $p H$ da solução de AuNFs que é levemente ácido (entre 5 e 6), torna a sua cadeia negativamente carregada. Com isso, apesar de haver a presença de moléculas de PEG-tiol, vemos que há, também, a presença de ácido ascórbico, o que torna a estrutura carregada negativamente.

A síntese química de nanopartículas é, no entanto, extremamente sensível a um grande número de fatores, que afetam diretamente a cinética da reação e, consequentemente, as características das partículas produzidas. Para o processo de desenvolvimento e padronização da síntese, foram então estudados alguns parâmetros que mostraram considerável influência no procedimento: a presença de íons de prata; a temperatura; e, a concentração de ouro. Outros parâmetros, como a velocidade de agitação e a adição de $\mathrm{NaOH}$ também foram avaliados, mas se mostraram pouco relevantes ou impeditivos na formação das AuNFs.

\section{Presença de Íons de Prata}

Um método comum de crescimento anisotrópico de nanopartículas de ouro consiste em realizar o processo de nucleação e crescimento das estruturas na presença de íons de prata. No caso AuNRs, a presença desses íons juntamente com CTAB, tem um papel crucial na definição da morfologia final das partículas, resultando em um crescimento unidirecional e na formação dos bastões. Na ausência do CTAB, o crescimento ainda é direcionado devido aos íons, contudo, o crescimento não é limitado pelo surfactante, dando origem a múltiplas ramificações. Para verificar tal hipótese, o papel dos íons de prata na formação das AuNFs foi avaliado através da síntese de duas dispersões, uma na presença e uma na ausência de íons de prata. 
Tabela 2 - Influência da presença de íons de prata na formação das AuNFs: Resumo das características físicoquímicas das nanopartículas.

\begin{tabular}{cccc}
\hline $\begin{array}{c}\text { Concentração de } \\
\text { Prata } \\
(m M)\end{array}$ & Máx. Extinção & $\begin{array}{c}\text { Diâmetro } \\
\text { Hidrodinâmico } \\
(\text { d.nm })\end{array}$ & Pdl \\
\hline 0,00 & $(n m)$ & 119 & 0,275 \\
0,13 & 630 & 120 & 0,121 \\
\hline
\end{tabular}

Fonte: Elaborada pelo autor.

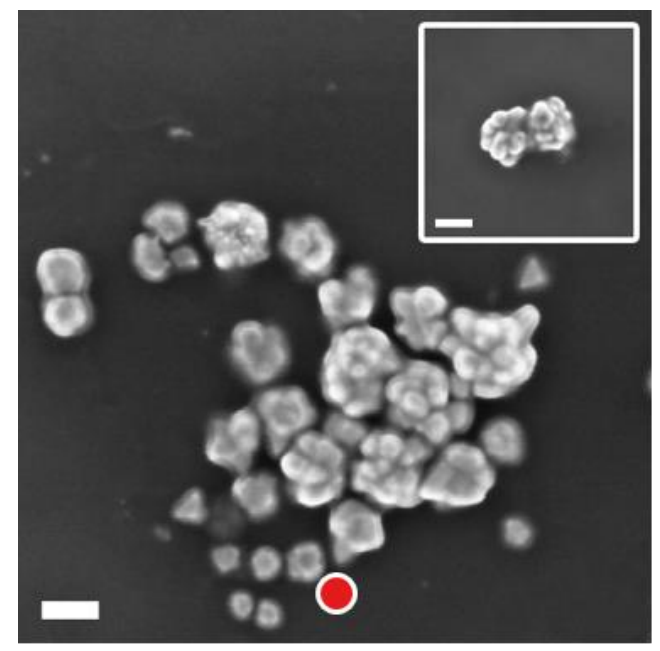

(a)

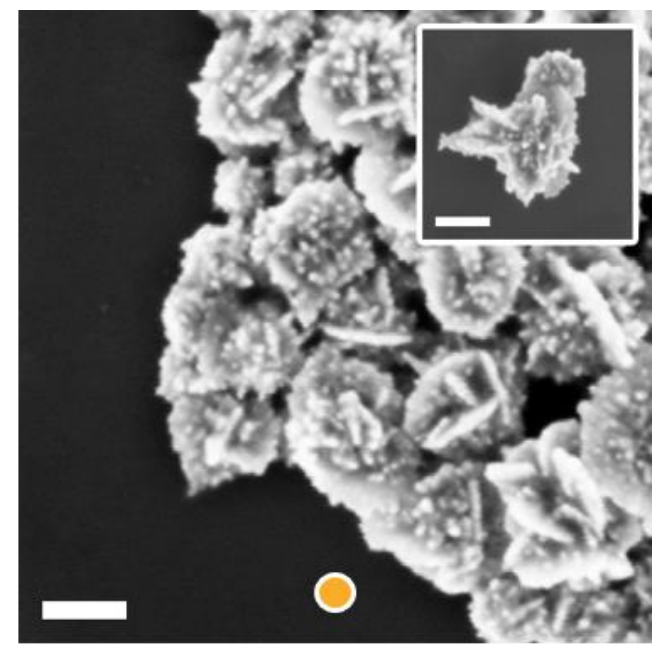

(b)

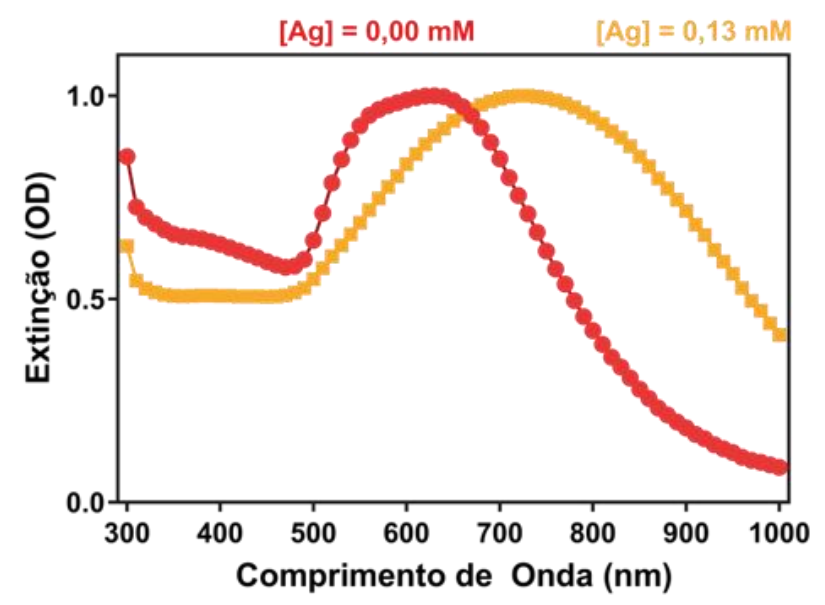

(c)

Figura 5 - Influência da presença de íons de prata na formação das AuNFs: Microscopias eletrônicas de varredura das nanopartículas obtidas na ausência (a) e na presença (b) de íons de prata. As barras de escala representam $100 \mathrm{~nm}$. (c) Espectro de extinção UV-visível das soluções.

Fonte: Elaborada pelo autor. 
Como vemos na Tabela 2 e na Figura 5, a ausência dos íons de prata provocou uma mudança morfológica drástica nas nanopartículas, resultando em nanopartículas esferoidais compostas pela junção de núcleos menores (Figura 5a). Vemos, também, uma grande heterogeneidade de tamanho e morfologia das nanopartículas, o que é coerente com o Pdl da solução. Seu espectro de extinção UV-visível, mostrado em vermelho na Figura $\mathbf{5 c}$, também se mostra heterogêneo, no qual pode-se identificar duas bandas sobrepostas. Isso se deve à presença de nanopartículas esféricas, cuja banda é centrada em torno de $560 \mathrm{~nm}$, e das estruturas formadas pelos aglomerados de núcleos esféricos e levemente anisotrópicos. Nestes últimos, ocorre a hibridização da ressonância plasmônica e, consequentemente, um leve deslocamento da banda para o NIR, cujo máximo encontrase em $630 \mathrm{~nm}$.

Na síntese realizada na presença da prata, como vemos na Figura 5b, temos um crescimento anisotrópico com a formação de ramos bem definidos. Além disso, nota-se, tanto pela microscopia quanto pelo Pdl da Tabela 2, a formação de uma população mais homogênea, tanto em tamanho, quanto em morfologia. Seu espectro, representado em amarelo na Figura 5c, apresenta um único pico largo e centralizado em $730 \mathrm{~nm}$, característico das AuNFs.

Assim, a presença de íons de prata é fundamental para a formação das nanoestruturas anisotrópicas ramificadas. Sua presença garante não apenas o crescimento dos ramos, mas, também, a monodispersividade das nanopartículas.

\section{Temperatura de Síntese}

Na maioria das rotas químicas de síntese, a temperatura tem um papel fundamental na determinação da morfologia e tamanho final das nanoestruturas por afetar sua velocidade de nucleação e de crescimento. Além disso, o crescimento das ramificações também é afetado, uma vez que os átomos dos ramos tendem a migrar para o núcleo, originando estruturas mais esféricas e termodinamicamente mais estáveis. Para verificar tal influência, AuNFs foram sintetizadas em três temperaturas distintas: à $4^{\circ} \mathrm{C}$; à $23^{\circ} \mathrm{C}$; e, à $38^{\circ} \mathrm{C}$, mantendo as demais condições inalteradas. 
Para minimizar desvios da temperatura de síntese, nos três casos todas as soluções usadas foram previamente aclimatadas e suas temperaturas monitoradas. Para o preparo da síntese à $4^{\circ} \mathrm{C}$, as soluções foram mantidas imersas em gelo durante toda a extensão da síntese, que só foi iniciada quando todos reagentes atingiram a temperatura estipulada. Para 23 e $38^{\circ} \mathrm{C}$, as soluções foram colocadas em banho-maria e, em seguida mantidas em um agitador magnético com controle de temperatura.

A primeira diferença observada entre as sínteses foi referente à velocidade de formação das AuNFs. A redução do $A u^{I I I}$ e formação das nanoestruturas com a adição do ácido ascórbico ocorreu em tempos significativamente diferentes. $\mathrm{O}$ processo que, à $23^{\circ} \mathrm{C}$, leva geralmente alguns segundos, foi reduzido ainda mais com o aumento da temperatura, ocorrendo quase que instantaneamente. Por outro lado, quando realizado à $4^{\circ} \mathrm{C}$, esse processo durou quase $1 \mathrm{~min}$.

Através da caracterização das dispersões obtidas, vemos que o aumento da temperatura resultou em grandes diferenças nas características físico-químicas das estruturas formadas. Como mostrado na Tabela 3, o aumento da temperatura resultou em populações mais polidispersas. As sínteses realizadas em temperaturas menores apresentaram Pdl baixos, em especial aquela realizada à $4^{\circ} \mathrm{C}$ que foi inferior a 0,100 . Além disso, vemos alterações significativas das bandas plasmônicas, as quais se mostraram mais estreitas e deslocadas significativamente para a região visível com o aumento da temperatura (Figura 6b). Tal fato está relacionado ao tamanho das ramificações formadas, como vemos pela variação de tamanho das nanoestruturas indicado na Figura 6 c e na Tabela 3. Quanto menor a temperatura, maiores as ramificações, o que resulta no deslocamento da banda para o NIR e no seu alargamento devido à hibridização da LSPR dos núcleos com as estruturas periféricas, estando de acordo com outros trabalhos encontrados na literatura. (108)

Para comprovar tal hipótese, foram realizadas duas novas sínteses, uma à $23^{\circ} \mathrm{C} \mathrm{e}$ outra à $30^{\circ} \mathrm{C}$, cujos máximos de extinção foram sintonizados em $850 \mathrm{~nm}$. Como vemos na Figura 6d-e, apesar de terem características físico-químicas semelhantes, as nanoestruturas apresentaram diferenças morfológicas significativas. Vemos que, de fato, a redução da temperatura permite o crescimento de ramificações maiores, originando 
estruturas largas e finas, com o aspecto de pétalas (Figura 6d). Por outro lado, o aumento da temperatura resultou em ramificações menores, com a aparência espinhosa (Figura 6e).

Tabela 3 - Influência da temperatura na formação das AuNFs: Resumo das características físico-químicas das nanopartículas.

\begin{tabular}{cccc}
\hline Temperatura & Máx. Extinção & $\begin{array}{c}\text { Diâmetro } \\
\text { Hidrodinâmico } \\
(\text { d.nm })\end{array}$ & PdI \\
\hline 4 & $(n m)$ & 160 & 0,096 \\
23 & 800 & 120 & 0,121 \\
38 & 730 & 116 & 0,263 \\
\hline
\end{tabular}

Fonte: Elaborada pelo autor.

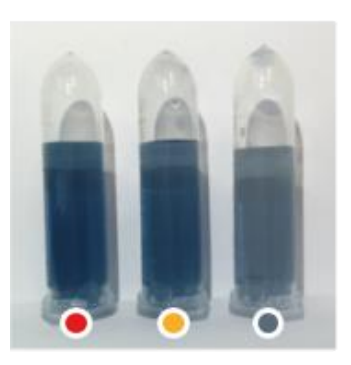

(a)

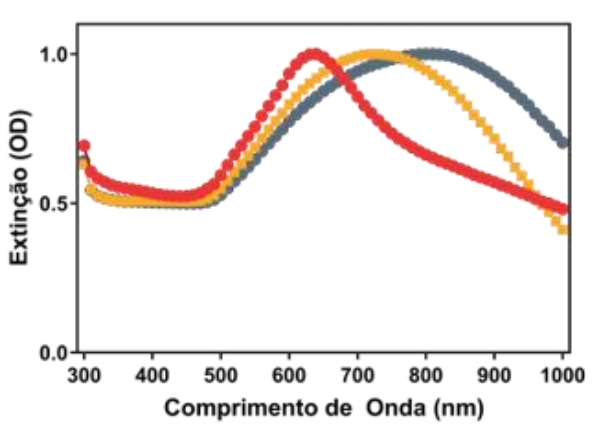

(b)

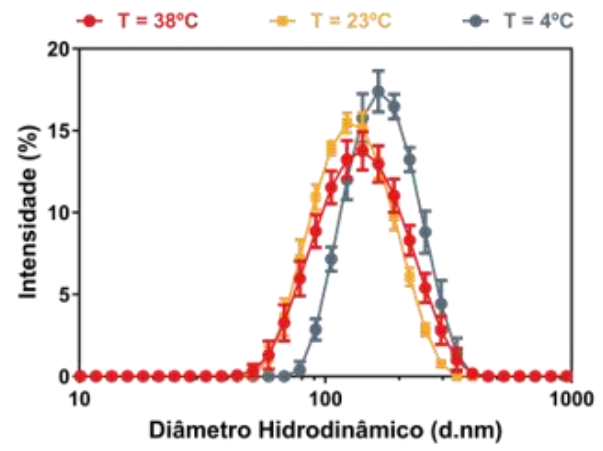

(c)

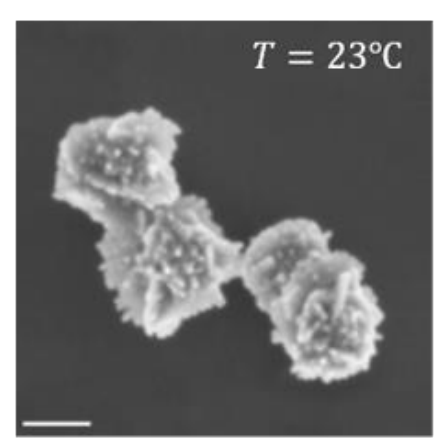

(d)

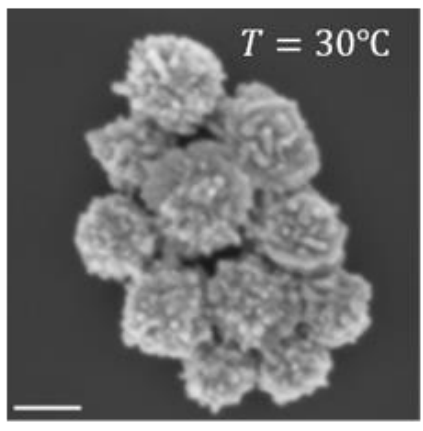

(e)

Figura 6 - Influência da temperatura na formação das AuNFs: (a) Foto das soluções obtidas com temperatura de 38, 23 e $4^{\circ} \mathrm{C}$, da esquerda para a direita, respectivamente. (b) Espectro de extinção das soluções. (c) Distribuições de tamanho das soluções obtidas por espalhamento de luz dinâmico. Microscopias eletrônicas das soluções obtidas a 23 (d) e a $30^{\circ} \mathrm{C}$ (e), cujas concentrações de ouro foram ajustadas para que o máximo de extinção se localizasse em $850 \mathrm{~nm}$. As barras de escala representam $100 \mathrm{~nm}$.

Fonte: Elaborada pelo autor. 
Assim, a temperatura da síntese mostrou grande influência nas estruturas produzidas. Por um lado, seu aumento resultou em maiores velocidades das reações de formação das nanopartículas. Contudo, as estruturas formadas em temperaturas mais altas se apresentaram menos ramificadas e mais polidispersas. As AuNFs produzidas à $23^{\circ} \mathrm{C}$ e à $4^{\circ} \mathrm{C}$ não apresentaram grandes diferenças na homogeneidade das populações formadas e ambas apresentaram máximos de extinção dentro da primeira janela de absorção biológica.

\section{Concentração de Ouro}

Para verificar a influência da concentração de ouro na formação das AuNFs, foram sintetizadas três soluções contendo concentrações finais de $H A u C l_{4}$ de 0,13, 0,29 e $0,37 \mathrm{mM}$.

Como vemos na Figura $\mathbf{7 a}$, as soluções obtidas são visivelmente distintas. Observando os espectros da Figura $\mathbf{7 b}$, nota-se que o aumento da concentração de ouro resulta tanto no alargamento, quanto no deslocamento da banda para o NIR, cujos máximos de extinção estão centrados em 590, 730 e 960 nm. Assim como vimos com a variação da temperatura, ambos fenômenos indicam o aumento das ramificações. Tal hipótese é corroborada pelo aumento do diâmetro hidrodinâmico das estruturas que, como vemos na Figura 7c e na Tabela 4, variou entre 93 e $202 \mathrm{~nm}$.

Podemos observar, ainda, que os Pdls das dispersões resultantes estão consideravelmente baixos em todos os casos. Isso é indicativo de uma excelente monodispersividade das nanopartículas, um fator crucial para sínteses dessas nanoestruturas. Vemos também que esses índices aumentam com a redução da concentração de ouro, mostrando que, para concentrações menores de ouro, as populações são levemente mais heterogêneas. 
Tabela 4 - Influência da concentração de ouro na formação das AuNFs: Resumo das características físico-químicas das nanopartículas.

\begin{tabular}{cccc}
\hline $\begin{array}{c}\text { Concentração de } \\
\text { Ouro } \\
(m M)\end{array}$ & Máx. Extinção & $\begin{array}{c}\text { Diâmetro } \\
\text { Hidrodinâmico } \\
(\text { d.nm })\end{array}$ & PdI \\
\hline 0,13 & $(n m)$ & 93 & 0,187 \\
0,29 & 590 & 120 & 0,121 \\
0,37 & 730 & 202 & 0,113 \\
\hline
\end{tabular}

Fonte: Elaborada pelo autor.

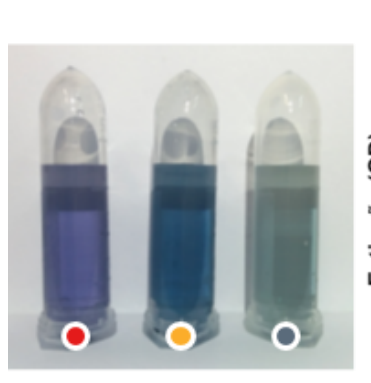

(a)

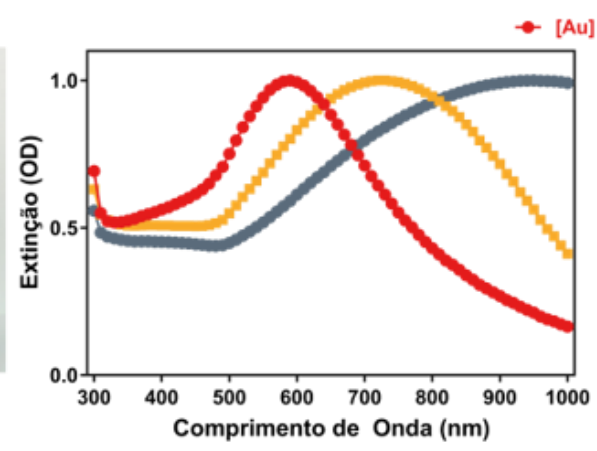

(b)

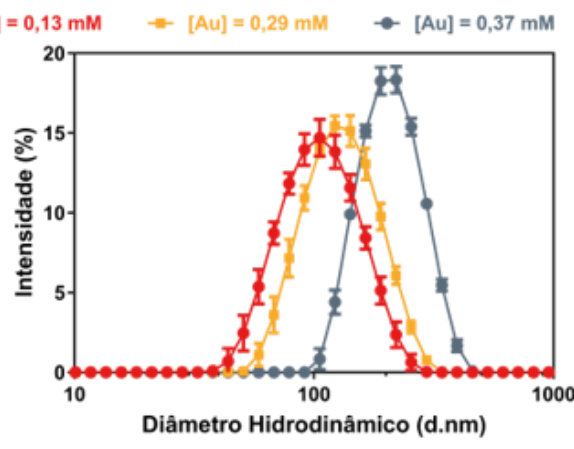

(c)

Figura 7 - Influência da concentração de ouro na formação de AuNFs: (a) Foto das soluções obtidas com concentração final de ouro de $0,13,0,29$ e $0,37 \mathrm{mM}$, da direita para a esquerda, respectivamente. (b) Espectro de extinção das soluções. (c) Distribuições de tamanho das soluções obtidas por espalhamento de luz dinâmico.

Fonte: Elaborada pelo autor.

A concentração de ouro se mostrou um fator chave no processo de sintonização da banda plasmônica das nanoestruturas. Sua simples variação permite o posicionamento do máximo de extinção de 590 até $960 \mathrm{~nm}$, podendo ser deslocado ainda mais para o NIR em sínteses com maior concentração, sendo consequência direta do tamanho das ramificações das AuNFs. Além disso, tal sintonização é alcançada sem influenciar a homogeneidade das populações obtidas, que se manteve monodispersa em todas as concentrações estudadas. 


\section{Outros Fatores}

Foi também avaliada a influência de dois outros fatores: a velocidade de agitação e adição de $\mathrm{NaOH}$ antes da redução do $A u^{I I I}$ pelo ácido ascórbico. Para analisar a velocidade de agitação, a síntese foi realizada sem agitação, com agitação branda (em torno de $400 \mathrm{rpm}$ ) e com forte agitação (cerca de $1000 \mathrm{rpm}$ ). O resultado não produziu diferenças expressivas. Contudo, visando a reprodutibilidade entre sínteses e buscando garantir a homogeneização da solução durante a adição dos reagentes, padronizou-se a síntese com uma agitação branda da solução.

O aumento do pH durante a reação de síntese do ouro tende a acelerar a redução de $A u^{3+}$ pelo ácido ascórbico, aumentando o número de núcleos durante a formação das AuNFs. $(4,109)$ Dessa forma, a adição de hidróxido de sódio na solução de síntese tende a produzir nanopartículas menores devido ao maior número de núcleos que competem entre si durante a etapa de crescimento. (110) Assim, foi avaliada a adição de $\mathrm{NaOH}$ na solução de síntese. Entretanto, o resultado obtido não gerou AuNFs, resultando em uma dispersão marrom-avermelhada cuja banda plasmônica localizava-se no visível, com diâmetro hidrodinâmico médio de $87 \mathrm{~nm}$ e Pdl de 0,208. Dessa forma, descartou-se seu uso na síntese.

\section{Padronização da Síntese}

As análises citadas acima mostraram que o método proposto é promissor, cumprindo todos os requisitos estabelecidos, produzindo AuNFs com alta eficiência e monodispersividade. A síntese permite, ainda, controle sobre a morfologia e tamanho, além da fácil sintonização da banda plasmônica no espectro UV-visível pelo controle da temperatura e, principalmente, da concentração de ouro. Dessa forma, considerando as aplicações almejadas, foi realizada a padronização dos parâmetros e foi realizada a síntese de volumes maiores para serem utilizados no restante do trabalho.

A síntese otimizada foi realizada a temperatura ambiente, de cerca de $23^{\circ} \mathrm{C}$, na presença de íons de prata e com uma concentração final de ácido cloroáurico de 0,29 $\mathrm{mM}$ sob agitação branda. Como vemos na Figura 8a, o resultado final obtido é composto por 


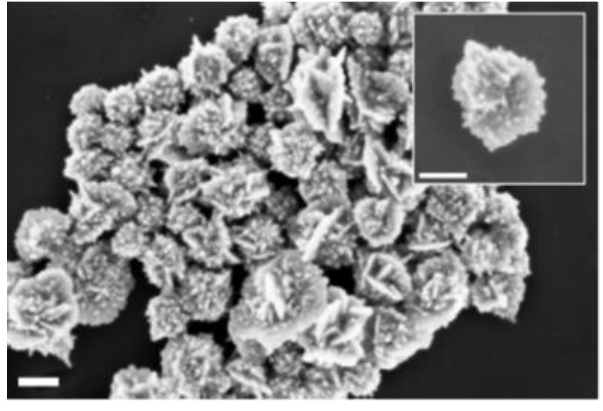

(a)

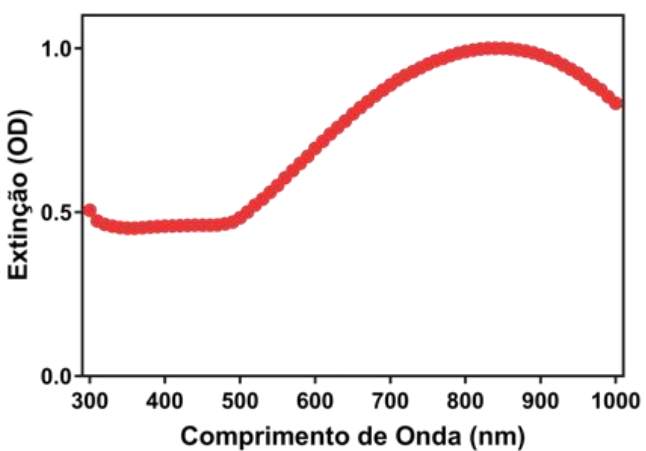

(b)

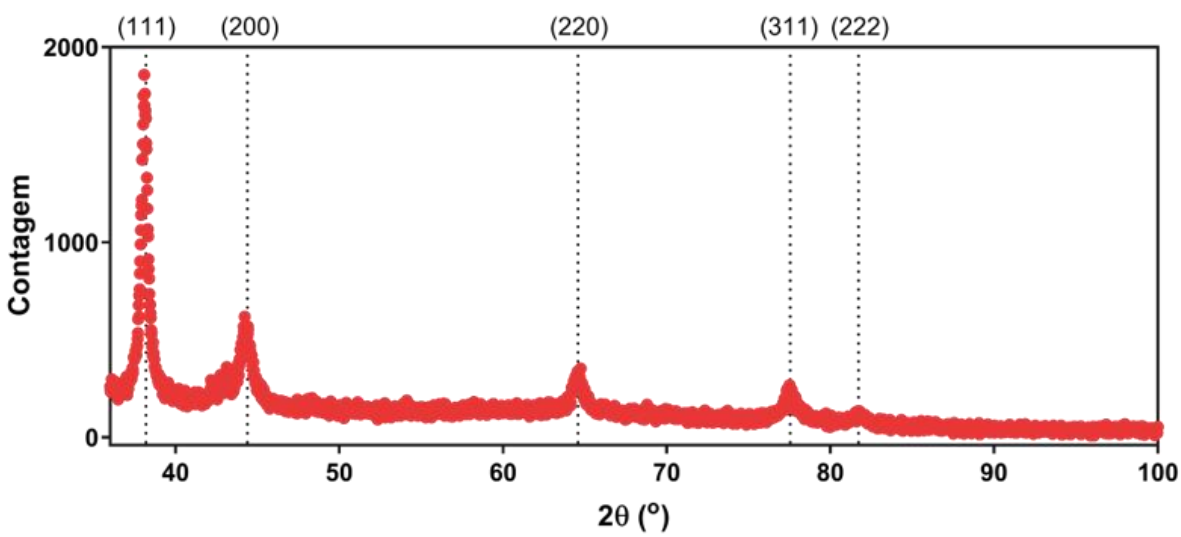

(c)

Figura 8 - Caracterização das AuNFs sintetizadas pelo protocolo otimizado: (a) Microscopia eletrônica de varredura. As barras de escala representam $100 \mathrm{~nm}$. (b) Espectro de extinção UV-visível. (c) Espectro de difração de raio-x.

Fonte: Elaborada pelo autor.

Tabela 5 - Caracterização das AuNFs sintetizadas pelo protocolo otimizado: Resumo das características físicoquímicas das nanopartículas.

\begin{tabular}{|c|c|c|c|}
\hline $\begin{array}{l}\text { Máx. } \\
\text { Extinção } \\
(n m)\end{array}$ & $\begin{array}{c}\text { Diâmetro } \\
\text { Hidrodinâmico } \\
(\text { d. } n m)\end{array}$ & Pdl & $\begin{array}{c}\text { Potencial } \\
\text { Zeta } \\
(m V)\end{array}$ \\
\hline 850 & 162 & 0,101 & -16 \\
\hline
\end{tabular}

Fonte: Elaborada pelo autor.

nanoestruturas de ouro ramificadas monodispersas. Seu espectro de extinção UV-visível apresenta uma única banda plasmônica larga centralizada em $850 \mathrm{~nm}$ (Figura 8b). O espectro apresentado é característico das AuNFs, estando de acordo com aqueles 
previamente reportados. (80) Como vemos na Tabela 5, as dispersões apresentaram um diâmetro hidrodinâmico de $162 \mathrm{~nm}$ e carga de superfície de $-16 \mathrm{mV}$. Além disso, o Pdl médio da dispersão é excepcionalmente baixo, indicando uma população de nanoestruturas monodispersas. Através da análise por difração de raio-x, vemos que as AuNFs apresentam uma rede cristalina cúbica de face centrada (JCPDS No.04-0784), típica de nanopartículas de ouro (Figura 8c). (111)

Com base no protocolo estabelecido, foi testada a escalabilidade da síntese, sendo produzidos 20, 30 e $50 \mathrm{~mL}$ de nanoflores, cujas características físico-químicas mantiveramse semelhantes às sintetizadas em escalas menores. Apesar de volumes maiores que $50 \mathrm{~mL}$ não terem sido produzidos, a síntese se mostrou escalável e capaz de produzir nanopartículas monodispersas de maneira rápida e reprodutível.

\section{EstABILIDADE}

De posse do protocolo de síntese otimizado, o próximo passo do desenvolvimento das AuNFs consistiu na análise da estabilidade das nanoestruturas. Para tanto, foram realizados testes de alguns fatores chave, como seu tempo de prateleira, sua estabilidade com relação ao aumento de temperatura, sua estabilidade no meio de cultura e sua estabilidade sob irradiação de laser.

Devido à sua fotossensibilidade e para evitar grandes oscilações de temperatura, as nanopartículas foram armazenadas em um vidro âmbar protegido com papel alumínio à $4^{\circ} \mathrm{C}$ na geladeira. Para as análises, a solução estoque era sonicada por $10 \mathrm{~min}$ e, em seguida, alíquotas eram retiradas e preparadas para as análises.

\section{Tempo de Prateleira}

A avaliação do tempo de prateleira é algo fundamental no desenvolvimento de uma nanopartícula, uma vez que nos permite monitorar o tempo que as nanoestruturas manterão suas características físico-químicas e, portanto, o tempo que poderão ser 
utilizadas de maneira confiável. Para tanto, foram monitoradas sua banda plasmônica através de seu espectro de extinção e, também, seu tamanho e sua polidispersividade através do espalhamento de luz dinâmico.

Como vemos na Tabela 6, as nanopartículas produzidas mantiveram suas características físico-químicas com pequenas variações durante o período observado. Tais mudanças, contudo, ocorreram nos primeiros 15 dias e, após esse período, mantiveram-se estáveis pelo restante do tempo (Figura 9). Sua banda plasmônica apresentou uma leve redução no máximo de absorção e um deslocamento em direção ao visível; inicialmente posicionada em $850 \mathrm{~nm}$, deslocando-se para $830 \mathrm{~nm}$ (Figura 9a,b). Contudo sua banda manteve seu aspecto geral, não apresentando a formação de novos picos e apresentando um estreitamento leve da banda, indicando que não houve mudanças morfológicas significativas (Figura 9b). Vemos, ainda, que o diâmetro hidrodinâmico das nanopartículas foi reduzido nesse período. Possuía, inicialmente, $162 \mathrm{~nm}$ e reduziu-se para $154 \mathrm{~nm}$ após 14 dias (Figura 9c). Por outro lado, seu Pdl manteve-se extremamente baixo em todo o período, variando entre 0,156 e 0,082, indicando que não houve variações expressivas na homogeneidade da população (Figura 9d).

Com base nessas observações, vemos que nos primeiros dias após a síntese, as nanoestruturas sintetizadas passam por mudanças físico-químicas para alcançar um estado mais estável. Como reportado previamente na literatura, AuNFs e nanopartículas de ouro com outras geometrias anisotrópicas tendem a passar por mudanças morfológicas devido ao fenômeno de intraparticle e Ostwald ripening. (112-113) Com base nisso, supõese que as mudanças observadas estejam relacionadas a esses fenômenos. Neles, os átomos de populações de partículas menores e de parte das extremidades das ramificações tendem a migrar para os núcleos das nanopartículas buscando o maior equilíbrio termodinâmico. No caso das AuNFs, o processo pode ter sido prolongado devido ao armazenamento da solução em baixas temperaturas. Durante esse tempo, ocorreu uma leve redução no comprimento das ramificações, resultando em uma redução do tamanho total das estruturas e um aumento de seu núcleo. Tais variações seriam responsáveis pelas mudanças na banda plasmônica das ramificações e do núcleo, resultando em alterações 
Tabela 6 - Tempo de prateleira das AuNFs: Resumo das características físico-químicas em 0 e 74 dias após a síntese.

\begin{tabular}{|c|c|c|c|c|c|c|c|}
\hline \multicolumn{4}{|c|}{ Dia 0} & \multicolumn{4}{|c|}{ Dia 74} \\
\hline $\begin{array}{c}\text { Max. } \\
\text { Extinção }\end{array}$ & Tamanho & PdI & $\begin{array}{c}\text { Potencial } \\
\text { Zeta }\end{array}$ & $\begin{array}{c}\text { Max. } \\
\text { Extinção }\end{array}$ & Tamanho & Pdl & $\begin{array}{c}\text { Potencial } \\
\text { Zeta }\end{array}$ \\
\hline$(n m)$ & $(d . n m)$ & & $(m V)$ & $(n m)$ & $(d . n m)$ & & $(m V)$ \\
\hline 850 & 162 & 0,101 & -17 & 830 & 158 & 0,109 & -13 \\
\hline
\end{tabular}

Fonte: Elaborada pelo autor.

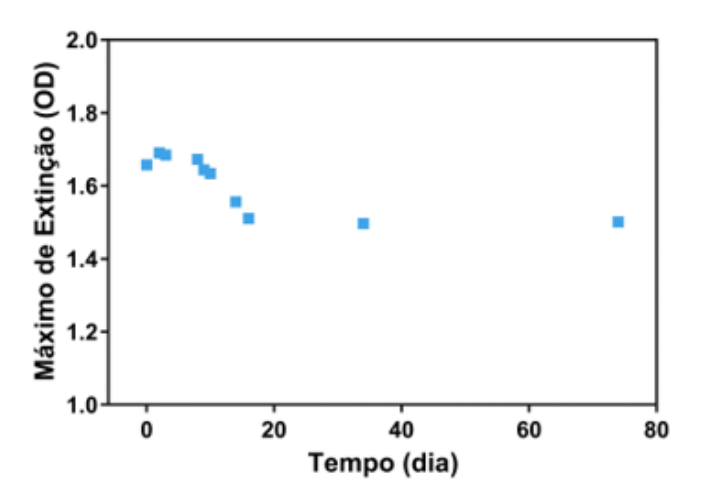

(a)

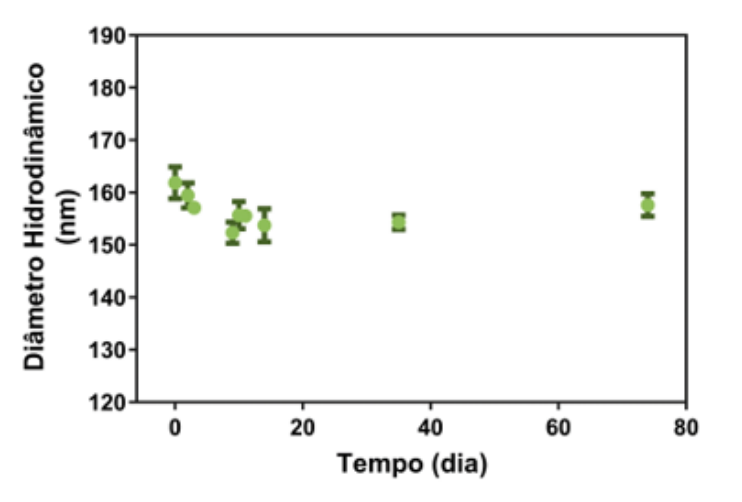

(c)

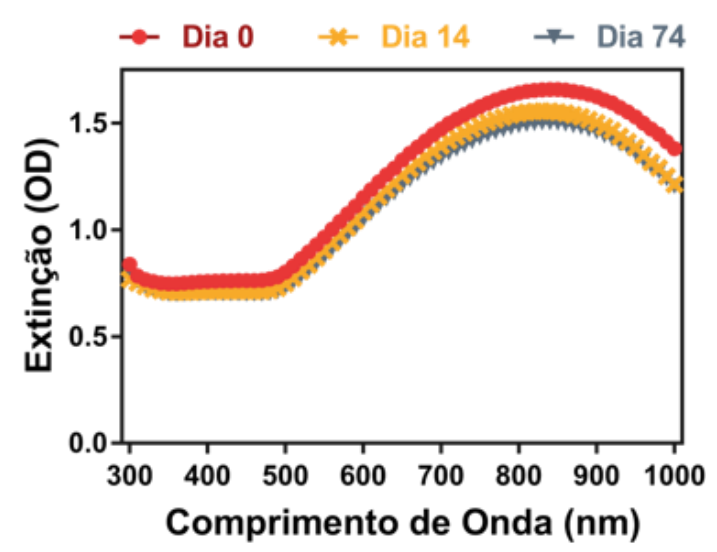

(b)

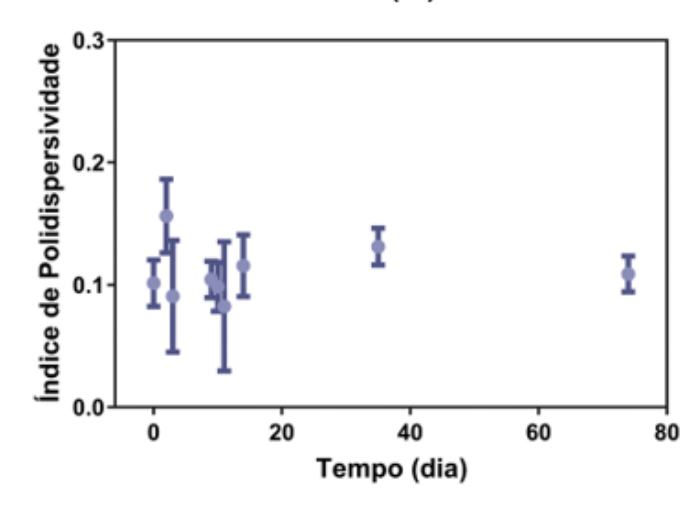

(d)

Figura 9 - Tempo de prateleira das AuNFs: (a) Espectro de extinção das nanopartículas após 0 (vermelho), 14 (amarelo) e 74 (cinza) dias. Variação da intensidade máxima do espectro de extinção (b), do diâmetro hidrodinâmico (c) e do índice de polidispersividade (d) das AuNFs pelo tempo.

Fonte: Elaborada pelo autor.

na hibridização da LSPR e, consequentemente, no deslocamento da banda em direção à região do visível e no seu leve estreitamento. 
Tabela 7 - Estabilidade com o aumento de temperatura: Resumo das características físico-químicas em $24^{\circ} \mathrm{C}$ e $60^{\circ} \mathrm{C}$.

\begin{tabular}{|c|c|c|c|c|c|c|c|}
\hline \multicolumn{4}{|c|}{$24^{\circ} \mathrm{C}$} & \multicolumn{4}{|c|}{$60^{\circ} \mathrm{C}$} \\
\hline $\begin{array}{c}\text { Max. } \\
\text { Extinção }\end{array}$ & Tamanho & Pdl & $\begin{array}{c}\text { Potencial } \\
\text { Zeta }\end{array}$ & $\begin{array}{c}\text { Max. } \\
\text { Extinção }\end{array}$ & Tamanho & PdI & $\begin{array}{c}\text { Potencial } \\
\text { Zeta }\end{array}$ \\
\hline$(n m)$ & $(d . n m)$ & & $(m V)$ & $(n m)$ & $(d . n m)$ & & $(m V)$ \\
\hline 810 & 155 & 0,095 & -17 & 800 & 138 & 0,218 & -13 \\
\hline
\end{tabular}

Fonte: Elaborada pelo autor.

Com isso, vemos que as AuNFs apresentaram estabilidade durante longos períodos de tempo, mantendo suas características físico-químicas após mais de dois meses de armazenamento. Contudo, as nanopartículas devem ser usadas, preferencialmente, após 15 dias de sua síntese, uma vez que alterações nas características do sistema ainda foram observadas nesse período.

\section{Aumento de Temperatura}

Em vista às aplicações escolhidas para o sistema, é imperativa a verificação da estabilidade de suas características físico-químicas com relação ao aumento da temperatura do sistema. Para tanto, foram monitoradas as principais propriedades das nanopartículas com a variação da temperatura entre $24,0^{\circ} \mathrm{C}$ e $60,0^{\circ} \mathrm{C}$.

Como explicitado na Tabela 7, o aumento da temperatura provocou variações consideráveis na população de AuNFs, provocando uma redução de $17 \mathrm{~nm}$ no diâmetro hidrodinâmico, um deslocamento da banda plasmônica, um leve aumento do potencial zeta e um aumento significativo da polidispersividade da solução. Tal processo pode ser visualizado com mais detalhes na Error! Reference source not found.

Vemos que as mudanças se tornam mais acentuadas a partir de $32,0^{\circ} \mathrm{C}$, em que as três propriedades monitoradas entram em um regime de mudança quase linear. Nele, notase uma redução constante do tamanho das nanopartículas, o que reflete diretamente na sua LSPR, modificando seu máximo de absorção (Error! Reference source not found.a-c). Vemos ainda que a elevação da temperatura gerou um aumento do Pdl, indicando 
crescimento da heterogeneidade da população decorrente das mudanças estruturais que ocorrem nessa faixa de temperatura (Error! Reference source not found.d).

Como observamos, as nanopartículas sofrem modificações estruturais nos primeiros dias após sua síntese, buscando melhorar a estabilidade termodinâmica do sistema. Com o aumento da temperatura, vemos processo semelhante ocorrer, em que as AuNFs começam a perder suas ramificações, tendendo a partículas mais esféricas e termodinamicamente mais estáveis.

Ao serem submetidas a aumentos de temperaturas, as AuNFs apresentam variações em suas características físico-químicas, mesmo em temperaturas relativamente baixas $\left(32-40^{\circ} \mathrm{C}\right)$. Com isso, estabelece-se que as nanopartículas produzidas devem,

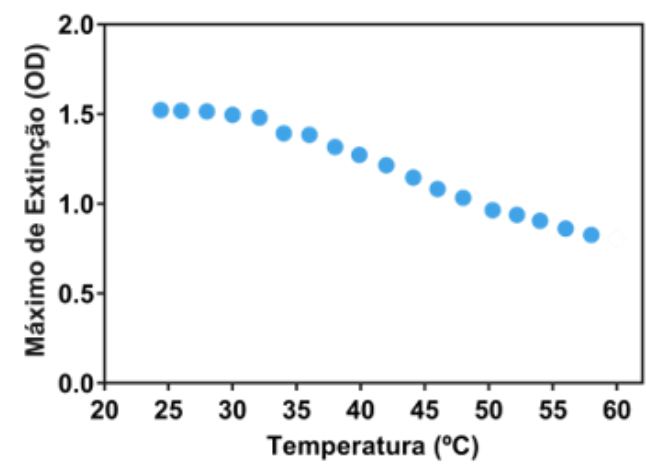

(a)

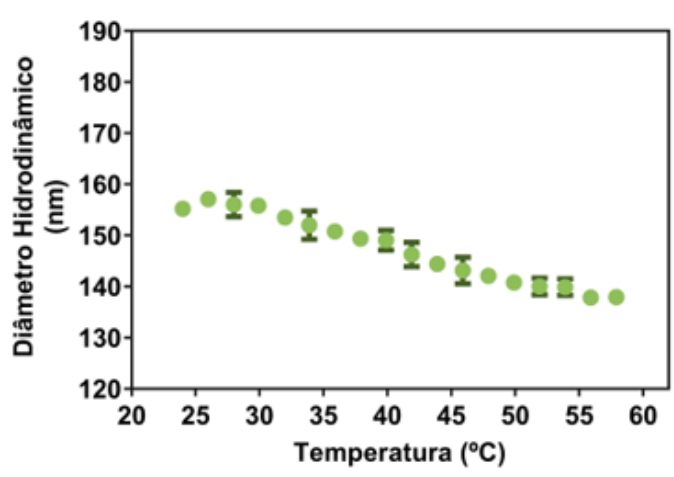

(c)

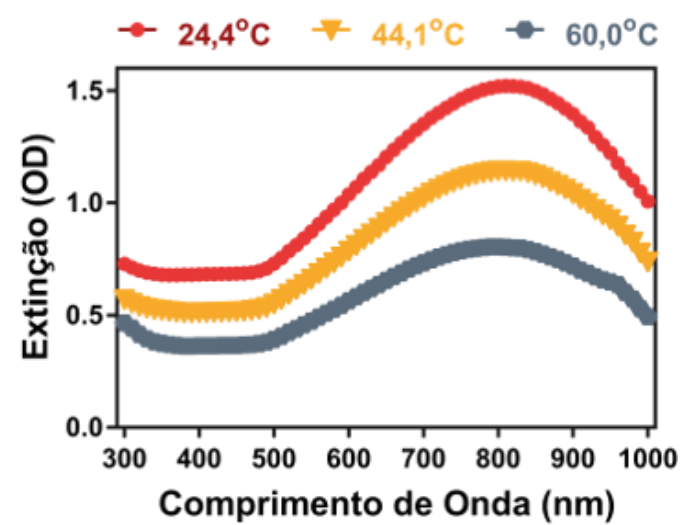

(b)

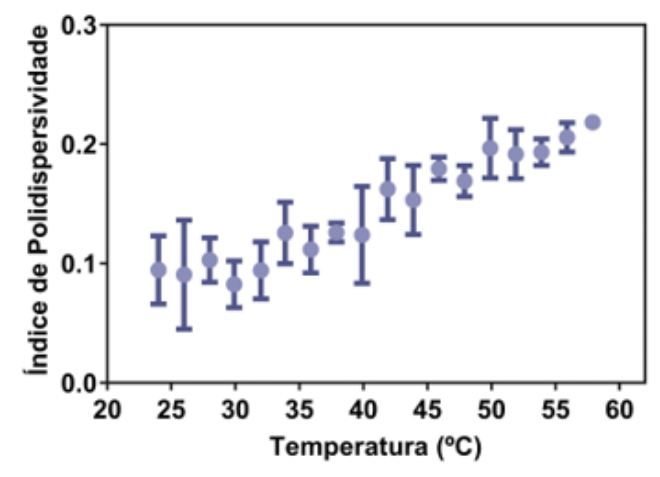

(d)

Figura 10 - Estabilidade com o aumento de temperatura: (a) Espectro de extinção de $24,4^{\circ} \mathrm{C}$ (vermelho), $30,0^{\circ} \mathrm{C}$ (amarelo), $39,9^{\circ} \mathrm{C}$ (cinza), $50,3^{\circ} \mathrm{C}$ (azul) e $60,0^{\circ} \mathrm{C}$ (verde). Variação da intensidade máxima do espectro de extinção (b), do diâmetro hidrodinâmico (c) e do índice de polidispersividade (d) das AuNFs pela temperatura. 
preferencialmente, ser armazenadas em baixas temperaturas. Ademais, vemos que em temperaturas normais do corpo $\left(37-38^{\circ} \mathrm{C}\right)$, as nanopartículas já apresentam indícios de variação em suas propriedades, sendo, portanto, necessária a investigação do comportamento das partículas nesse intervalo com mais cuidado.

\section{Interação em Meio Biológico e Estabilidade a $38^{\circ} \mathrm{C}$}

A inserção de nanopartículas em meios biológicos ricos em proteínas proporciona um ambiente muito diferente daquele no qual estudamos o comportamento das AuNFs até o momento. Proteínas presentes no meio tendem a interagir com as nanoestruturas devido à sua carga de superfície através de ligações não-específicas, originando uma nova camada conhecida como corona. A formação dessa camada, além de influenciar a biodistribuição em aplicações in vivo, pode gerar alterações significativas nas propriedades das nanopartículas. Além disso, vimos que, quando mantidas em temperaturas mais elevadas, as AuNFs podem sofrer mudanças estruturais. Dessa forma, é fundamental analisarmos seu comportamento quando mantidas por longos períodos à temperatura corpórea e em meios ricos em proteínas.

Duas dispersões de nanopartículas foram preparadas, uma suspensa em meio de cultura celular DMEM contendo $10 \%$ de FBS e uma em água. Para tanto, a dispersão

Tabela 8 - Interação em meio biológico e estabilidade a $38^{\circ} \mathrm{C}$ : Resumo das características fisico-químicas das AuNFs mantidas à $38^{\circ} \mathrm{C}$ em água e em meio de cultura após $0 \mathrm{~h}$ e $16 \mathrm{~h}$.

\begin{tabular}{c|ccccc}
\hline \multicolumn{1}{c}{} & Tempo & $\begin{array}{c}\text { Máx. } \\
\text { Extinção } \\
(n)\end{array}$ & $\begin{array}{c}\text { Diâmetro } \\
\text { Hidrodinâmico } \\
(\mathrm{nm})\end{array}$ & $\begin{array}{c}\text { Pdl } \\
(\mathrm{d} . n \mathrm{~m})\end{array}$ & $\begin{array}{c}\text { Potencial } \\
\text { Zeta } \\
(\mathrm{mV})\end{array}$ \\
\hline \multirow{2}{*}{ Água } & 0 & 830 & 155 & 0,129 & -16 \\
\cline { 2 - 6 } & 16 & 830 & 154 & 0.115 & -14 \\
\hline \multirow{2}{*}{$\begin{array}{c}\text { Meio de } \\
\text { cultura }\end{array}$} & 0 & 830 & 155 & 0.107 & -19 \\
\cline { 2 - 6 } & 16 & 890 & 244 & 0,293 & -19 \\
\hline
\end{tabular}

Fonte: Elaborada pelo autor. 
estoque de AuNFs foi sonicada por $10 \mathrm{~min}$ e duas alíquotas foram centrifugadas e ressuspendidas, uma em água e a outra em meio de cultura. Para garantir a monodispersividade das populações, as dispersões foram sonicadas por 10 min após sua ressuspensão. Em seguida, ambas dispersões foram caracterizadas e mantidas sob agitação à $38^{\circ} \mathrm{C}$, por $16 \mathrm{~h}$. Por fim, as dispersões foram novamente centrifugadas e ressuspendidas em água para remover proteínas não aderidas.

Como vemos na Tabela 8, as nanopartículas mantidas em água não apresentaram grandes variações em suas propriedades físico-químicas. Notamos que, após sua exposição, não houve deslocamentos de seu máximo de extinção, nem variações significativas em seu diâmetro hidrodinâmico e na sua polidispersividade. Vemos uma pequena variação em sua carga superficial, que se tornou levemente mais positiva. Tais resultados indicam que, apesar das AuNFs serem suscetíveis a alterações em suas propriedades devido ao aumento da temperatura, tanto suas características ópticas quanto físico-químicas se mantiveram estáveis à temperatura corpórea.

Por outro lado, vemos alterações expressivas nas propriedades das nanoestruturas mantidas no meio rico em proteínas. Observa-se, também, um aumento de quase $60 \%$ do

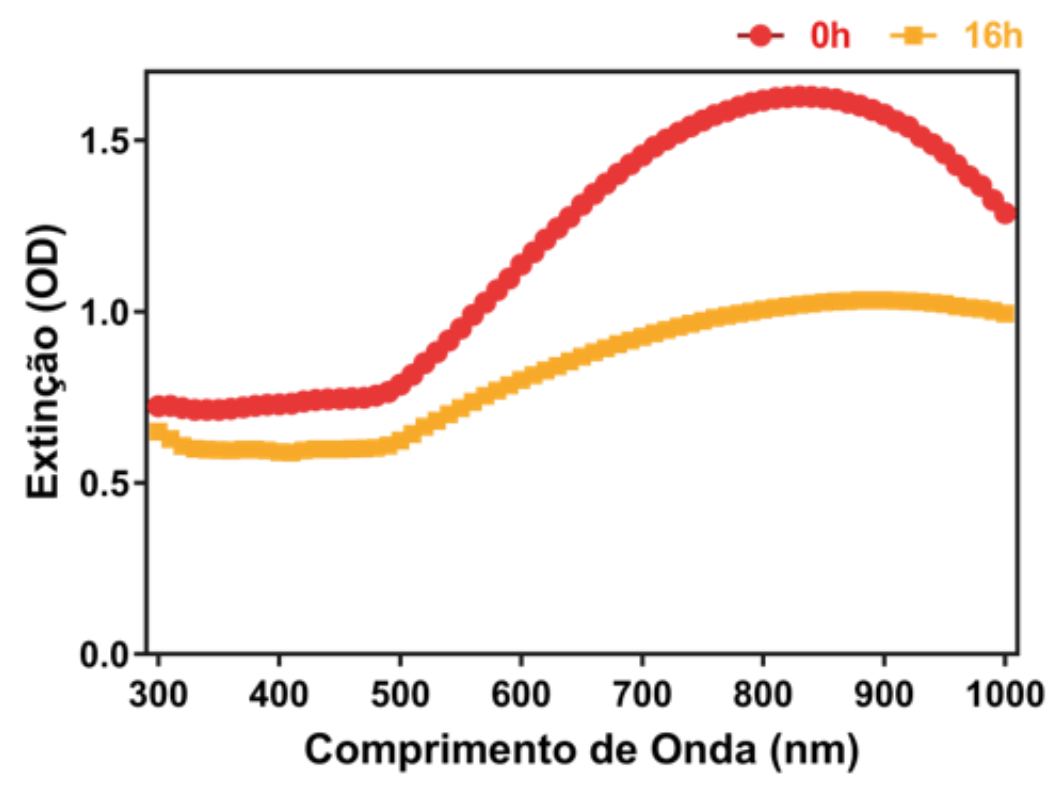

Figura 11 - Interação em meio biológico e estabilidade a $38^{\circ} \mathrm{C}$ : Espectro de extinção das AuNFs mantidas à $38^{\circ} \mathrm{C}$ em meio de cultura com $10 \%$ de FBS após $0 h$ (vermelho) e 16 (amarelo). Fonte: Elaborada pelo autor. 
diâmetro hidrodinâmico das estruturas, que apresentou uma população polidispersa com um Pdl médio consideravelmente alto. Além disso, notam-se grandes alterações na sua banda plasmônica, que foi deslocada para o NIR e apresentou um alargamento e uma redução na sua intensidade (Figura 11).

Tais mudanças estão intrinsecamente relacionadas com a formação da camada proteica na superfície das nanopartículas. (114) Com tal formação, há um aumento não homogêneo do tamanho das partículas, resultando no aumento do diâmetro hidrodinâmico e do Pdl. Além disso, a corona formada proporciona uma mudança da constante dielétrica entre o meio e a superfície de ouro que afeta diretamente a LSPR da estrutura.

Dessa forma, os resultados indicam que a exposição prolongada das AuNFs à temperatura corpórea não causa mudanças significativas nas suas características físicoquímicas. Além disso, o sistema não apresentou sinais de agregação quando suspensas em meio biológico, um fator crucial para seu uso em aplicações biológicas. Entretanto, vemos que sua imersão em um meio rico em proteína resulta na interação entre as proteínas do meio e as nanopartículas, indicando a possível formação da corona. Isso, não só poderá ter grandes influências na biodistribuição e no tempo de circulação das AuNFs, como provoca mudanças na sua interação com a luz, um fator chave para sua aplicação em modalidades fotoativadas. (115-116) Dessa forma, sua resposta ao laser deverá ser realizada em meios biológicos e ricos em proteínas.

\section{Estabilidade com a Irradiação por Laser no NIR}

Existem dois tipos de modos de operação de lasers utilizados em aplicações fotoativadas: lasers pulsados (PW) e lasers contínuos (CW). Dado seu modo de funcionamento, cada um desses tipos proporciona respostas distintas do sistema nanoparticulado, tanto da forma de interação entre o estímulo e as nanopartículas, quanto do mecanismo de danos causados nos tecidos. Apesar de algumas aplicações possibilitarem sua realização com ambos, outras restringem seu funcionamento a um tipo 
específico de laser. Assim, faz-se necessário a verificação da estabilidade das nanopartículas quando irradiadas por tipos de laser.

Para verificar a estabilidade das AuNFs sob irradiação dos lasers PW e CW, alíquotas da dispersão estoque foram sonicadas por $10 \mathrm{~min}$ e foram irradiadas sem diluição. Para o laser PW, um total de 3000 tiros foram incididos com energia de $12 \mathrm{~mJ}$, a $10 \mathrm{~Hz}$.

Como vemos na Tabela 9, a irradiação pelo laser pulsado gerou enormes modificações nas partículas. Após a irradiação, as AuNFs tiveram seu diâmetro hidrodinâmico reduzido em $27 \mathrm{~nm}$ e sua banda plasmônica deslocada de 850 para $580 \mathrm{~nm}$. Comparando as microscopias da Figura 12a-b, vemos que tais mudanças estão atreladas às mudanças morfológicas severas sofridas pelas partículas, que perderam suas ramificações e tornaram-se esféricas. Como já discutimos, a mudança da geometria acarreta modificações das propriedades ópticas das nanopartículas, cuja banda plasmônica se tornou mais estreita e foi deslocada significativamente para a região do visível (Figura 12c). Apesar de mudanças consideráveis à sua morfologia, vemos que não houve alterações em sua rede cristalina após a irradiação. Os picos apresentados no espectro de DRX mantiveram-se inalterados, sendo característicos da rede cúbica típica das nanopartículas de ouro (Figura 12d). Além disso, vemos que a solução se manteve monodispersa, indicando que a mudança morfológica ocorreu em grande parte da população.

Tal modificação na geometria de nanopartículas anisotrópicas de ouro é um fenômeno conhecido na literatura. Isso ocorre pelo fato de que, em lasers PW, uma grande quantidade de energia é emitida em um pulso extremamente curto. Isso gera um grande aumento de temperatura das nanopartículas, levando-as à temperatura de fusão, na qual tendem a se reestruturar em uma morfologia termodinamicamente mais estável. Quando considerando aplicações fotoativadas, tais mudanças podem ser problemáticas, uma vez que a banda plasmônica é deslocada para fora das janelas biológicas, podendo, também, alterar significativamente a interação do sistema nanoparticulado com o meio biológico.

Para avaliar a estabilidade das partículas sob irradiação de um laser CW, as amostras foram irradiadas por $1 \mathrm{~h}$ e $30 \mathrm{~min}$, com 2,42 W. $\mathrm{cm}^{-2}$. Como vemos na Figura 13, 
Tabela 9 - Estabilidade das AuNFs à irradiação por um laser pulsado: Resumo das características físico-químicas das nanoflores de ouro antes e depois da irradiação com um laser pulsado.

\begin{tabular}{ccccccc}
\hline \multicolumn{3}{c}{ Pré irradiação } & & \multicolumn{3}{c}{ Pós irradiação } \\
\cline { 5 - 7 } $\begin{array}{c}\text { Tamanho } \\
(n m)\end{array}$ & Pdl & $\begin{array}{c}\text { Potencial Zeta } \\
(m V)\end{array}$ & & $\begin{array}{c}\text { Tamanho } \\
(n m)\end{array}$ & Pdl & Potencial Zeta \\
170 & 0.048 & -23 & & 143 & 0.068 & -20 \\
\hline
\end{tabular}

Fonte: Elaborada pelo autor.

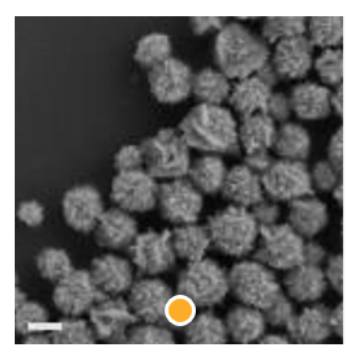

(a)

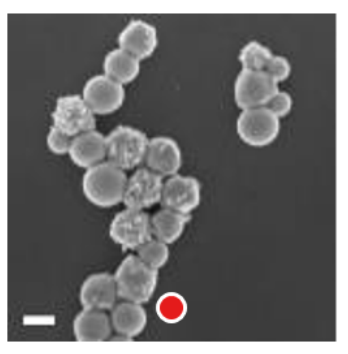

(b)

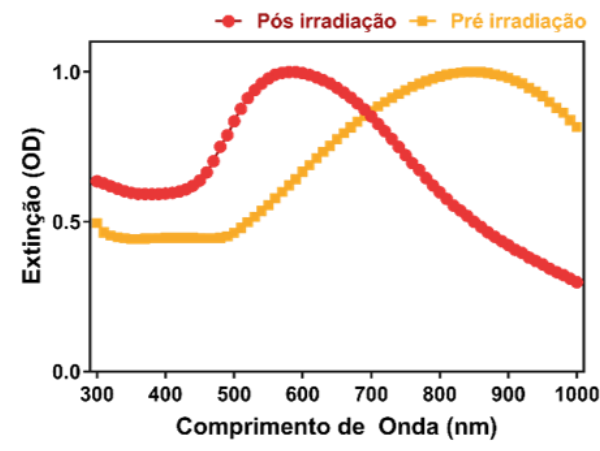

(c)

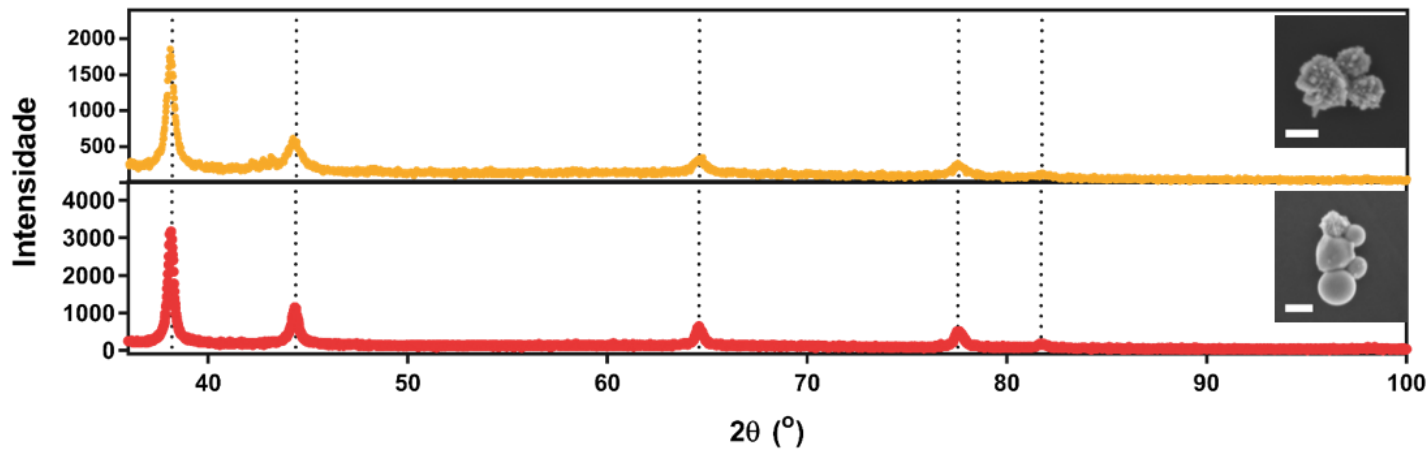

(d)

Figura 12 - Estabilidade das AuNFs à irradiação por um laser pulsado: Microscopia eletrônica de varredura antes (a) e depois (b) da irradiação das AuNFs por um laser pulsado. (c) Espectro de extinção das nanoflores de ouro pré (amarelo) e pós (vermelho) irradiação. (d) Espectro de difração de raio-x das AuNFs pré (amarelo) e pós (vermelho). Os insets são microscopias eletrônicas de varredura que mostram mudanças morfológicas das AuNFs. As barras de escala das microscopias de (a), (b) e (d) representam $100 \mathrm{~nm}$.

Fonte: Elaborada pelo autor.

a irradiação não resultou em variações significativas das características físico-químicas das AuNFs, fato que reflete nas microscopias da Figura 13a-b. Vemos que, mesmo após um longo período de irradiação, a geometria das nanopartículas permaneceu inalterada. 
Através do monitoramento da dispersão durante a irradiação pelo laser contínuo, foi observado um aumento significativo da temperatura (Figura 13c-d). Para entender melhor a estabilidade da resposta fototérmica do sistema, o experimento foi repetido com uma dispersão diluída em 10 vezes de AuNFs, tendo concentração final de $23,8 \mu \mathrm{g} \cdot \mathrm{mL}^{-1}$. Primeiramente, foram realizados três ciclos consecutivos de irradiação, em que a dispersão era irradiada por 12 min e deixada atingir a temperatura ambiente (Figura 13c). Vemos que a solução apresentou um perfil de variação de temperatura consistente entre um ciclo e outro, com pequenas variações entre as temperaturas máximas. Tais variações podem estar relacionadas a variações da temperatura inicial, considerando variações da temperatura ambiente e a pequenas variações no tempo de irradiação. Contudo, a caracterização físico-química da dispersão após ser irradiada não apresentou variações significativas.

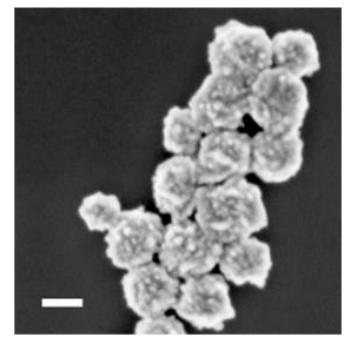

(a)

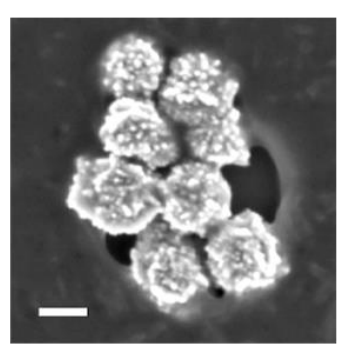

(b)

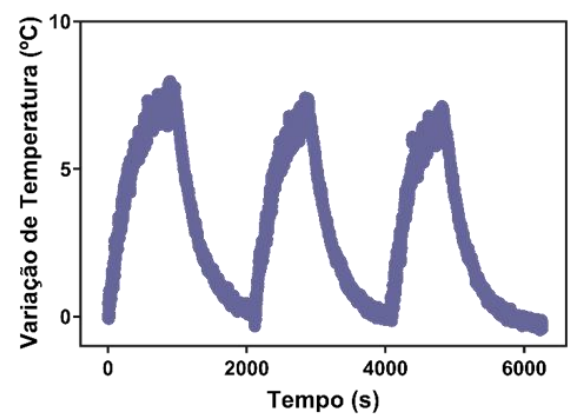

(c)

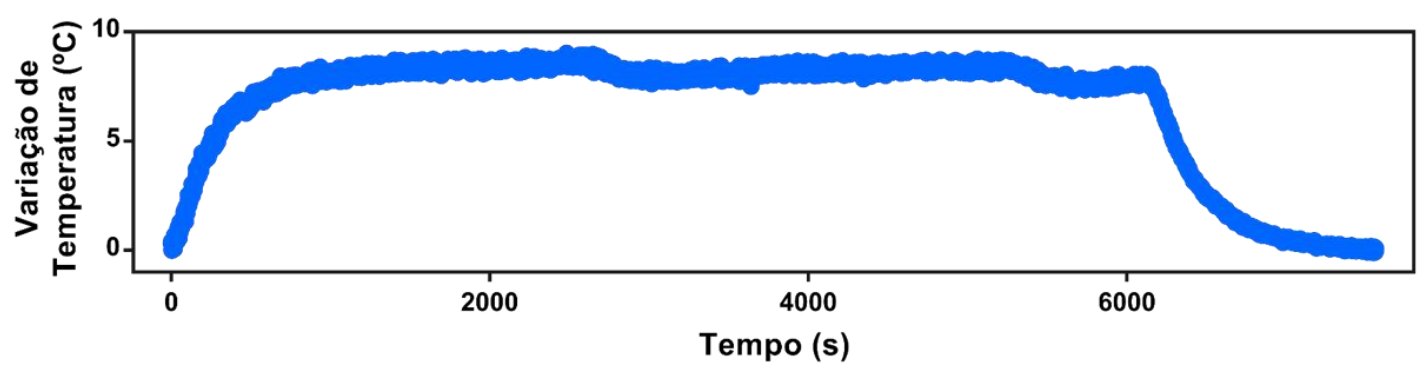

(d)

Figura 13 - Estabilidade das AuNFs à irradiação por um laser contínuo: Microscopia eletrônica de varredura antes (a) e depois (b) da irradiação das AuNFs por um laser pulsado. As barras de escala representam $100 \mathrm{~nm}$. (c) Dependência da variação de temperatura pelo número de ciclos de irradiação. (d) Estabilidade da variação da temperatura pelo tempo de irradiação. Para (b), (c) e (d), utilizou-se uma solução de AuNFs com concentração de $23,8 \mu \mathrm{g} \cdot \mathrm{mL}^{-1}$ irradiadas com $2,42 \mathrm{~W} . \mathrm{cm}^{-2}$.

Fonte: Elaborada pelo autor. 
Por fim, foi avaliada a estabilidade do sinal fototérmico em longo período de irradiação (Figura 13d). A dispersão diluída foi irradiada por $1 \mathrm{~h}$ e $42 \mathrm{~min}$, com $2,42 \mathrm{~W} \cdot \mathrm{cm}^{-2}$. Como vemos, após atingir um valor máximo, a temperatura do sistema foi mantida relativamente constante até o laser ser desligado. As variações observadas podem estar relacionadas a instabilidades da configuração experimental, podendo ser resultado de oscilações da potência do laser. A temperatura máxima de $8,8^{\circ} \mathrm{C}$ foi atingida após cerca de $45 \mathrm{~min}$, mas vemos que após $4 \mathrm{~min}$ o sistema já havia atingido um aumento de $5^{\circ} \mathrm{C}$. Considerando uma temperatura inicial de $38^{\circ} \mathrm{C}$, tal aumento já seria suficiente para levar o local ao regime de hipertermia, que requer temperaturas entre $43-48^{\circ} \mathrm{C}$.

Assim, vemos que as AuNFs apresentaram grande estabilidade quando irradiado por um laser CW, tanto nas características físico-químicas quanto no sinal fototérmico. Ademais, seu sinal fototérmico produziu um aumento de temperatura significativo, sendo suficiente para levar um sistema com temperatura corpórea ao regime de hipertermia. Por outro lado, o uso de lasers PW induziu alterações morfológicas significativas no sistema, que perdeu suas ramificações e tornou-se inativa no NIR. Com isso, o sistema deve ser, preferencialmente, utilizado com lasers contínuos para evitar modificações nas características das nanopartículas.

\section{APLICAÇões}

O sistema de AuNFs produzidos pelo método aqui proposto se mostrou estável nas condições avaliadas, apresentando longo tempo de prateleira e boa estabilidade com o aumento de temperatura quando irradiadas por um laser CW. Além disso, a irradiação mostrou sinais fototérmicos extremamente interessantes, resultando em aumentos de temperatura consideráveis. Dessa forma, as AuNFs produzidas foram consideradas como fortes candidatas para serem aplicadas como agentes teranósticos de tumores. Com isso, as nanopartículas foram avaliadas em duas modalidades: primeiro atuando como agentes de contraste fotoacústico e, em seguida, como agentes terapêuticos na hipertermia de tumores in vitro. 


\section{CONTRASTE DE IMAgENS FotoACÚSTICA}

A técnica de imagens fotoacústica é uma modalidade de imagem emergente que mostra grande potencial para pesquisa pré-clínica e para prática clínica. A técnica baseiase na geração de ondas acústicas pela expansão térmica, que, por sua vez, é dependente do tempo. Para tanto, é necessária a utilização de lasers PW ou de lasers CW com modulação de intensidade. Contudo, a excitação pulsada produz uma maior relação sinal/ruído. Dessa forma, a utilização de um laser PW é preferencial, apesar de sua capacidade de induzir mudanças morfológicas nas nanopartículas anisotrópicas, como discutido acima.

O estudo da resposta fotoacústica das AuNFs foi realizado em duas etapas. Primeiramente, foi feita uma caracterização da resposta fotoacústica das nanopartículas e, em seguida, foi analisada a produção de contraste nas imagens obtidas pela técnica. Todos os experimentos relacionados com essa aplicação foram desenvolvidos em parceria com o professor Théo Z. Pavan, do Grupo de Inovação em Instrumentação Médica e Ultrassom (GIIMUS), do Departamento de Física da Faculdade de Filosofia, Ciências e Letras de Ribeirão Preto, da Universidade de São Paulo. No laboratório, o grupo desenvolve o equipamento de aquisição de imagens fotoacústicas.

Como vemos na Figura 14a, o sistema é composto por um laser PW acoplado com um seletor de frequência que permite o ajuste do comprimento de onda do feixe de luz entre $680-950 \mathrm{~nm}$. Utilizando um espelho em $45^{\circ}$, o feixe é desviado e incide no phantom contendo a amostra na inclusão localizada em seu centro (Figura 14b-c). Com o disparo do laser, um sistema de ultrassom é acionado e faz-se a leitura do sinal.

O sistema de ultrassom utilizado foi modificado para atuar através de dois modos distintos. O primeiro modo consiste no pulso-eco, que é o funcionamento padrão do sistema, em que um pulso de ultrassom é emitido e a resposta das reflexões é capitada gerando uma imagem. O segundo modo, o fotoacústico, ao invés de emitir um pulso, 


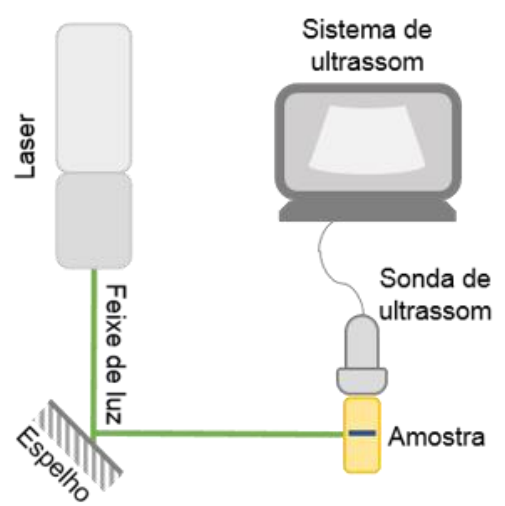

(a)

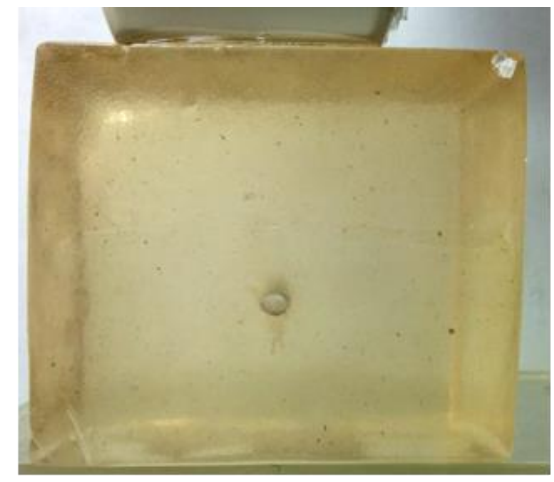

(b)

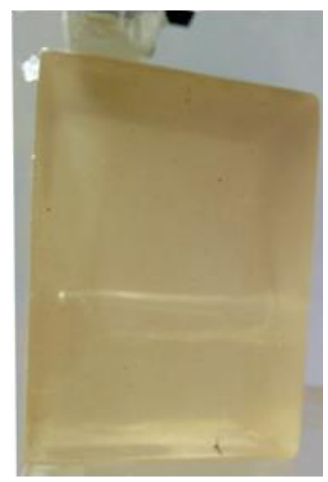

(c)

Figura 14 - Configuração experimental do sistema de fotoacústica: (a) Desenho esquemático do sistema de fotoacústica. Foto frontal (b) e lateral (c) do phantom utilizado como porta amostra.

Fonte: Elaborada pelo autor.

funciona realizando apenas a capitação de ondas acústicas produzidas pelo fenômeno da fotoacústica, a partir do qual forma uma imagem.

O phantom utilizado era formado por um material gelatinoso sintetizado no próprio laboratório GIIMUS. O material foi desenvolvido para simular o comportamento de absorção do laser e da propagação das ondas acústicas em tecidos humanos.

\section{Caracterização Fotoacústica}

Para estabelecermos um protocolo de aquisição das imagens fotoacústicas, foi realizado um estudo para verificar a capacidade das AuNFs de produzir sinais fotoacústicos. Para isso, foi feita uma caracterização da resposta fotoacústica das nanopartículas, na qual foi estudada a influência de alguns parâmetros envolvidos na geração do sinal, incluindo o comprimento de onda de excitação, a potência do laser, a frequência de pulsos do laser e a concentração das nanopartículas. Para tanto, foram realizadas variações com base em um protocolo inicial, que estabelecia a potência de $12 \mathrm{~mJ}$, a frequência de pulsos de $10 \mathrm{~Hz}$ e uma concentração de $238 \mu \mathrm{g} \cdot m L^{-1}$ de nanopartículas.

Primeiramente foi realizada a espectroscopia fotoacústica, na qual variou-se o comprimento de onda de excitação entre 680 e $950 \mathrm{~nm}$, com um passo de $10 \mathrm{~nm}$. Como vemos na Figura 15a, o sinal fotoacústico mais intenso foi observado na região entre 680 e 
$800 \mathrm{~nm}$, diferente do sinal observado no sinal de extinção, cujo máximo encontrava-se em $850 \mathrm{~nm}$. Isso se dá pelo fato de que o sinal fotoacústico depende da absorção da luz pelas partículas, ao passo que a extinção é o resultado da soma da absorção e do espalhamento da luz. Isso evidencia que as AuNFs produzidas possuem máximo de absorção na região citada e que, na região entre $800-1000 \mathrm{~nm}$, predomina o fenômeno de espalhamento. Com base nisso, os demais experimentos foram realizados utilizando o comprimento de onda de $770 \mathrm{~nm}$, ponto no qual o sistema apresentou sinal máximo e ainda se encontra na primeira janela de absorção.

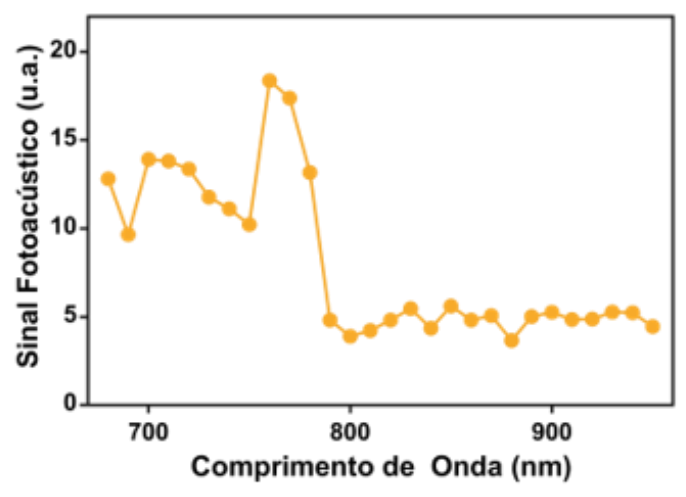

(a)

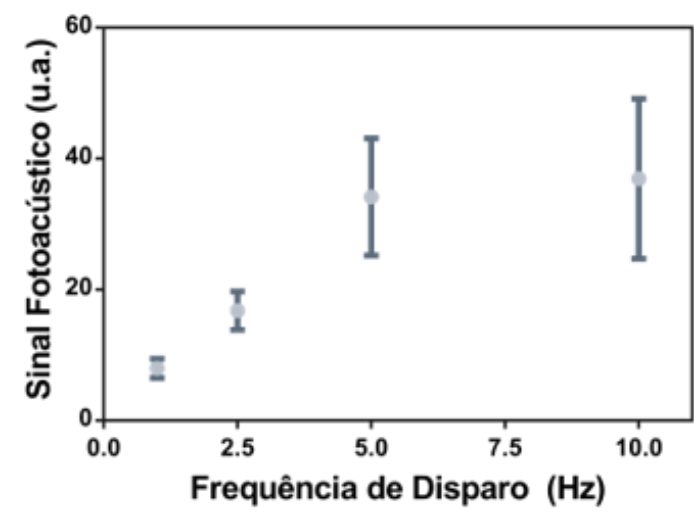

(c)

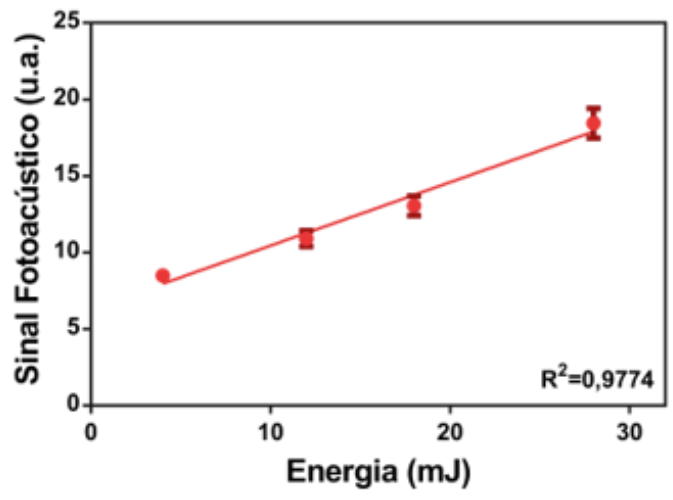

(b)

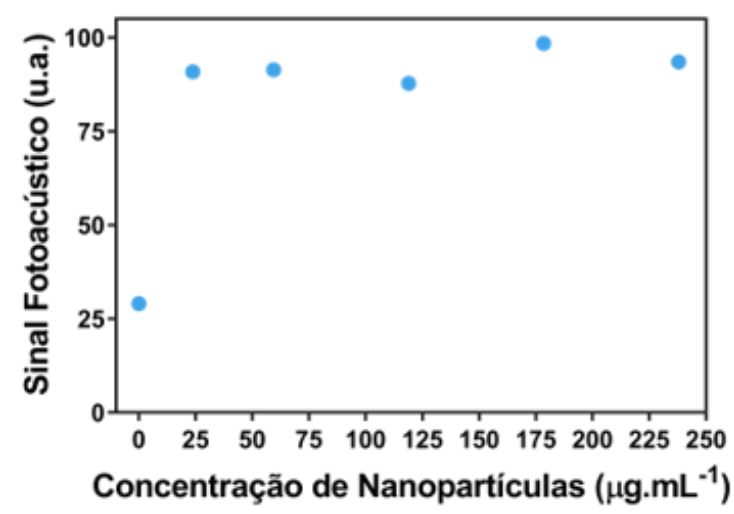

(d)

Figura 15 - Caracterização fotoacústica das AuNFs: (a) Espectroscopia fotoacústica das nanopartículas. (b) Dependência do sinal fotoacústico com a potência do laser. (c) Dependência do sinal fotoacústico com a frequência de disparo do laser. (d) Dependência do sinal fotoacústico com a concentração de nanopartículas. Os experimentos foram realizados com base em variações do protocolo padrão que utilizou uma potência de $12 \mathrm{~mJ}$, no comprimento de onda de $770 \mathrm{~nm}$, com frequência de disparo de $10 \mathrm{~Hz}$ e soluções de nanopartículas com concentração de $238 \mu \mathrm{g} \cdot \mathrm{mL}^{-1}$. As barras de erro dos gráficos (b) e (c) representam o desvio padrão de 10 tiros.

Fonte: Elaborada pelo autor. 
O segundo parâmetro estudado foi a energia do laser. Para tanto, o sinal fotoacústico foi monitorado com excitação de 4, 12, 18 e $28 \mathrm{~mJ}$. Durante o experimento, observou-se considerável flutuação da energia emitida pelo laser. Para minimizar a influência de tais oscilações, foi utilizada a média de um total de 10 repetições. Como vemos na Figura 15b, a resposta fotoacústica das AuNFs apresentou uma dependência linear com a energia de excitação. Além disso, vemos sinais fotoacústicos consideráveis quando utilizamos energias acima de $12 \mathrm{~mJ}$. Como discutimos anteriormente, as nanopartículas são menos estáveis quando consideramos o uso de lasers PW. Dessa forma, a fim de prolongar a estabilidade das partículas, foi utilizada uma energia de $12 \mathrm{~mJ}$ no restante dos experimentos.

Em seguida, foi avaliada a dependência do sinal fotoacústico com a frequência de pulsos do laser. Para isso, o laser foi ajustado para disparar a 1,0, 2,5, 5,0 e 10,0 Hz e o sinal fotoacústico foi monitorado. Novamente, foram constatadas grandes oscilações da potência do laser, o que gerou flutuações consideráveis no sinal fotoacústico. Para minimizar o erro associado, utilizou-se a média de 10 excitações para cada frequência. Como vemos na Figura $\mathbf{1 5 c}$, o sinal se mostrou linearmente crescente entre 1 e $5 \mathrm{~Hz}$. Contudo, pouca diferença foi vista entre 5 e $10 \mathrm{~Hz}$. Possivelmente, o aumento da frequência de excitação promove uma maior variação de temperatura, devido à absorção e conversão da energia em calor pelas nanopartículas. Contudo, o sistema apresenta um limite de conversão da energia, que é atingido quando a frequência de excitação aumenta. Dessa forma, apesar de ser apenas ligeiramente maior, foi utilizada a frequência de $10 \mathrm{~Hz}$ para os demais experimentos buscando um maior sinal fotoacústico.

Por fim, foi verificada a dependência do sinal fotoacústico com a concentração de nanopartículas. Para tanto, foram utilizadas soluções com concentração de AuNFs de $238,0,178,5,119,0,59,5$ e 23,8 $\mu g . m L^{-1}$ e uma solução controle apenas com água. Como vemos na Figura 15d, não houve variações expressivas do sinal fotoacústico entre as concentrações analisadas, sendo todas significativamente maiores que o sinal da água. Isso mostra que, mesmo em concentrações baixas, as AuNFs apresentam uma resposta significativa, sendo, assim, ótimas candidatas para serem utilizadas como agentes de 
contraste. Dessa forma, foi estabelecido o uso de soluções com concentração de 23,8 $\mu \mathrm{g} \cdot m L^{-1}$ de nanopartículas.

\section{Obtenção de Imagens Fotoacústicas}

Após a caracterização, imagens fotoacústicas foram obtidas utilizando os parâmetros otimizados. Para tanto, foram utilizadas uma solução de nanopartículas de 23,8 $\mu \mathrm{g} \cdot \mathrm{mL}^{-1}$, excitadas em $770 \mathrm{~nm}$, com uma frequência de $10 \mathrm{~Hz}$ e com uma potência de $12 \mathrm{~mJ}$.

O experimento foi realizado colocando a solução das AuNFs na inclusão cilíndrica localizada no centro do phantom (Figura 16a). Utilizando o modo pulso-eco, pudemos visualizar a posição da inclusão no interior do phantom (Figura 16b). Utilizando o modo fotoacústico, o sinal produzido pelas nanopartículas foi captado e a imagem produzida. Como vemos na Figura 16c, as AuNFs produziram sinal fotoacústico significativamente alto. O sinal produzido resultou em um contraste com baixo ruído de fundo, possibilitando a fácil identificação da localização das nanopartículas na imagem.

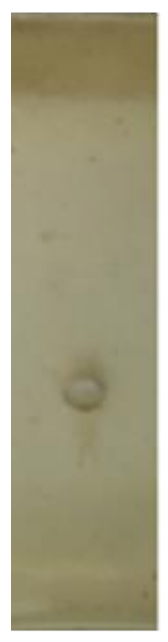

(a)

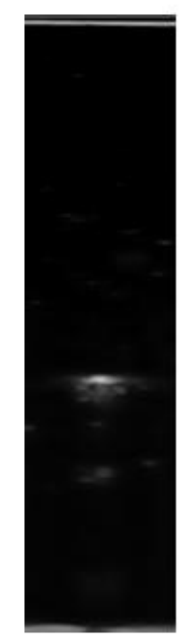

(b)

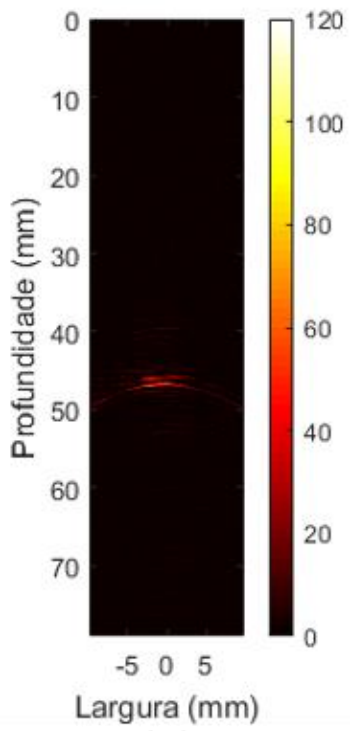

(c)

Figura 16 - Imagem fotoacústica das AuNFs: (a) Foto frontal do phantom utilizado para as medidas fotoacústicas. (b) Sinal pulso-eco obtido do phantom. (c) Imagem fotoacústica das nanopartículas obtidos em $770 \mathrm{~nm}$ obtidas com solução contendo $23,8 \mu \mathrm{g} \cdot \mathrm{mL}^{-1}$ de AuNFs e irradiação com potência de $12 \mathrm{~mJ}$ e frequência de excitação de $10 \mathrm{~Hz}$. 
Com isso, vemos que as AuNFs produzidas são boas candidatas a serem usadas como agentes de contraste de imagens fotoacústicas. A excitação das nanopartículas resultou em um sinal fotoacústico significativo, produzindo uma imagem clara de sua localização no interior do phantom. Ainda, as nanopartículas produziram sinais consideravelmente altos, mesmo em baixas concentrações, característica fundamental para seu uso em aplicações in vivo nas quais apenas uma fração das nanopartículas são interiorizadas pelo tumor.

\section{HiPERTERMiA DE TUMORES}

A terapia fototérmica in vitro de células tumorais utilizando nanopartículas possui uma grande variedade de fatores que influenciam a eficiência do procedimento que dependem, por exemplo, do sistema de irradiação, das nanopartículas e da linhagem de células utilizadas. Com isso, os protocolos reportados são extremamente variados e devem ser adaptados para cada situação. Dessa forma, o estudo da aplicação das AuNFs como agentes terapêuticos na hipertermia de tumores foi dividido em três etapas, nas quais foram estudadas a resposta fototérmica das nanopartículas, a interação célulananopartícula e, por fim, a sua eficiência na hipertermia in vitro.

\section{Resposta Fototérmica}

Em modalidades fotoativadas, a resposta fototérmica das nanoestruturas é um dos principais fatores que determina seu potencial de serem empregadas como agentes ativos em tais aplicações. Assim, é imprescindível que as partículas tenham uma boa conversão fototérmica e que o sistema seja estável quando irradiado.

Existem três aspectos fundamentais a serem analisados: o tipo de laser, sua potência e a concentração das nanopartículas. (14) Cada uma dessas propriedades tem grandes influências na eficiência do procedimento, podendo alterar não apenas a resposta fototérmica das partículas, mas também afetando a viabilidade das células devido a danos inespecíficos. 
Como vimos, as nanopartículas se mostraram mais estáveis com a utilização do laser CW. Assim, utilizou-se um laser CW de diodo com comprimento de onda de $808 \mathrm{~nm}$, que foi ajustado utilizando um sistema óptico para irradiar uma área circular de $0,32 \mathrm{~cm}^{2}$. Para garantir maior estabilidade, o sistema foi ligado $20 \mathrm{~min}$ antes dos experimentos e sua potência foi aferida utilizando um potenciômetro.

Com base nos resultados discutidos anteriormente, modificações significativas nas propriedades ópticas das nanopartículas foram observadas quando suspensas em meio biológico. Assim, todos os experimentos foram realizados em meio rico em proteínas. Para tanto, AuNFs armazenadas foram sonicadas e centrifugadas. As nanopartículas sedimentadas foram ressuspendidas em meio de cultura celular com $10 \%$ de FBS e sonicadas por 10 min para garantir sua monodispersividade. O sistema foi, então, deixado em repouso por $6 h$ antes de seu uso nos experimentos para simular o período de incubação das nanopartículas nos experimentos seguintes.

Buscando a maior eficiência da terapia e a redução dos danos inespecíficos, devemos estabelecer um protocolo que alcance o regime de hipertermia e se mantenha nela, uma vez que os danos produzidos não são instantâneos. Quando consideramos a terapia térmica de tumores, devemos elevar a temperatura da região doente à região de hipertermia $\left(43-48^{\circ} \mathrm{C}\right)$. Logo, considerando uma temperatura basal de $38^{\circ} \mathrm{C}$, devemos buscar um aumento de 5 a $10^{\circ} \mathrm{C}$ pela irradiação das nanopartículas.

Na Figura 17a, podemos comparar a irradiação pelo laser com $2,42 \mathrm{~W} . \mathrm{cm}^{-2}$ de potência, por cerca de $12 \mathrm{~min}$, de uma solução contendo $23,8 \mu \mathrm{g} \cdot \mathrm{mL}^{-1}$ de AuNFs e uma solução contendo somente meio de cultura. Apesar de vermos uma elevação da temperatura da amostra contendo somente meio de cultura, observa-se um aumento consideravelmente maior da solução contendo nanopartículas, que atingiu uma temperatura final $67 \%$ mais alta. Além disso, vemos que a solução contendo nanopartículas elevou a temperatura para a região desejada, produzindo um aumento final de $9,8^{\circ} \mathrm{C}$. 
Para compreender melhor seu comportamento e estabelecer um protocolo para a terapia in vitro, a dependência da resposta fototérmica das AuNFs tanto pela potência, quanto pela concentração das partículas foi verificada.

Tipicamente, a intensidade do laser CW reportada na literatura, pode variar de 1 a cerca de $100 \mathrm{~W} \cdot \mathrm{cm}^{-2}$. (14) Dessa forma, para aferir a influência da potência da irradiação, soluções de $23,8 \mu \mathrm{g} \cdot \mathrm{mL}^{-1}$ de AuNFs foram preparadas e sua resposta fototérmica foi monitorada para irradiações com 0,73, 2,42 e 5,95 W. $\mathrm{cm}^{-2}$, durante $10 \mathrm{~min}$. Como vemos na Figura 17b, a irradiação do sistema com $0,73 \mathrm{~W} . \mathrm{cm}^{-2}$ produziu um aquecimento

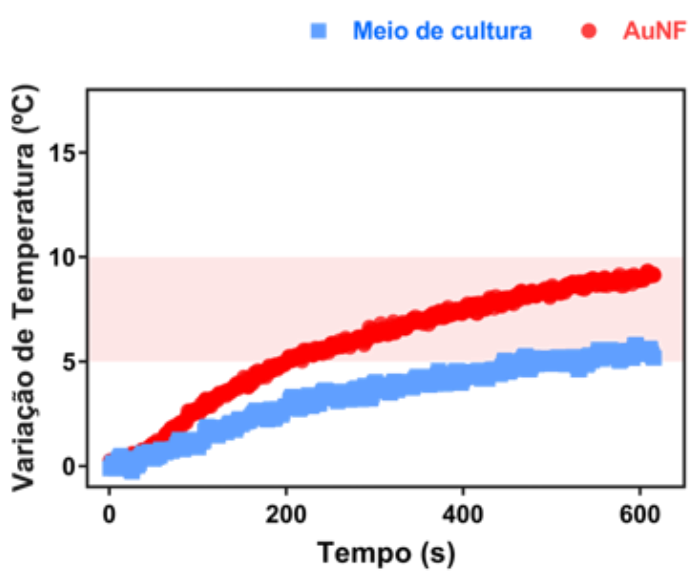

(a) v $0.73 \mathrm{~W} . \mathrm{cm}^{-2} \bullet 2.42 \mathrm{~W} . \mathrm{cm}^{-2} \bullet 5.95 \mathrm{~W} . \mathrm{cm}^{-2}$

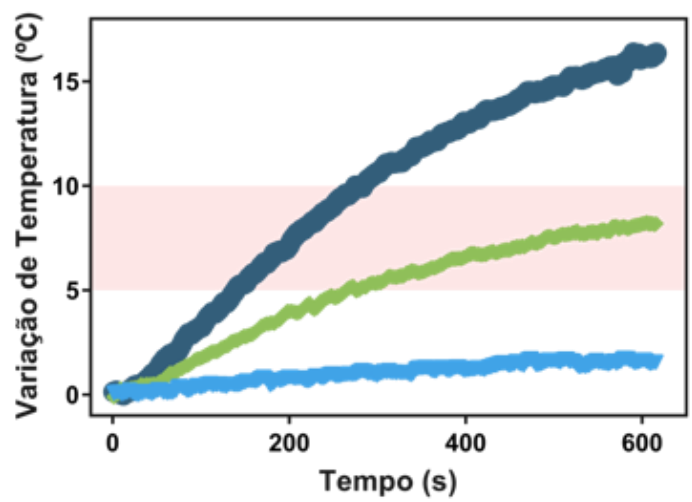

(b)

= $23.8 \mu \mathrm{g} \cdot \mathrm{mL}^{-1} \bullet 35.7 \mu \mathrm{g} \cdot \mathrm{mL}^{-1} \Delta 59.5 \mu \mathrm{g} \cdot \mathrm{mL}^{-1}$

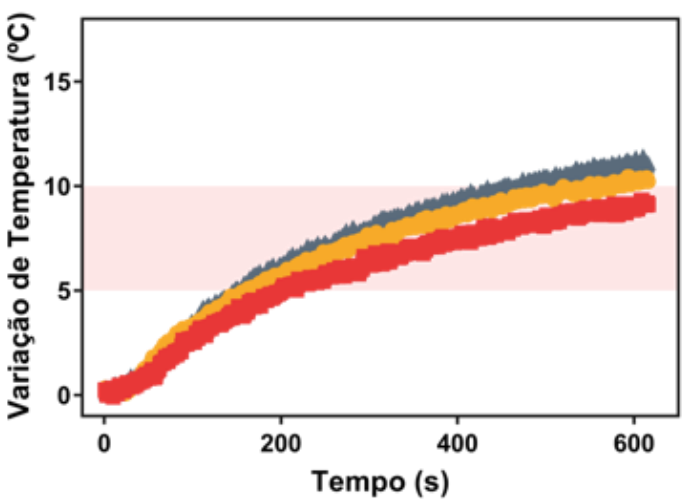

(c)

Figura 17 - Resposta fototérmica das AuNFs: (a) Irradiação de soluções contendo 23,8 $\mu \mathrm{g} \cdot m L^{-1}$ de nanopartículas (vermelho claro) e contendo apenas meio de cultura (azul) com 2,42 W. $\mathrm{cm}^{-2}$. (b) Irradiação de soluções com 23,8 $\mu \mathrm{g} \cdot \mathrm{mL}^{-1}$ com 0,73 (azul claro), 2,42 (verde) e 5,95 W. $\mathrm{cm}^{-2}$ (azul escuro). (c) Irradiação de soluções contendo 23,8 (vermelho), 35,7 (amarelo) e 59,5 $\mu \mathrm{g} \cdot \mathrm{mL}^{-1}$ (cinza) com 2,42 W. $\mathrm{cm}^{-2}$. A região em destaque representa a região de hipertermia considerando uma temperatura inicial de $38,0^{\circ} \mathrm{C}$.

Fonte: Elaborada pelo autor. 
insuficiente, que elevou a temperatura em apenas $1,7^{\circ} \mathrm{C}$. Quando irradiado com 2,42 e $5,95 \mathrm{~W} . \mathrm{cm}^{-2}$, verificou-se que os sistemas foram levados à região de hipertermia (região destacada nas figuras), resultando em um aumento da temperatura da solução de 8,2 e $16,1^{\circ} \mathrm{C}$, respectivamente.

Quando irradiado por $5,95 \mathrm{~W} . \mathrm{cm}^{-2}$, vemos que o sistema alcançou a condição de hipertermia após $2 \min$ e $20 \mathrm{~s}$, permanecendo na região por $2 \min$ e $15 \mathrm{~s}$, após o qual o sistema foi levado às temperaturas que poderiam gerar danos irreversíveis não-específicos. Por outro lado, a irradiação do sistema por $2,42 \mathrm{~W} . \mathrm{cm}^{-2}$ alcançou a região desejada após $4 \min$ e $25 s$, na qual manteve-se pelos restantes 6 min e $35 s$ que o sistema foi monitorado. Dessa forma, a potência de $2,42 W \cdot \mathrm{cm}^{-2}$ é mais apropriada para a terapia, uma vez que esta manteve o sistema na condição de hipertermia por um período mais longo e não excedeu o intervalo de temperatura estipulado.

Por fim, foi avaliada a dependência da resposta fototérmica pela concentração de AuNFs. Para tanto, foi monitorada a irradiação de soluções contendo 23,8, 35,7 e $59,5 \mu \mathrm{g} \cdot \mathrm{mL}^{-1}$, que representou diluições da solução estoque de 10, 15 e 25\%, respectivamente. Como vemos na Figura 17c, as dispersões atingiram uma temperatura máxima de $9,3,10,2$ e $11,3^{\circ} \mathrm{C}$, alcançando o intervalo de hipertermia após $3 \mathrm{~min}$ e $21 \mathrm{~s}$, $2 \min$ e $43 s$ e, $2 \min$ e $28 s$, respectivamente. As dispersões com 35,7 e 59,5 $\mu$ g. $m L^{-1}$ mantiveram o sistema na região desejada por $6 \min$ e $7 s$ e 4 min e $52 \mathrm{~s}$, nessa ordem, e extrapolaram o limite de $10^{\circ} \mathrm{C}$. A dispersão com $23,8 \mu \mathrm{g} \cdot \mathrm{mL}^{-1}$, por outro lado, não extrapolou o limite e manteve o sistema na condição de hipertermia por 6 min e $55 \mathrm{~s}$.

$\mathrm{Na}$ hipertermia de tumores utilizando nanopartículas, devemos levar em consideração que apenas uma fração das partículas será internalizada pelas células. Pelo estudo, vemos que mesmo em concentrações mais baixas, as dispersões irradiadas produziram o aumento de temperatura desejado e mantiveram o sistema no intervalo estabelecido. Além disso, as duas maiores concentrações avaliadas, apesar de terem extrapolado a temperatura limite, atingiram temperaturas pouco acima do intervalo estipulado, ainda sendo concentrações interessantes para aplicação. Com isso, vemos que as AuNFs são candidatas promissoras para atuarem como agentes terapêuticos na hipertermia de tumores. 


\section{Interação Célula-Nanopartícula in vitro}

Devido à importância do desenvolvimento de terapias efetivas para tumores de fígado, linhagens de células tumorais e saudáveis de fígado, HTC e FC3H, respectivamente, foram escolhidas para os testes in vitro. Ademais, com base em testes in vivo reportados na literatura, nanopartículas com características semelhantes às AuNFs sintetizadas tendem a apresentar altas concentrações no fígado e no baço após injeção intravenosa. (117) Assim, por possuírem uma tendência natural de acúmulo no fígado, essas nanoestruturas se tornam candidatas promissoras a serem aplicadas em procedimentos teranósticos dessa classe de tumores.

Antes de verificar a eficiência terapêutica das nanopartículas, devemos estudar sua interação com as células, avaliando sua toxicidade e verificando a interiorização das nanoestruturas.

Primeiramente, a toxicidade das AuNFs foi monitorada em um período de $24 h$. Para tanto, as células saudáveis e tumorais foram tratadas com soluções de 23,8, 35,7 e $59,5 \mu \mathrm{g} \cdot \mathrm{mL}^{-1}$ de nanopartículas e a viabilidade celular dos grupos foi verificada por testes colorimétricos após 6, 12 e 24 de incubação. Todos os experimentos foram realizados em triplicatas, cujos resultados estão na Figura 18.

Como vemos, o tratamento com as AuNFs produziu efeitos distintos no grupo tumoral e no grupo saudável. Notam-se sinais de toxicidade das nanopartículas na linhagem de células tumorais, cuja viabilidade foi reduzida com o passar do tempo, atingindo uma redução de até 35\% após $24 h$ (Figura 18a). Os testes mostraram, ainda, que a toxicidade não apresentou uma relação direta com a concentração das nanopartículas no meio, apresentando viabilidade semelhante para todas as concentrações nos três momentos aferidos. Por outro lado, os testes com linhagens saudáveis não apresentaram sinais de toxicidade em nenhuma das concentrações (Figura 18b).

Para confirmar a internalização das AuNFs, foi realizado um estudo com base na granulosidade das células, analisadas pelo espalhamento lateral da citometria de fluxo (SSC, do inglês side scattering). Como reportado na literatura (105), existe uma relação 


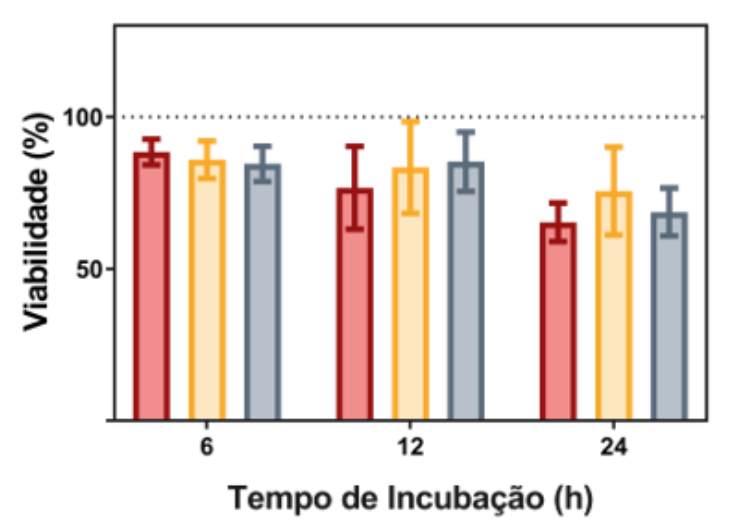

(a)

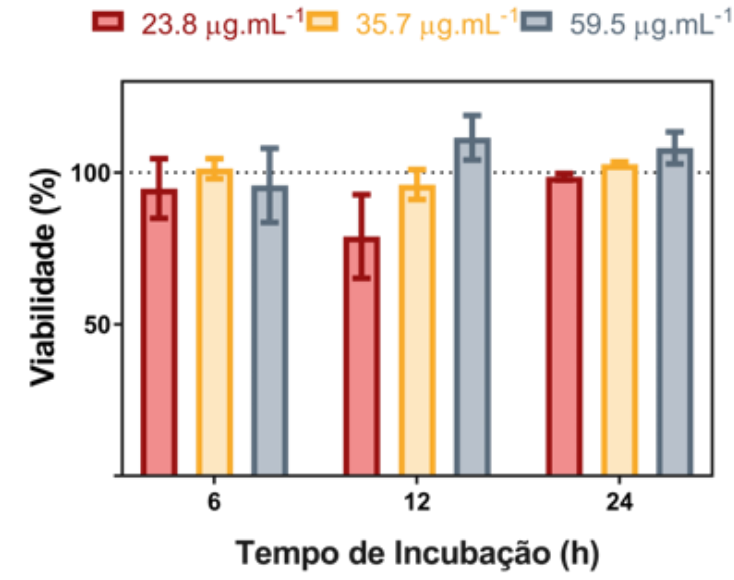

(b)

Figura 18 - Toxicidade in vitro das AuNFs: Toxicidade de soluções de 23,8, 35,7 e 59,5 $\mu \mathrm{g} \cdot \mathrm{mL}^{-1}$ de nanopartículas após 6, 12 e $24 h$ de incubação em linhagens tumorais (a) e linhagens saudáveis (b). As barras de erro representam o desvio padrão de 3 repetições.

Fonte: Elaborada pelo autor.

direta entre a quantidade de nanopartículas interiorizadas e a granulosidade das células medidas pelo sinal de SSC. Dessa forma, utilizando o sinal normalizado de SSC de células tratadas com nanopartículas pelo sinal de um grupo controle (nSSC), podemos verificar a interiorização das nanopartículas pelas células.

Apesar dos parâmetros estarem relacionados, não é possível quantificar as nanopartículas interiorizadas apenas por esse método, uma vez que tal relação depende das características físico-químicas das partículas e da linhagem celular utilizada. Para a quantificação, são necessárias análises complementares por outras técnicas, como espectrometria de massa por plasma acoplado indutivamente (ICP-MS). Contudo, a análise do nSSC fornece uma forma simples de verificação qualitativa da interiorização das partículas amplamente utilizada na literatura de nanotoxicidade. (118-119)

Para avaliar a interiorização das AuNFs, o nSSC das células tumorais foi monitorado no período de $24 h$ para células tratadas com soluções de 23,8, 35,7 e 59,5 $\mu \mathrm{g} \cdot \mathrm{mL}^{-1}$ de nanopartículas, realizado em triplicata. Como vemos na Figura 19, há sinais de interiorização das nanoestruturas tanto na linhagem tumoral, quanto na saudável. Vemos, também, que há uma relação direta entre a interiorização e a concentração das nanopartículas do meio, mostrando sinais de quantidades maiores de nanopartículas 


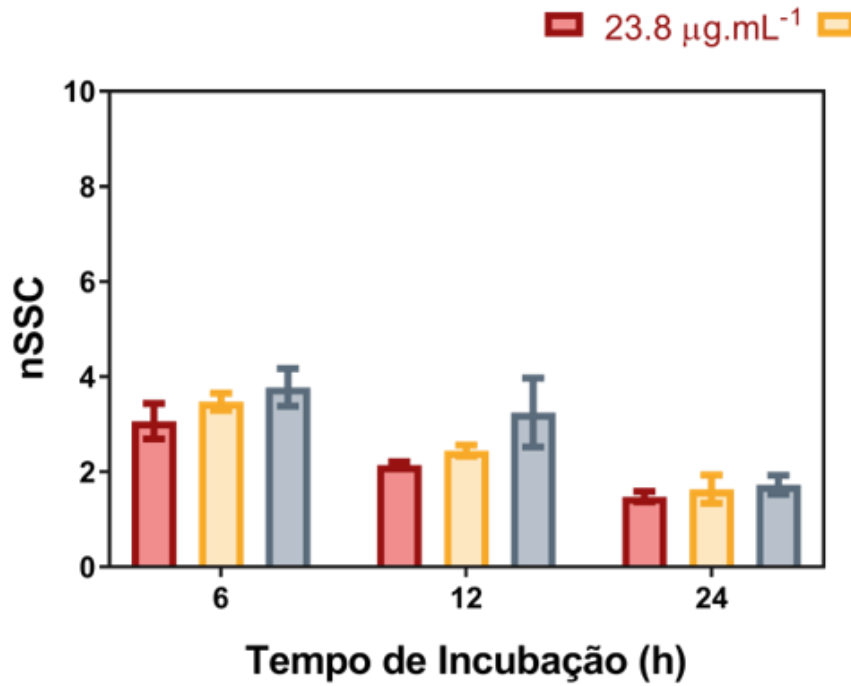

(a)

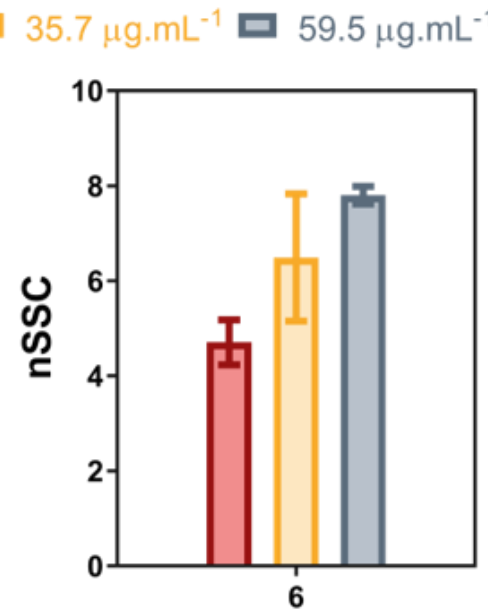

Tempo de Incubação (h)

(b)

Figura 19 - Interiorização das AuNFs in vitro: Sinal de dispersão lateral normalizado (nSSC) do histograma de dispersão lateral $(S S C)$ da linhagem tumoral (HTC) (a) e da linhagem saudável (FC3H) (b) pelo tempo de incubação. A intensidade $S S C$ média de cada amostra incubada com nanopartículas $\left(S S C_{i}\right)$ foi dividida pelo $S S C$ do grupo controle $\left(S S C_{0}\right)$. As barras de erro representam o desvio padrão de 3 repetições.

Fonte: Elaborada pelo autor.

interiorizadas nas amostras de 35,7 e $59,5 \mu \mathrm{g} \cdot \mathrm{mL}^{-1}$, mostrando uma internalização concentração dependente.

Como vemos na Figura 19a, a interiorização das nanoestruturas atinge valores máximos nas primeiras horas de incubação, mostrando consideráveis reduções após 12 e $24 \mathrm{~h}$. Tal redução pode estar relacionada com as modificações da superfície das nanopartículas resultantes da interação com as proteínas do meio. Como vimos, devido à interação das AuNFs com as proteínas do meio, ocorre a formação da corona que, além de mudar as propriedades de superfície das partículas, gera um aumento considerável do tamanho podendo, então, dificultar sua interiorização. Assim, podemos supor que o fluxo de nanopartículas sendo interiorizadas é menor do que o fluxo de partículas sendo eliminadas pelas células, resultando na redução progressiva da quantidade de nanopartículas interiorizadas vistas na Figura 19a.

Com base nisso, verificamos que as AuNFs são interiorizadas por ambas linhagens e que a irradiação das células deve ser realizada após $6 h$, quando houve maior concentração de nanopartículas interiorizadas. Ademais, observamos que as nanopartículas, quando não 
irradiadas, apresentaram baixa toxicidade para a linhagem tumoral avaliada e, apesar de apresentarem sinais de interiorização, não mostram sinais de toxicidade para as linhagens saudáveis.

\section{Eficiência Terapêutica}

A eficiência terapêutica das AuNFs foi avaliada. Para isso, linhagens tumorais e saudáveis foram tratadas com soluções de 23,8, 35,7 e 59,5 $\mu \mathrm{g} \cdot \mathrm{mL}^{-1}$ de nanopartículas e incubadas por $6 h$. Em seguida, as células foram irradiadas por um laser CW com $2,42 \mathrm{~W} . \mathrm{cm}^{-2}$ por $12 \mathrm{~min}$. Dois grupos controle foram utilizados, um irradiado sem nanopartículas e um grupo referência, sem partículas e sem irradiação. Os experimentos foram realizados em triplicata.

Como vemos na Figura 20, a hipertermia utilizando as AuNFs se mostrou seletiva, eficiente na terapia da linhagem tumoral (Figura 20a) e não reduzindo a viabilidade celular das células saudáveis nas primeiras horas após sua irradiação (Figura 20b). As células de tumor irradiadas apresentaram redução significativa em todas as concentrações de nanopartículas estudadas. Na menor concentração, a viabilidade média observada foi de $76,4 \%$, enquanto que nas células tratadas com 35,7 e $59,5 \mu g \cdot m L^{-1}$, a população de

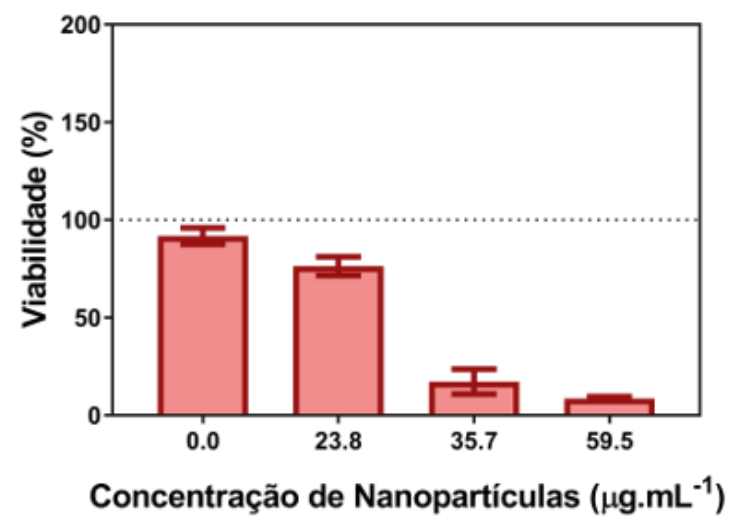

(a)

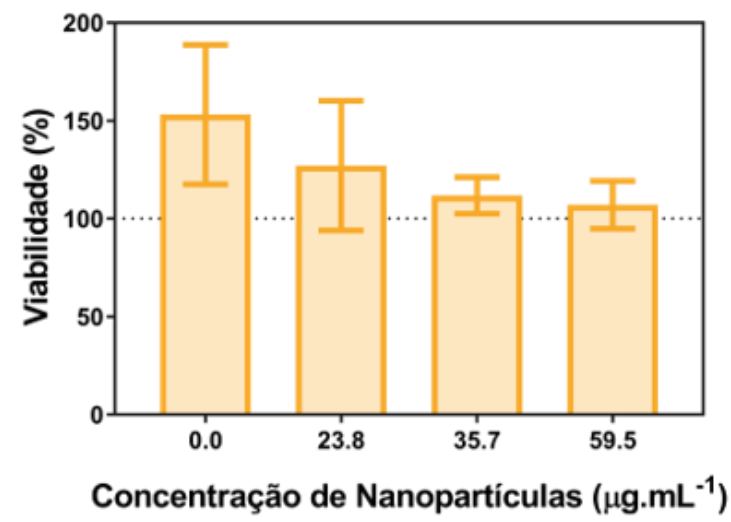

(b)

Figura 20 - Eficiência terapêutica das AuNFs: Viabilidade celular das linhagens tumorais (a) e saudáveis (b) após irradiação com contendo 0, 23,8, 35,7 e 59,5 $\mu \mathrm{g} \cdot \mathrm{mL}^{-1}$ de nanopartículas. As amostras foram incubadas por $6 \mathrm{~h}$ e irradiadas por $12 \mathrm{~min}$ cada poço por um laser $\mathrm{CW}$ com 2,42 W. $\mathrm{cm}^{-2}$. As barras de erro correspondem ao desvio padrão obtidos a partir de 3 repetições.

Fonte: Elaborada pelo autor. 
células foi reduzida a $17,2 \%$ e $8,6 \%$, respectivamente. Comparando, vemos que a viabilidade observada nos testes de toxicidades em $6 h$ mostraram uma redução da viabilidade celular para 88,4\%, 85,9\% e 84,5\% nas mesmas concentrações (Figura 18a). Isso reforça que, de fato, a redução da viabilidade é resultado da resposta fototérmica das AuNFs.

Levando em consideração o resultado apresentado na Figura 19b, observamos que, mesmo com sinais de interiorização, a linhagem saudável não foi afetada pela terapia, de modo que a viabilidade não apresentou valores inferiores a 100\% (Figura 20b). Isso pode estar relacionado com o fato de que a maioria dos tecidos saudáveis não é danificado pelo tratamento em temperatura de até $44^{\circ} \mathrm{C}$ por até $1 h$. (13). A viabilidade apresentada apresentou valores maiores que $100 \%$ em todas as concentrações avaliadas. Nesse caso, os valores de viabilidade maiores que $100 \%$ indicam, apenas, que as populações proliferaram mais que aquelas pertencente ao grupo controle. Com isso, nota-se que, mesmo no grupo tratado com 59,5 $\mu \mathrm{g} \cdot \mathrm{mL}^{-1}$, a viabilidade manteve-se acima da referência. Apesar de não podermos descartar efeitos a longo prazo produzidos por alterações metabólicas do procedimento, os resultados obtidos indicam que a linhagem não foi afetada pela terapia de maneira imediata.

As partículas apresentaram grande eficiência na terapia da linhagem tumoral, mostrando redução de até 91,4\% da viabilidade celular após a irradiação com o laser CW. Além disso, as nanopartículas mostraram toxicidade reduzida à linhagem saudável não reduzindo sua viabilidade, mesmo sem funcionalização da superfície das nanoestruturas. Com isso, concluímos que as AuNFs produzidas são excelentes candidatas para atuarem como agentes ativos na hipertermia de tumores de fígado. 


\section{CONCLUSÕES}

Os resultados desse trabalho sugerem uma rota de síntese de nanopartículas de ouro anisotrópicas para aplicações teranósticas. Neste aspecto, o estudo buscou elucidar aspectos cruciais da síntese que manifestaram grande influência na nanoestrutura desenvolvida. Ademais, os resultados visaram certificar-se da estabilidade do nanomaterial fabricado, bem como sua aplicabilidade em modalidades diagnósticas e terapêuticas.

No campo da síntese, o procedimento proposto se mostrou eficiente no preparo das nanopartículas anisotrópicas com aspecto de flores, fornecendo um método simples, reprodutível e escalável de obtenção de sistemas monodispersos dessas nanoestruturas. Além disso, o método permitiu a fácil sintonização da banda plasmônica em grande parte do espectro visível e do infravermelho-próximo através da modificação de parâmetros da síntese, como a temperatura e, principalmente, a concentração de ouro.

De acordo com os resultados, as nanopartículas se mostraram estáveis durante um longo período de tempo, apresentando baixa variação de suas propriedades físicoquímicas após mais de dois meses de armazenamento. Ainda, os resultados indicam que, apesar de apresentarem indícios de alterações morfológicas com o aumento de temperatura, as partículas mostraram-se inalteradas à temperatura corpórea.

O uso das AuNFs como agentes de contraste de imagens fotoacústicas se mostrou muito promissor, permitindo a obtenção de uma imagem com baixo ruído, cuja localização das nanoestruturas é facilmente identificada. Quando irradiadas por lasers pulsados, as partículas produziram respostas fotoacústicas significativas, mesmo em concentrações mais baixas. A caracterização de sua resposta permitiu a otimização do sinal através do ajuste de parâmetros do sistema, que se mostrou crescente com a energia e com a frequência de pulsos do laser. Entretanto, a irradiação das partículas por lasers PW resultou em modificações morfológicas severas da nanoestrutura e a consequente perda de sua atividade no infravermelho-próximo.

Por fim, as nanopartículas produzidas apresentaram grande potencial terapêutico ao serem empregadas como agentes ativos para hipertermia de tumores de fígado. Sua 
irradiação por lasers CW exibiu excelente estabilidade produzindo aumentos significativos de temperatura sob irradiação. As AuNFs apresentaram baixa toxicidade quando não ativadas pelo laser e boa eficiência terapêutica sob irradiação, resultando em reduções de até $91,4 \%$ da viabilidade da linhagem de células tumorais. Por outro lado, as nanoestruturas não apresentaram sinais de toxicidade à linhagem de células saudáveis analisada, mostrando seletividade à fototermia mesmo sem modificações da superfície das nanopartículas.

Nossos resultados apresentam um processo simples de produção de nanoestruturas monodispersas, estáveis, com morfologia complexa e com desempenho promissor em modalidades diagnósticas e terapêuticas. Dada a importância das aplicações contempladas, o desenvolvimento de procedimentos simples para a obtenção dessas nanoestruturas é um fator fundamental para a evolução de seu uso laboratorial para uma possível tradução clínica futura. 


\section{Perspectivas}

Análise por microscopia eletrônica de transmissão de alta definição (HRTEM) pode ser útil para um estudo mais detalhado da estrutura das AuNFs. Além disso, a investigação de outros aspectos da estabilidade das nanopartículas, como variações de $\mathrm{pH}$, é fundamental para um melhor entendimento do comportamento dessas estruturas.

Dado os indícios de interação das AuNFs com as proteínas do meio, ensaios de calorimetria de titulação isotérmica (ITC, do inglês isothermal titration calorimetry) utilizando proteínas, como a BSA e a HSA, pode ajudar a explicitar a formação da corona e seu comportamento no meio biológico.

A realização de testes utilizando outras linhagens celulares é indispensável para melhor compreensão de seu comportamento in vivo, incluindo macrófagos que são um dos

principais agentes de remoção das nanopartículas da circulação. Ademais, o aprofundamento da análise da interação nanopartícula-célula, incluindo o estudo sobre o processo interiorização-eliminação das nanopartículas pelas células, é imprescindível para entender sua ação teranóstica e possíveis modificações sofridas pelas nanopartículas no processo.

Por fim, estudos do desempenho das AuNFs em outras modalidades diagnósticas como microscopia de dois-fótons e espectroscopia Raman - e terapêuticas - como o carreamento de fármacos - podem ajudar a expandir ainda mais as possibilidades de aplicações dessas nanoestruturas. 


\section{REFERÊNCIAS}

1 SENGUPTA, A.; SARKAR, C.K. Introduction to nano: basics to nanoscience and nanotechnology. Berlin: Springer Verlag, 2015. ISBN 3662473143.

$2 \mathrm{SHAH}, \mathrm{M}$. et al. Nanotechnology applications for improvements in energy efficiency and environmental management. Hershey:IGI Global, 2015. ISBN 1466663057.

3 HUANG, X. et al. Cancer cell imaging and photothermal therapy in the near-infrared region by using gold nanorods. Journal of the American Chemical Society, v. 128, n. 6, p. 21152120, 2006. ISSN 0002-7863.

4 YANG, X. et al. Gold nanomaterials at work in biomedicine. Chemical Reviews, v. 115, n. 19, p. 10410-10488, 2015. ISSN 0009-2665.

5 CHEN, G. et al. Nanochemistry and Nanomedicine for Nanoparticle-based Diagnostics and Therapy. Chemical Reviews, v. 116, n. 5, p. 2826-2885, 2016. ISSN 0009-2665.

6 WALMSLEY, G.G. et al. Nanotechnology in bone tissue engineering. Nanomedicine: nanotechnology, biology and medicine, v. 11, n. 5, p. 1253-1263, 2015. ISSN 1549-9634.

7 PEER, D. et al. Nanocarriers as an emerging platform for cancer therapy. Nature Nanotechnology, v. 2, n. 12, p. 751-760, 2007. ISSN 1748-3387.

8 SHAH, M., BADWAIK, V.D. e DAKSHINAMURTHY, R. Biological applications of gold nanoparticles. Journal of Nanoscience and Nanotechnology, v. 14, n. 1, p. 344-362, 2014. ISSN 1533-4880.

9 SPERLING, R.A. et al. Biological applications of gold nanoparticles. Chemical Society Reviews, v. 37, n. 9, p. 1896-1908, 2008.

10 EUSTIS, S.; EL-SAYED, M.A. Why gold nanoparticles are more precious than pretty gold: noble metal surface plasmon resonance and its enhancement of the radiative and nonradiative properties of nanocrystals of different shapes. Chemical Society Reviews, v. 35, n. 3, p. 209-217, 2006.

11 YOO, J.W.; CHAMBERS, E.; MITRAGOTRI, S. Factors that control the circulation time of nanoparticles in blood: challenges, solutions and future prospects. Current Pharmaceutical Design, v. 16, n. 21, p. 2298-2307, 2010. ISSN 1381-6128.

12 MANIVASAGAN, P. et al. Doxorubicin-loaded fucoidan capped gold nanoparticles for drug delivery and photoacoustic imaging. International Journal of Biological Macromolecules, v. 91, p. 578-588, 2016. ISSN 0141-8130.

13 HABASH, R.W. et al. Thermal therapy, part 2: hyperthermia techniques. Critical Reviews in Biomedical Engineering, v. 34, n. 6, p. 491-542, 2006. ISSN 0278-940X.

14 JAQUE, D. et al. Nanoparticles for photothermal therapies. Nanoscale, v. 6, n. 16, p. 94949530, 2014. 
15 YUN, S.H.; KWOK, S.J. Light in diagnosis, therapy and surgery. Nature Biomedical Engineering, v. 1, p. 0008, 2017. ISSN 2157-846X.

16 ZHAO, P.; LI, N.; ASTRUC, D. State of the art in gold nanoparticle synthesis. Coordination Chemistry Reviews, v. 257, n. 3, p. 638-665, 2013. ISSN 0010-8545.

17 AHMED, W. et al. Controlling the morphology of multi-branched gold nanoparticles. Nanotechnology, v. 21, n. 12, p. 125605, 2010. ISSN 0957-4484.

18 NIKALJE, A. P. G. Nanotechnology and its applications in medicine. Medicinal Chemistry, v. 5, n. 2, 2015 . doi:10.4172/2161-0444.1000247.

19 RODUNER, E. Size matters: why nanomaterials are different. Chemical Society Reviews, v. 35, n. 7, p. 583-592, 2006.

20 LIN, P.C. et al. Techniques for physicochemical characterization of nanomaterials. Biotechnology Advances, v. 32, n. 4, p. 711-726, 2014. ISSN 0734-9750.

21 KUNO, M.K. Introduction to nanoscience and nanotechnology: a workbook. CreateSpace Independent Publishing Platform, 2003. ISBN 1505583233.

22 JEONG, Y.S. et al. Study on the catalytic activity of Noble metal nanoparticles on reduced graphene oxide for oxygen evolution reactions in lithium-air batteries. Nano Letters, v. 15, n. 7, p. 4261-4268, 2015. ISSN 1530-6984.

23 DENG, H.H. et al. Fabrication of water-soluble, green-emitting gold nanoclusters with $65 \%$ photoluminescence quantum yield via host-guest recognition. Chemistry of Materials, v. 9, n. 3, p. 1362-1369, 2017. ISSN 0897-4756.

24 TORCHILIN, V.; AMIJI, M.M. Handbook of Materials for Nanomedicine. United Kingdom: Pan Stanford Publishing. 2010. 1-856 ISBN 978-9-81426-758-8.

25 MULVANEY, P. Not all that's gold does glitter. MRS Bulletin, v. 26, n. 12, p. 1009-1014, 2001. ISSN 1938-1425.

26 FARADAY, M. The Bakerian lecture: experimental relations of gold (and other metals) to light. Philosophical Transactions of the Royal Society of London, v. 147, p. 145-181, 1857. ISSN 0261-0523.

27 KHLEBTSOV, N.; DYKMAN, L. Biodistribution and toxicity of engineered gold nanoparticles: a review of in vitro and in vivo studies. Chemical Society Reviews, v. 40, n. 3, p. 1647-1671, 2011.

28 KHARLAMOV, A.N. et al. Silica-gold nanoparticles for atheroprotective management of plaques: results of the NANOM-FIM trial. Nanoscale, v. 7, n. 17, p. 8003-8015, 2015.

29 GILES, P.K.F.J. NU-0129 in Treating Patients With Recurrent Glioblastoma or Gliosarcoma Undergoing Surgery. ClinicalTrials.gov, 11 de janeiro de 2017. Disponível em: < https://clinicaltrials.gov/ct2/show/NCT03020017 >. Acesso em: 03 set. de 2017.

30 DAYAN, C.M. Enhanced epidermal antigen specific immunotherapy trial -1 (EE-ASI-1). ClinicalTrials.gov, 18 de julho de 2016. Disponível em: < https://clinicaltrials.gov/ct2/show/study/NCT02837094 >. Acesso em: 03 set. 2017. 
31 HUMBERT, M. Exhaled Breath Olfactory Signature of Pulmonary Arterial Hypertension (SNOOPY2). ClinicalTrials.gov, 07 de dezembro de 2016. Disponível em: < https://clinicaltrials.gov/ct2/show/study/NCT02782026 >. Acesso em: 03 set. 2017.

32 AMAL, $H$. et al. Detection of precancerous gastric lesions and gastric cancer through exhaled breath. Gut, v. 65, n. 3, p. 400-407, 2016. ISSN 1468-3288.

33 JAIN, P.K. et al. Calculated absorption and scattering properties of gold nanoparticles of different size, shape, and composition: applications in biological imaging and biomedicine. Journal of Physical Chemistry B, v. 110, n. 14, p. 7238-7248, 2006.

34 XIA, Y.; HALAS, N.J. Shape-controlled synthesis and surface plasmonic properties of metallic nanostructures. MRS Bulletin, v. 30, n. 05, p. 338-348, 2005. ISSN 1938-1425.

35 COBLEY, C.M. et al. Gold nanostructures: a class of multifunctional materials for biomedical applications. Chemical Society Reviews, v. 40, n. 1, p. 44-56, 2011.

36 QIAN, H.; ZHU, Y.; JIN, R. Atomically precise gold nanocrystal molecules with surface plasmon resonance. Proceedings of the National Academy of Sciences, v. 109, n. 3, p. 696700, 2012. ISSN 0027-8424.

37 AVERITT, R.; SARKAR, D.; HALAS, H.J. Plasmon resonance shifts of Au-coated Au 2 S nanoshells: insight into multicomponent nanoparticle growth. Physical Review Letters, $\mathrm{v}$. 78, n. 22, p. 4217, 1997.

38 JANA, N.R.; GEARHEART, L.; MURPHY, C.J. Wet chemical synthesis of high aspect ratio cylindrical gold nanorods. Journal of Physical Chemistry B, v. 105, n. 19, p. 4065-4067, 2001. ISSN 1520-6106.

39 KUMARI, S.; SINGH, R.P. Glycolic acid-g-chitosan-gold nanoflower nanocomposite scaffolds for drug delivery and tissue engineering. International Journal of Biological Macromolecules, v. 50, n. 3, p. 878-883, 2012. ISSN 0141-8130.

40 MAHYARI, F.A.; TOHIDI, M.; SAFAVI, A. Synthesis of gold nanoflowers using deep eutectic solvent with high surface enhanced Raman scattering properties. Materials Research Express, v. 3, n. 9, p. 095006, 2016. ISSN 2053-1591.

41 LI, N.; ZHAO, P.; ASTRUC, D. Anisotropic gold nanoparticles: synthesis, properties, applications, and toxicity. Angewandte Chemie International Edition, v. 53, n. 7, p. 17561789, 2014. ISSN 1521-3773.

42 FANG, J. et al. Recent advances in the synthesis and catalytic applications of ligandprotected, atomically precise metal nanoclusters. Coordination Chemistry Reviews, v. 322, p. 1-29, 2016. ISSN 0010-8545.

$43 \mathrm{LEE}, \mathrm{Y}$.J. et al. Ultrasmooth, highly spherical monocrystalline gold particles for precision plasmonics. ACS Nano, v. 7, n. 12, p. 11064-11070, 2013. ISSN 1936-0851.

44 PICCIOLINI, S. et al. Hydroquinone based synthesis of gold nanorods. Journal of Visualized Experiments, n. 114, p. e54319-e54319, 2016. ISSN 1940-087X. 
45 BRANN, T. et al. Gold nanoplates as cancer-targeted photothermal actuators for drug delivery and triggered release. Journal of Nanomaterials, v. 2016, 2016. doi.org/10.1155/2016/2036029.

46 WANG, $H$. et al. One-pot seedless synthesis of uniform gold nanoshells and their photothermal conversion property. ChemistrySelect, v. 1, n. 4, p. 659-663, 2016. ISSN 23656549.

47 SAIRA, F. et al. In vitro investigations of gold nanocages: toxicological profile in human keratinocyte cell line. Food and Chemical Toxicology, v. 97, p. 89-95, 2016. ISSN 0278-6915.

48 LIU, B.; YANG, M.; LI, H. Synthesis of gold nanoflowers assisted by a CH-CF hybrid surfactant and their applications in SERS and catalytic reduction of 4-nitroaniline. Colloids and Surfaces A: physicochemical and engineering aspects, v. 520, p. 213-221, 2017. ISSN $0927-7757$.

49 TIAN, F. et al. Gold nanostars for efficient in vitro and in vivo real-time SERS detection and drug delivery via plasmonic-tunable Raman/FTIR imaging. Biomaterials, v. 106, p. 8797, 2016. ISSN 0142-9612.

50 MARTINEZ-GARCIA, M.; CARDOSO-AVILA, P.; PICHARDO-MOLINA, J. Concave gold nanocubes on Al-6063 alloy as a simple and efficient SERS substrate. Colloids and Surfaces A: physicochemical and engineering aspects, v. 493, p. 66-73, 2016. ISSN 0927-7757.

51 MARANGONI, V.S. et al. Enhancing T1 magnetic resonance imaging contrast with internalized gadolinium (III) in a multilayer nanoparticle. Proceedings of the National Academy of Sciences, v. 114, n. 27, p. 6960-6965, 2017. ISSN 0027-8424.

52 AYALA-OROZCO, C. et al. Au nanomatryoshkas as efficient near-infrared photothermal transducers for cancer treatment: benchmarking against nanoshells. ACS Nano, v. 8, n. 6, p. 6372-6381, 2014. ISSN 1936-0851.

53 STONE, J.W. et al. Biomedical applications of anisotropic gold nanoparticles. In: HUNYADI MURPH. S. E. (Ed.). Anisotropic and shape-selective nanomaterials. Berlin: Springer International Publishing, 2017. p.399-426.

54 NIKOOBAKHT, B.; EL-SAYED, M.A. Preparation and growth mechanism of gold nanorods (NRs) using seed-mediated growth method. Chemistry of Materials, v. 15, n. 10, p. 19571962, 2003. ISSN 0897-4756.

55 GAMBHIR, K. et al. Morphology dependent two photon absorption in plasmonic structures and plasmonic-organic hybrids. Optics \& Laser Technology, v. 90, p. 201-210, 2017. ISSN 0030-3992.

56 BAKR, O.M.; WUNSCH B.H.; STELLACCI, F. High-yield synthesis of multi-branched urchinlike gold nanoparticles. Chemistry of Materials, v. 18, n. 14, p. 3297-3301, 2006. ISSN 08974756.

57 LI, D.; SHI, X.; J IN, D. Polydopamine-coated gold nanostars for CT imaging and enhanced photothermal therapy of tumors. In: SPIE BioPhotonics Australasia, v.10013, 2016. p.100133L-100133L-1. 
58 PATEL, A. S. et al. Gold nanoflowers as efficient hot-spots for surface enhanced Raman scattering. Disponivel em:< https://arxiv.org/abs/1604.02793>. Acesso em: 5 set. 2017.

59 ZHANG, X.L. et al. One-pot synthesis of gold nanostars using plant polyphenols for cancer photoacoustic imaging and photothermal therapy. Journal of Nanoparticle Research, v. 18, n. 7, p. 1-12, 2016. ISSN 1388-0764.

$60 \mathrm{HAO}$, F. et al. Plasmon resonances of a gold nanostar. Nano Letters, v. 7, n. 3, p. 729-732, 2007. ISSN 1530-6984.

61 ZHANG, T. et al. Photoluminescence of a single complex plasmonic nanoparticle. Scientific Reports, v. 4, p. 3867, 2014. ISSN 2045-2322.

62 CHENG, L. et al. Functional nanomaterials for phototherapies of cancer. Chemical Reviews, v. 114, n. 21, p. 10869-10939, 2014. ISSN 0009-2665.

63 SONG, C. et al. Gold nanoflowers with tunable sheet-like petals: facile synthesis, SERS performances and cell imaging. Journal of Materials Chemistry B, v. 4, n. 44, p. 7112-7118, 2016.

64 MOORE, T.L. et al. Nanoparticle colloidal stability in cell culture media and impact on cellular interactions. Chemical Society Reviews, v. 44, n. 17, p. 6287-6305, 2015.

65 POLTE, J. Fundamental growth principles of colloidal metal nanoparticles-a new perspective. CrystEngComm, v. 17, n. 36, p. 6809-6830, 2015.

66 CAO, G. Nanostructures and Nanomaterials: synthesis, properties and applications. Singapore: World Scientific, 2004. ISBN 1783260882.

67 LOURENCO, C. et al Steric stabilization of nanoparticles: size and surface properties. International Journal of Pharmaceutics, v. 138, n. 1, p. 1-12, 1996. ISSN 0378-5173.

68 ARVIZO, R.R. et al. Modulating pharmacokinetics, tumor uptake and biodistribution by engineered nanoparticles. PLoS One, v. 6, n. 9, p. e24374, 2011. ISSN 1932-6203.

69 BOSTRÖM, M.; WILLIAMS, D.; NINHAM, B. Specific ion effects: why DLVO theory fails for biology and colloid systems. Physical Review Letters, v. 87, n. 16, p. 168103, 2001.

70 PIELLA, J.; BASTÚS N, G.; PUNTES, V. Size-dependent protein-nanoparticle interactions in citrate-stabilized gold nanoparticles: the emergence of the protein corona. Bioconjugate Chemistry, v. 28, n. 1, p. 88-97, 2016. ISSN 1043-1802.

71 ALBANESE, A.; TANG, P.S.; CHAN, W.C. The effect of nanoparticle size, shape, and surface chemistry on biological systems. Annual Review of Biomedical Engineering, v. 14, p. 1-16, 2012. ISSN 1523-9829.

72 NIE, S. Understanding and overcoming major barriers in cancer nanomedicine. Nanomedicine, v. 5, n. 4, p. 523-528, 2010. ISSN 1743-5889.

73 LANDSIEDEL, R. et al. Toxico-/biokinetics of nanomaterials. Archives of Toxicology, v. 86, n. 7, p. 1021-1060, 2012. ISSN 0340-5761. 
74 HUSEN, A. Gold nanoparticles from plant system: synthesis, characterization and their application. In: GHORBANPOUR, M., MANIKA, K. e VARMA, A. (Ed.). Nanoscience and plantsoil systems. Berlin: Springer Verlag, 2017. p.455-479.

75 BESNER, S. et al. Synthesis of size-tunable polymer-protected gold nanoparticles by femtosecond laser-based ablation and seed growth. Journal of Physical Chemistry C, v. 113, n. 22, p. 9526-9531, 2009. ISSN 1932-7447.

76 SIVARAMAN, S.K.; KUMAR, S.; SANTHANAM, V. Monodisperse sub-10nm gold nanoparticles by reversing the order of addition in Turkevich method-The role of chloroauric acid. Journal of Colloid and Interface Science, v. 361, n. 2, p. 543-547, 2011. ISSN 0021-9797.

77 NGUYEN, D.T.; KIM, D.J.; KIM, K.S. Controlled synthesis and biomolecular probe application of gold nanoparticles. Micron, v. 42, n. 3, p. 207-227, 2011. ISSN 0968-4328.

78 GRZELCZAK, M. et al. Shape control in gold nanoparticle synthesis. Chemical Society Reviews, v. 37, n. 9, p. 1783-1791, 2008.

79 ROGERS, L. et al. The electrodeposition behavior of traces of silver. Journal of the Electrochemical Society, v. 95, n. 2, p. 33-46, 1949. ISSN 0013-4651.

$80 \mathrm{XIE}$, J. et al. The synthesis of SERS-active gold nanoflower tags for in vivo applications. ACS Nano, v. 2, n. 12, p. 2473-2480, 2008. ISSN 1936-0851.

81 KUMAR, P.S. et al. High-yield synthesis and optical response of gold nanostars. Nanotechnology, v. 19, n. 1, p. 015606, 2007. ISSN 0957-4484.

82 PALLAVICINI, P. et al. Triton X-100 for three-plasmon gold nanostars with two photothermally active NIR (near IR) and SWIR (short-wavelength IR) channels. Chemical Communications, v. 49, n. 56, p. 6265-6267, 2013.

83 PALLAVICINI, P. et al. Self-assembled monolayers of gold nanostars: a convenient tool for near-IR photothermal biofilm eradication. Chemical Communications, v. 50, n. 16, p. 19691971, 2014.

84 MOUKARZEL, W.; FITREMANN, J.; MARTY, J.D. Seed-less amino-sugar mediated synthesis of gold nanostars. Nanoscale, v. 3, n. 8, p. 3285-3290, 2011.

85 INSTITUTO NACIONAL DO CÂNCER. Estimativa 2016: incidência de câncer no Brasil. Disponivel em:<http://www.inca.gov.br/estimativa/2016/>. Acesso em: 5 set. 2017.

86 WONG, M.C. et al. International incidence and mortality trends of liver cancer: a global profile. Scientific Reports, v. 7, p. 45846, 2017.

87 HER, S.; JAFFRAY, D.A.; ALLEN, C. Gold nanoparticles for applications in cancer radiotherapy: mechanisms and recent advancements. Advanced Drug Delivery Reviews, v. 109, p. 84-101, 2017. ISSN 0169-409X.

88 BRIGGER, I.; DUBERNET, C.; COUVREUR, P. Nanoparticles in cancer therapy and diagnosis. Advanced Drug Delivery Reviews, v. 54, n. 5, p. 631-651, 2002. ISSN 0169-409X. 
89 GROSSWEINER, L. I. The science of phototherapy: an introduction. Netherlands: Springer Netherlands, 2005. ISBN 1402028857.

90 MENON, J.U. et al. Nanomaterials for photo-based diagnostic and therapeutic applications. Theranostics, v. 3, n. 3, p. 152, 2013.

91 HAMBLIN, M.R.; AVCI, P. Applications of nanoscience in photomedicine. United Kingdom: Chandos Publishing, 2015. ISBN 1908818786.

92 WILSON, K.E.; VALLURU, K.S.; WILLMANN, J.K. Nanoparticles for photoacoustic imaging of cancer. In: BULTE, J.W.M.; MODO, M.M.J. (Ed.). Design and applications of nanoparticles in biomedical imaging. Amsterdam: Springer, 2017. p.315-335.

93 PAVAN, T.; CARNEIRO, A.; EMELIANOV, S. Fotoacústica: imagens da interação de luz e som no corpo humano. Ciência Hoje, v. 50, p. 38-42, 2012.

94 GAO, D.; YUAN, Z. Photoacoustic-based multimodal nanoprobes: from constructing to biological applications. International Journal of Biological Sciences, v. 13, n. 4, p. 401, 2017.

95 JIANG, Y. et al. Gold nanoflowers for 3D volumetric molecular imaging of tumors by photoacoustic tomography. Nano Research, v. 8, n. 7, p. 2152-2161, 2015. ISSN 1998-0124.

96 RAGHAVAN, V. et al. Dual plasmonic gold nanostars for photoacoustic imaging and photothermal therapy. Nanomedicine, v. 12, n. 5, p. 457-471, 2017. ISSN

97 KIM, J.; SANTOS, O.A.; PARK, J.H. Selective photosensitizer delivery into plasma membrane for effective photodynamic therapy. Journal of Controlled Release, v. 191, p. 98-104, 2014. ISSN 0168-3659.

98 DICKERSON, E.B. et al. Gold nanorod assisted near-infrared plasmonic photothermal therapy (PPTT) of squamous cell carcinoma in mice. Cancer Letters, v. 269, n. 1, p. 57-66, Sep 2008. ISSN 0304-3835.

99 ROPER, D.K.; AHN, W.; HOEPFNER M. Microscale heat transfer transduced by surface plasmon resonant gold nanoparticles. Journal of Physical Chemistry C, v. 111, n. 9, p. 3636-3641, 2007. ISSN 1932-7447.

100 HASHIMOTO, S.; WERNER, D.; UWADA, T. Studies on the interaction of pulsed lasers with plasmonic gold nanoparticles toward light manipulation, heat management, and nanofabrication. Journal of Photochemistry and Photobiology C: photochemistry reviews, v. 13, n. 1, p. 28-54, 2012. ISSN 1389-5567.

101 GOVOROV, A.O.; RICHARDSON, H.H. Generating heat with metal nanoparticles. Nano Today, v. 2, n. 1, p. 30-38, 2007. ISSN 1748-0132.

102 YUAN, H.; FALES, A.M.; VO-DINH, T. TAT peptide-functionalized gold nanostars: enhanced intracellular delivery and efficient NIR photothermal therapy using ultralow irradiance. Journal of the American Chemical Society, v. 134, n. 28, p. 11358-11361, 2012. ISSN 0002-7863. 
103 LU, W. et al. Gold nano-popcorn-based targeted diagnosis, nanotherapy treatment, and in situ monitoring of photothermal therapy response of prostate cancer cells using surfaceenhanced Raman spectroscopy. Journal of the American Chemical Society, v. 132, n. 51, p. 18103-18114, 2010. ISSN 0002-7863.

104 CABRELLI, L.C. et al. Stable phantom materials for ultrasound and optical imaging. Physics in Medicine and Biology, v. 62, n. 2, p. 432, 2016. ISSN 0031-9155.

105 PARK, J. et al. Flow cytometry-based quantification of cellular au nanoparticles. Analytical Chemistry, v. 89, n. 4, p. 2449-2456, 2017. ISSN 0003-2700.

106 HÄKKINEN, H. The gold-sulfur interface at the nanoscale. Nature Chemistry, v. 4, n. 6 , p. 443-455, 2012. ISSN 1755-4330.

107 D'SOUZA, S. L.; PATI, R. K.; KAILASA, S. K. Ascorbic acid functionalized gold nanoparticles as a probe for colorimetric and visual read-out determination of dichlorvos in environmental samples. Analytical Methods, v. 6, n. 22, p. 9007-9014, 2014.

108 BARBOSA, S. et al. Tuning size and sensing properties in colloidal gold nanostars. Langmuir, v. 26, n. 18, p. 14943-14950, 2010. ISSN 0743-7463.

109 NEHL, C.L.; LIAO, H.; HAFNER, J.H. Optical properties of star-shaped gold nanoparticles. Nano Letters, v. 6, n. 4, p. 683-688, 2006. ISSN 1530-6984.

110 TRIGARI, S. et al. Synthesis and modelling of gold nanostars with tunable morphology and extinction spectrum. Journal of Materials Chemistry, v. 21, n. 18, p. 6531-6540, 2011.

111 PETKOV, V. et al. Structure of gold nanoparticles suspended in water studied by x-ray diffraction and computer simulations. Physical Review B, v. 72, n. 19, p. 195402, 2005.

$112 \mathrm{ZHAO}$, L. et al. Formation and stability of gold nanoflowers by the seeding approach: the effect of intraparticle ripening. Journal of Physical Chemistry C, v. 113, n. 38, p. 1664516651, 2009. ISSN 1932-7447.

113 ZHANG, G. et al. Tunability and stability of gold nanoparticles obtained from chloroauric acid and sodium thiosulfate reaction. Nanoscale Research Letters, v. 7, n. 1, p. 337, 2012. ISSN 1556-276X.

114 CHEN, A.L. et al. Changes in optical properties of plasmonic nanoparticles in cellular environments are modulated by nanoparticle pegylation and serum conditions. Nanoscale Research Letters, v. 11, n. 1, p. 1-12, 2016. ISSN 1931-7573.

115 MONOPOLI, M.P. et al. Physical-chemical aspects of protein corona: relevance to in vitro and in vivo biological impacts of nanoparticles. Journal of the American Chemical Society, v. 133, n. 8, p. 2525-2534, 2011.

116 AGGARWAL, P. et al. Nanoparticle interaction with plasma proteins as it relates to particle biodistribution, biocompatibility and therapeutic efficacy. Advanced Drug Delivery Reviews, v. 61, n. 6, p. 428-437, 2009. ISSN 0169-409X. 
117 HUANG, J. et al. Rational design and synthesis of $\gamma F$ Fe2O3@ Au magnetic gold nanoflowers for efficient cancer theranostics. Advanced Materials, v. 27, n. 34, p. 50495056, 2015. ISSN 1521-4095.

118 PAINO, I.D.M. et al. Zinc oxide flower-like nanostructures that exhibit enhanced toxicology effects in cancer cells. ACS Applied Materials \& Interfaces, v. 8, n. 48, p. 3269932705, 2016. ISSN 1944-8244.

119 SUZUKI, H.; TOYOOKA, T.; IBUKI, Y. Simple and easy method to evaluate uptake potential of nanoparticles in mammalian cells using a flow cytometric light scatter analysis. Environmental Science \& Technology, v. 41, n. 8, p. 3018-3024, 2007. ISSN 0013-936X. 